UCRL-TR-200953

\title{
Radionuclide Mobility at the Nevada Test Site
}

\author{
Qinhong (Max) $\mathrm{Hu}^{*}{ }^{* 1}$ \\ David K. Smith ${ }^{*}, 1$ \\ Timothy Rose ${ }^{1}$ \\ Lee Glascoe ${ }^{2}$ \\ Carl Steefel ${ }^{2}$ \\ Mavrik Zavarin $^{2}$ \\ ${ }^{1}$ Chemical Biology and Nuclear Science Division \\ ${ }^{2}$ Environmental Science Division \\ Lawrence Livermore National Laboratory \\ 7000 East Avenue \\ Livermore, CA 94550
}

This report is submitted to the

Office of Civilian Radioactive Waste Management of the Department of Energy

October 2003

*Corresponding authors:

Max Hu: phone: 925-422-6774; fax: 925-422-3160; e-mail: hu7@1lnl.gov

David Smith: phone: 925-423-5793; fax: 925-422-3160; e-mail: smith24@1lnl.gov

Approved for public release; further dissemination unlimited 
UCRL-TR-200953

\section{DISCLAIMER}

This document was prepared as an account of work sponsored by an agency of the United States Government. Neither the United States Government nor the University of California nor any of their employees, makes any warranty, express or implied, or assumes any legal liability or responsibility for the accuracy, completeness, or usefulness of any information, apparatus, product, or process disclosed, or represents that its use would not infringe privately owned rights. Reference herein to any specific commercial product, process, or service by trade name, trademark, manufacturer, or otherwise, does not necessarily constitute or imply its endorsement, recommendation, or favoring by the United States Government or the University of California. The views and opinions of authors expressed herein do not necessarily state or reflect those of the United States Government or the University of California, and shall not be used for advertising or product endorsement purposes.

This work was performed under the auspices of the U. S. Department of Energy by the University of California, Lawrence Livermore National Laboratory under Contract No. W-7405-Eng-48.

This report has been reproduced directly from the best available copy.

Available to DOE and DOE contractors from the

Office of Scientific and Technical Information

P.O. Box 62, Oak Ridge, TN 37831

Prices available from (423) 576-8401

http://apollo.osti.gov/bridge/

Available to the public from the

National Technical Information Service

U.S. Department of Commerce

5285 Port Royal Rd., Springfield, VA 22161

http://www.ntis.gov/

OR

Lawrence Livermore National Laboratory

Technical Information Department's Digital Library

http://www.llnl.gov/tid/Library.html 


\section{Executive Summary}

Underground nuclear tests conducted at the Nevada Test Site (NTS) are characterized by abundant fission product and actinide source terms. Included are ${ }^{99} \mathrm{Tc}$ and other soluble radionuclides $\left({ }^{3} \mathrm{H},{ }^{14} \mathrm{C},{ }^{36} \mathrm{Cl},{ }^{85} \mathrm{Kr}\right.$, and $\left.{ }^{129} \mathrm{I}\right)$, which are presumably mobile in groundwater and potentially toxic to down-gradient receptors. NTS provides the Office of Civilian Radioactive Waste Management (OCRWM) with an analog of the release of these radionuclides from a nuclear waste repository in the absence of engineered barriers. The investigation described in this report synthesizes a substantial body of data collected on the identity and distribution of soluble radionuclides at field scales over distances of hundreds of meters, for durations up to 40 years, and under hydrogeologic conditions very similar to the proposed geological repository at Yucca Mountain. This body of data is complemented by laboratory transport studies and a synthesis of recent modeling investigations from the NTS, with an emphasis on the ongoing Yucca Mountain Program (YMP) efforts. Overall, understanding the controls of radionuclide mobility associated with these nuclear tests will provide insight into the repository's future performance as well as bounds and calibrations for the numerical predictions of long-term radionuclide releases and migration.

In this work, we specifically performed the following tasks:

- Summarized the phenomenology of nuclear tests, within the context of their influence on radionuclide distribution and mobility, and two major forced-gradient-radionuclidemigration experiments (CAMBRIC and CHESHIRE).

- From archival technical reports, compiled a database with radionuclide concentration data from 18 monitoring wells for 14 nuclear tests, with a total of 210 sampling events, at the NTS. Collated data for ${ }^{3} \mathrm{H},{ }^{14} \mathrm{C},{ }^{36} \mathrm{Cl},{ }^{85} \mathrm{Kr},{ }^{99} \mathrm{Tc}$, and ${ }^{129} \mathrm{I}$, as available.

- Using an unclassified radionuclide inventory for the NTS, evaluated radionuclide concentrations (e.g., that of ${ }^{14} \mathrm{C} /{ }^{3} \mathrm{H},{ }^{99} \mathrm{Tc} /{ }^{3} \mathrm{H},{ }^{129} \mathrm{I} /{ }^{3} \mathrm{H}$ ) in nuclear test cavities and adjacent satellite wells. Compared these concentrations to that of ${ }^{3} \mathrm{H}$ to assess field-scale migration behavior.

- Employing ${ }^{3} \mathrm{H}$, stable chloride (as an analog for ${ }^{36} \mathrm{Cl}$ ), rhenium and molybdenum (for ${ }^{99} \mathrm{Tc}$ ), and stable ${ }^{127} \mathrm{I}$ (for ${ }^{129} \mathrm{I}$ ) in synthetic $\mathrm{J}-13$ groundwater, conducted laboratory flowthrough column experiments with alluvium and crushed tuff collected at the NTS. The results provided a direct comparison of the mobilities of these species through media representative of Yucca Mountain and NTS.

- Highlighted results from recent modeling investigations about radionuclide transport at the NTS and how these results may be of interest to ongoing YMP efforts.

Our main findings are summarized as follows:

- Knowledge of the speciation and reactions of presumably mobile radionuclides, such as long-lived ${ }^{99} \mathrm{Tc}$ and ${ }^{129} \mathrm{I}$, is very important for understanding the transport behavior of these radionuclides at the NTS. 
- Tc does not necessarily exist as the mobile and conservative species $\mathrm{TcO}_{4}^{-}$, as commonly assumed. Recent in situ redox potential measurements have indicated that groundwaters at the NTS are not uniformly oxidizing, as previously believed. The mobility of Tc is greatly reduced in a nonoxidizing environment.

- Dependent upon the redox conditions, the speciation and migration behavior of iodine are complex, and different species have different reactivities and mobilities.

- Numerous lines of evidence suggest that the underground test cavity environment is likely to have a reducing nature immediately following a detonation. These conditions may persist for decades after a test.

- The interaction of ${ }^{3} \mathrm{H}$ with a solid surface via an isotopic exchange with clay lattice hydroxyls may cause a slight delay in the transport of ${ }^{3} \mathrm{H}$.

- The transport of ${ }^{14} \mathrm{C}$ is likely retarded by its isotopic exchange with carbonate minerals, and the exchange may be more pronounced in the vadose zone.

- Without information about clay content, clay mineralogy, iron sesquioxides content, and cation/anion exchange capacity of the host medium, the effect of anion exclusion on transport of anions, such as chloride, may be mistakenly ascribed.

- Laboratory column studies under saturated and oxidizing conditions confirm the conservative transport behavior of ${ }^{3} \mathrm{H}$, chloride, and iodide, as well as molybdate and perrhenate (which serve as analogs for pertechnetate) in alluvium and tuff samples representative of Yucca Mountain and NTS.

- Numerical simulations are used to examine the effect of residual test heat on flow and transport, geostatistical approaches to mineral distribution and its effects on radionuclide adsorption, and fully coupled reactive-transport models of radionuclide migration at the NTS. The insight gained from these simulations will assist the modeling efforts for radionuclide migration from the proposed repository at Yucca Mountain.

- Fractures around the test cavity (an analog to waste emplacement drift) are in some cases sealed by secondary-mineral deposition due to the residual heat from nuclear tests (or high-level nuclear waste). Such "isolated" systems will contribute to the performance of the potential Yucca Mountain repository because of limited hydraulic communication with the surrounding.

- Phenomenology is critical in the initial distribution and subsequent migration behavior of radionuclides (both refractory and volatile) from an underground nuclear test.

- The leaching of melt-glass samples indicates that, for a majority of radionuclides studied, only a fraction (less than $1 \%$ ) of their initial activity is released at $25^{\circ} \mathrm{C}$ over 420 days. The leach rate for most radionuclides decreases over time, and the kinetics of leaching implies that the release of radionuclides occurs by a process that is more complex than simple dissolution. 


\section{Introduction}

The current Total System Performance Assessment (TSPA) model for the proposed Yucca Mountain high-level nuclear waste repository assumes that ${ }^{99} \mathrm{Tc}$ moves at the same rate as water in the subsurface (i.e., without retardation). However, applying a retardation factor of one is probably conservative and may result in higher estimated doses than is realistic. Other presumably nonreactive species, like ${ }^{129}$ I, may exhibit similar behavior and warrant improved understanding in performance assessment modeling.

At the Nevada Test Site (NTS), a large number of radionuclides (tritium, fission products, activation products, actinides, etc.) are present at various concentrations as a result of the 828 underground nuclear weapons tests that were conducted between 1951 and 1992 (see Figure 1). Radionuclide contamination at the NTS is large both in area and inventory. For example, the NTS radionuclide inventory is similar in size to that of Hanford, although 2 orders of magnitude lower than the planned inventory of the Yucca Mountain repository (Figure 2). Among the radionuclide contaminants, a suite of long-lived and environmentally mobile radionuclides is found in both the radiologic inventory and in the groundwater.

Most nuclear tests were conducted between $\sim 500$ and $1200 \mathrm{~m}$ below the land surface. The geologic media that hosted the underground tests at the NTS consists primarily of tuffs, rhyolites, and tuffaceous alluvium. Approximately 300 tests were detonated either below or within $100 \mathrm{~m}$ above the water table; the cavities produced by these tests have since refilled with water, a scenario similar to water seepage into the waste emplacement drifts in the potential repository.

In 1973, the Radionuclide Migration (RNM) Program was initiated by the U.S. Department of Energy, Nevada Operations Office (DOE/NV) to evaluate the radiological and hydrological consequences of underground nuclear weapons testing at the NTS (Hoffman et al., 1977). In 1983, the RNM program evolved into the Hydrologic Resources Management Program (HRMP), which was sponsored by DOE's Defense Programs to study radiochemistry and resource management related to the Defense Programs mission. In 1991, the Underground Test Area (UGTA) project was initiated as an Environmental Management activity of DOE/NV that supports a Federal Facilities Agreement and Consent Order between DOE, the Department of Defense, and the state of Nevada to assess contamination resulting from the underground nuclear tests conducted at the NTS. Participants in the RNM/HRMP and UGTA programs include the Lawrence Livermore National Laboratory (LLNL), Los Alamos National Laboratory (LANL), the U.S. Geological Survey (USGS), the Desert Research Institute (DRI), and several additional technical support organizations. Over the past three decades, a significant body of information regarding radiologic distribution has been accumulated, and a synthesis of this information will provide insight into radionuclide migration at the NTS.

The characterization of several dozen underground tests conducted beneath the water table, two forced-gradient-radionuclide-migration experiments (the CAMBRIC and CHESHIRE tests), and long-term environmental monitoring of groundwater over the past 30 years provide insight into the mobility and distribution of radionuclides at field scales under hydrogeologic conditions very similar to the proposed Yucca Mountain repository (Smith et al., 2001). At some of these sites,

${ }^{99} \mathrm{Tc}$ and other mobile radionuclides were detected in groundwater and in posttest debris samples. These radionuclide data provide valuable field-scale information to elucidate the chemical controls on the mobility of these species. Such controls are necessary to reliably model the 
migration of radionuclides from the proposed repository. To obtain insight into the mobility of radionuclides, existing NTS data can be analyzed quickly and cheaply. Because of the comparable hydrogeologic settings, understanding gained from NTS about radionuclide mobility is directly applicable to the performance of the proposed repository to store high-level nuclear waste at Yucca Mountain on the western edge of NTS (Figure 1). However, we like to point out that most of the NTS work has focused on saturated zones, as these programs assume that radionuclides from tests conducted more than $100 \mathrm{~m}$ above the water table are unavailable for groundwater transport.

The work in this report consists of several closely related components. We first briefly summarize the phenomenology of nuclear tests, within the context of their influence on radionuclide distribution and mobility, and two major forced-gradient-radionuclide-migration experiments (CAMBRIC and CHESHIRE). We then compile and examine existing monitoring data of radionuclide concentration in the collapsed shot cavities and in the satellite wells near underground tests. By comparing the concentration of radionuclides in groundwater (both in and near nuclear test cavities) relative to the average radiologic inventory, we can assess the radionuclides' field-scale migration behavior. The migration behavior of ${ }^{3} \mathrm{H},{ }^{14} \mathrm{C},{ }^{36} \mathrm{Cl},{ }^{85} \mathrm{Kr}$, ${ }^{99} \mathrm{Tc}$, and ${ }^{129} \mathrm{I}$ is discussed individually. We also describe the results of laboratory column studies that we conducted to directly compare the transport behavior of aqueous species under oxidizing conditions in representative alluvium and crushed tuff samples. We then review the radionuclide transport modeling that has been carried out to date to understand radionuclide migration at the NTS, with an emphasis on its relevance to Yucca Mountain. After that, we discuss various issues at the NTS, including radionuclide migration within the vadose zone, radionuclide distribution in the subsurface, thermal effects on radionuclide migration, and the mobility of radionuclides in melt glasses, which are relevant to the proposed repository at Yucca Mountain. Finally, we summarize our research findings and suggest future work. 


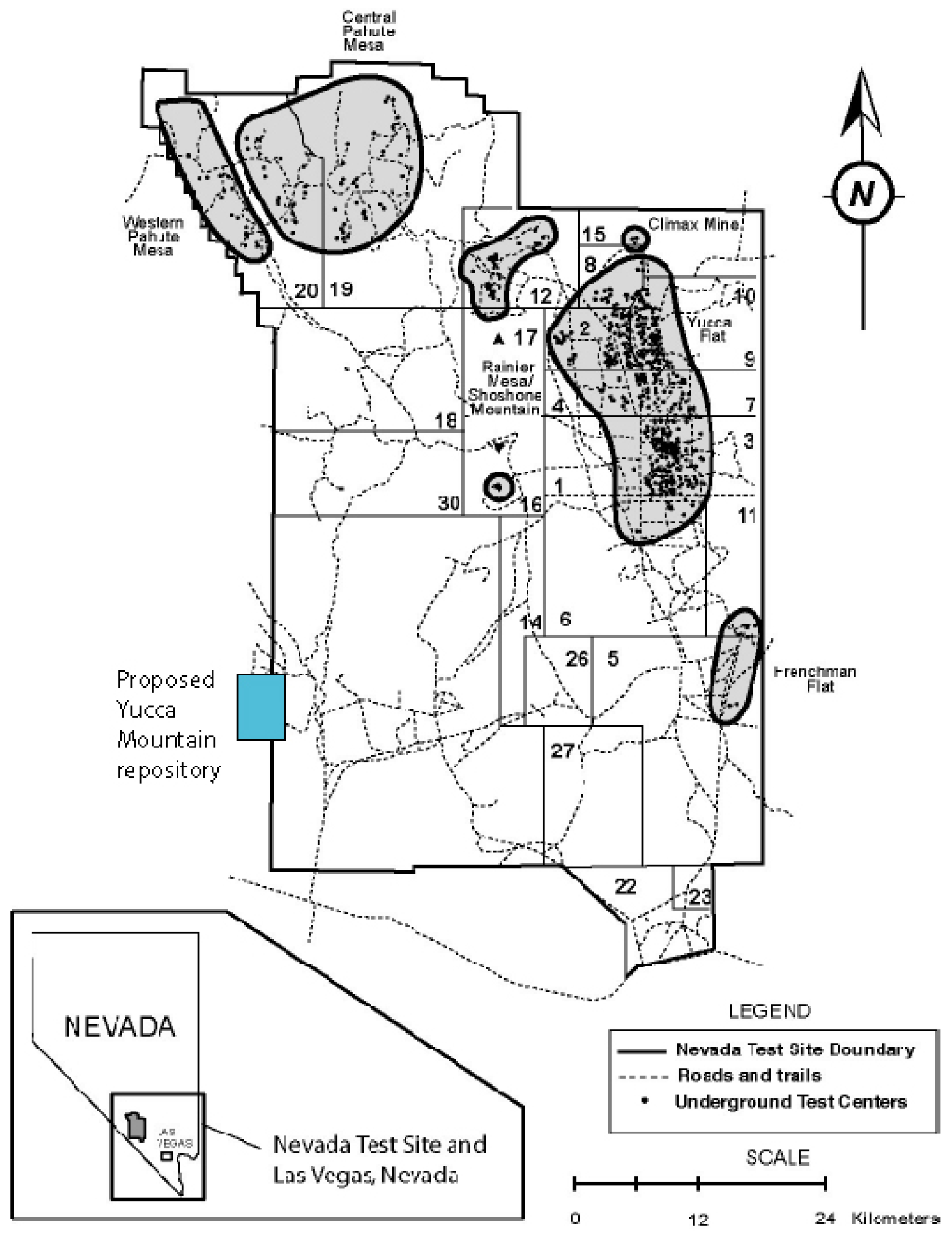

Figure 1. The locations of the potential Yucca Mountain repository and of the 828 underground nuclear explosions fired at the Nevada Test Site between 1951 and 1992. 


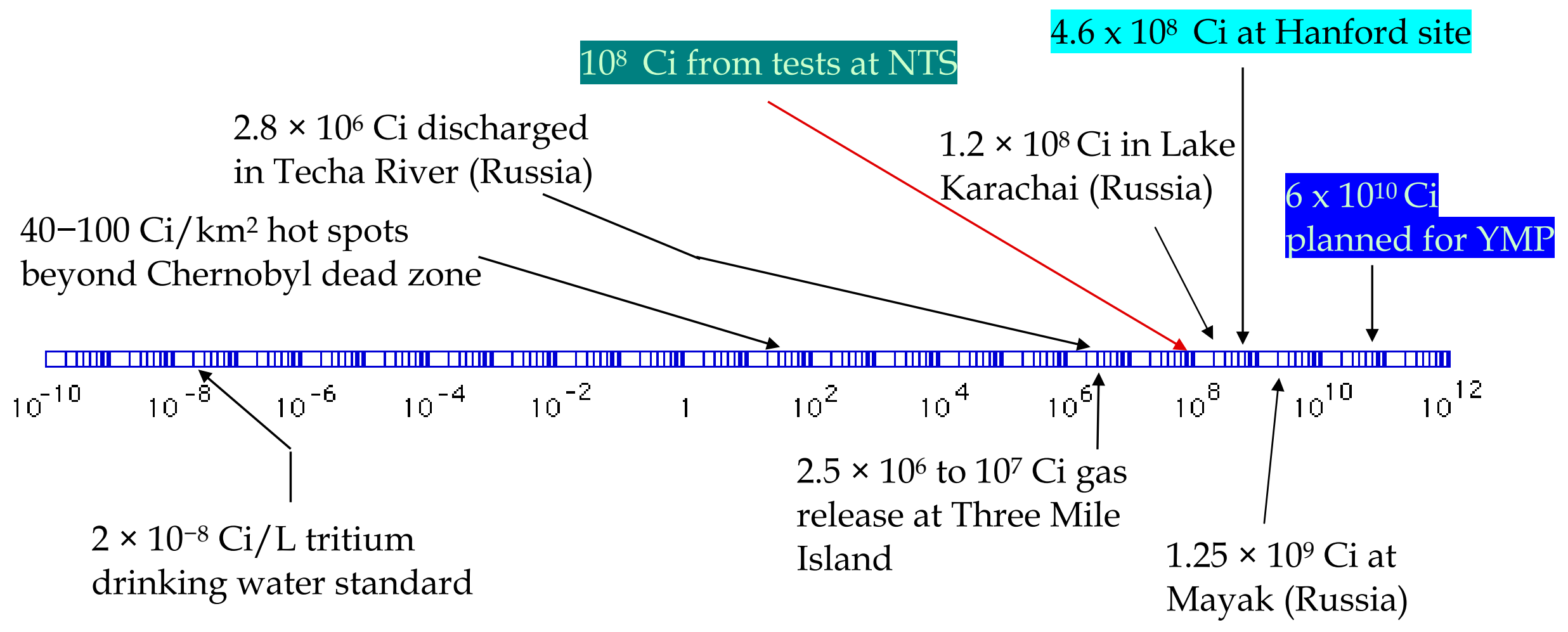

Figure 2. Radionuclide contamination (measured in total $\mathrm{Ci}$ ) for various contaminated sites. 


\section{Background}

\section{General phenomenology}

Phenomenology describes the effects of the nuclear explosion on the surrounding geologic medium. The phenomenology of a subsurface nuclear weapons test is important to review, as the initial processes determine the radionuclide source term that is available for hydrologic transport. The following description is mainly derived from Borg et al. (1976), Smith (1995), IAEA (1998), and Tompson et al. (1999).

The initial detonation produces high temperature (as high as $10^{8}{ }^{\circ} \mathrm{C}$ ) and a high-pressure (above $10^{10} \mathrm{~Pa}$ ) shock wave that moves outward and vaporizes the emplacement canister and surrounding rock (Figure 3). This forms a cavity that continues to expand due to the pressure and momentum imparted to the surrounding geological materials, causing additional vaporization and compression. Within a few tenths of a second, the pressure drops to the weight of the overburden, and cavity growth stops. Geologic materials outside the immediate cavity are then altered through melting, compression, or fracturing. After a few seconds when the shock and elastic waves have dissipated, the less-volatile rock vapors begin to condense and gather at the cavity bottom to form a puddle of molten material. This molten debris is produced by the condensation of vaporized rock, shock melting of the surrounding rock, and melting of the rock medium in contact with melt or vapor (Borg et al., 1976). It has been estimated that between 700 and 1300 metric ton $(t)$ of debris are ultimately formed for each kiloton of yield (Borg et al., 1976; Smith, 1993). Water vapor, noncondensable gases (such as $\mathrm{CO}_{2}$ and $\mathrm{H}_{2}$ ), and other noncondensed radionuclides (such as tritiated water vapor, ${ }^{85} \mathrm{Kr}$, or ${ }^{137} \mathrm{Xe}$ ) are still present in the cavity.

The final size of the cavity depends on the yield of the explosion, the overburden stresses, and the characteristics of the surrounding rock. Nuclear explosions in high-water-content rock will form larger cavities than equivalent explosions in dry rock, because of the enhancement caused by the larger amount of steam and wet rock has weak strength. Some rocks (e.g., rhyolite) also melt at lower temperature in the presence of water than under anhydrous conditions. Furthermore, it is probable that the upper portion of the cavity is larger than the lower hemisphere. Cavity-radius measurements, however, usually define the smaller lower hemisphere of the cavity.

Within the first few minutes after a nuclear detonation, the pressurized cavity gas is mostly steam. Calculations for a theoretical cratering experiment in a silicate rock containing $10 \mathrm{wt} \%$ water predict that the cavity environment will consist of melted $\mathrm{SiO}_{2}$ dispersed in superheated steam at a ratio of 1:200 $\left(\mathrm{SiO}_{2}: \mathrm{H}_{2} \mathrm{O}\right)$ with a cavity pressure of 10-20 bars and a temperature of $2000{ }^{\circ} \mathrm{C}$ (Smith et al., 1996). It is reported that temperatures in excess of $1000^{\circ} \mathrm{C}$ are possible at distances of $10 \mathrm{~m}$ or more away from ground zero.

Temperatures in the cavity environment will dissipate over time as a function of the heat capacity and thermal diffusivities of the formation materials (with or without groundwater) and of the groundwater motion itself. Some tests have thermal signatures that have lasted for decades, while most tests have returned to ambient temperature relatively quickly (within a year-particularly as water infills the saturated cavity). 


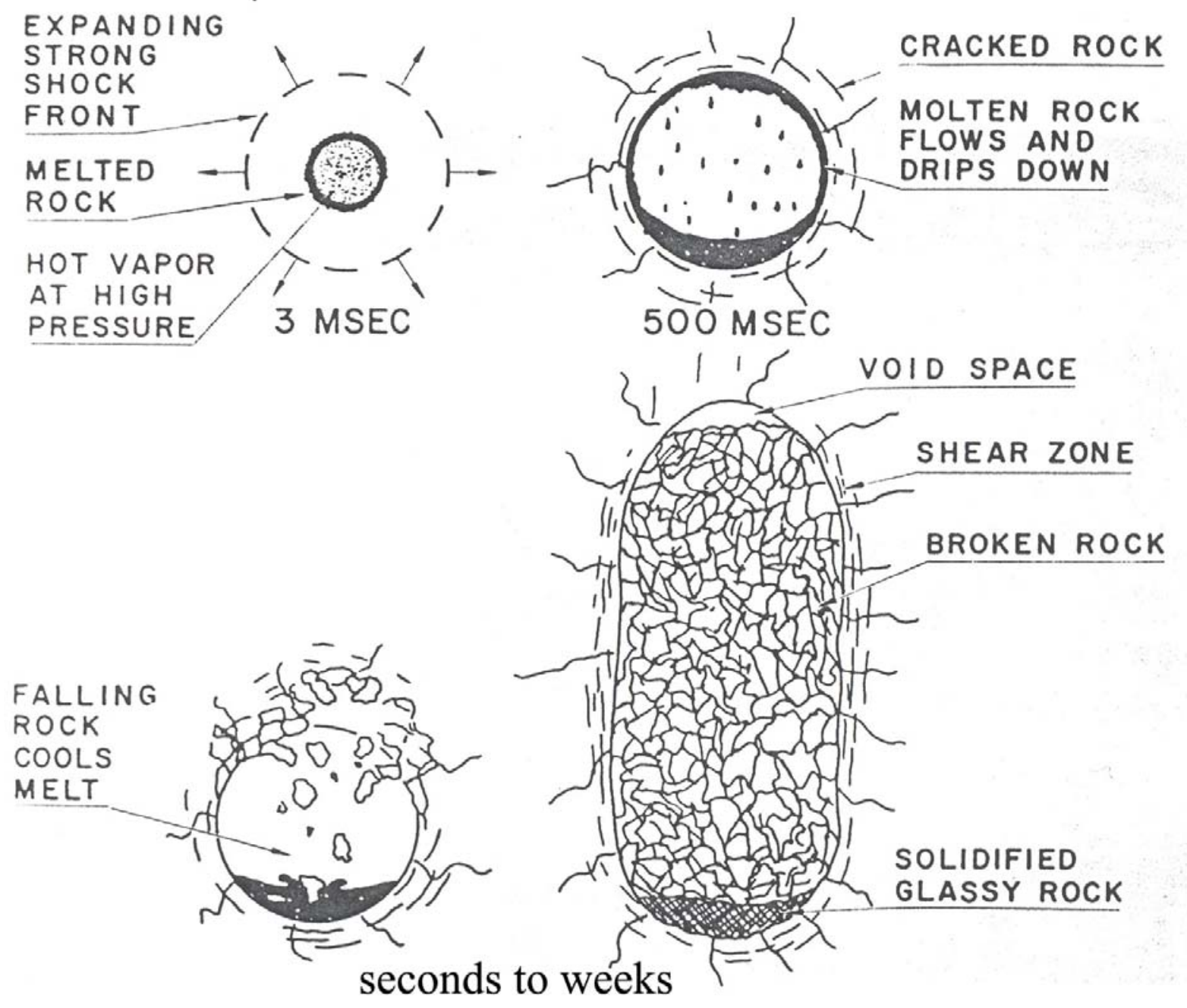

Figure 3. Conceptual illustration of the phenomenology of an underground nuclear explosion in competent rock. Illustration shows the accretion of a glass puddle and the redistribution of more volatile radionuclides - initially as vapor and later as condensate. (Reproduced from Schwartz et al., 1984; Tompson et al., 1999.)

\section{Radionuclide distribution and behavior}

The radionuclides deposited in the subsurface as a result of an underground nuclear explosion consist of radionuclides produced from the nuclear reaction (fission products and tritium), neutron activation of surrounding host medium, and unreacted nuclear material. The total inventory of residual radioactivity is called the radiologic source term, while the hydrologic source term is the portion of the radiologic source term that is or becomes available for groundwater transport. The physical and chemical distributions of the radiologic source term are heterogeneous, which is a function of the device design, host geologic media, properties of the specific radionuclides, and the rate and character of cavity growth and collapse. 
Field investigations at the NTS have yielded information regarding the initial distribution of radionuclides after a nuclear test, as discussed in Smith $(1993,1995)$ and Kersting (1996). The inferred partitioning of selected radionuclides among glass, rubble, water, and gas is shown in Table 1. This table reflects how and where the radionuclides (as components of a complex vapor mixture produced during detonation) are distributed during the cooling and condensation process following an underground nuclear explosion. The data in Table 1 originate from measurements derived from radiochemical diagnostics of nuclear tests (e.g., Borg et al., 1976), augmented by general thermodynamic properties (e.g., boiling points, vapor pressures) of these elements. With the exception of ${ }^{90} \mathrm{Sr}$ and ${ }^{137} \mathrm{Cs}$, the data apply to the general experience of radionuclide distributions from underground nuclear testing. The partitioning behavior of ${ }^{90} \mathrm{Sr}$ and ${ }^{137} \mathrm{Cs}$, to be discussed later, between rubble and melt glass is strongly dependent on the cooling time of the glass as well as on the presence of volatile, noncondensible gases (e.g., $\mathrm{CO}_{2}, \mathrm{H}_{2}$ ) in the cavitychimney region.

In general, refractory radionuclides (e.g., $\mathrm{Pu}, \mathrm{Am}, \mathrm{Np}, \mathrm{Ce}, \mathrm{Eu}$ ) with higher boiling points and lower vapor pressures are largely incorporated into the melt glass that coalesces at the base of the cavity (Figure 3). However, refractory radionuclides can also be distributed more broadly in the cavity region as fine droplets become entrained with escaping cavity gases (Levy, 1972) or as a result of splashing if the melt glass is still molten when rubble in the cavity-chimney area collapses. Volatile species with lower boiling points (e.g., tritium, Cl, I, alkalis, Ru, U, Sb) circulate up cracks in the rubble chimney. As the cooling progresses, the melt begins to quench, and elements with lower boiling points subsequently condense onto exposed mineral and fracture surfaces within the cavity and the collapsed rubble. A portion of the volatile species can also be volumetrically incorporated into any late-stage melt residual. Tritium will condense as molecular HTO together with the large amounts of steam produced by the explosion. Fractions of volatile radionuclides with higher solubilities (e.g., ${ }^{36} \mathrm{Cl}$ and $\left.{ }^{129} \mathrm{I}\right)$ will also be partitioned into the condensed water. Gas species (e.g., ${ }^{90} \mathrm{Kr}$ and ${ }^{137} \mathrm{Xe}$ ) are transported through the rubble and will be concentrated higher in the cavity and in the chimney relative to the refractory radionuclides. Drillback samples systematically exhibit higher volatile to refractory radionuclide ratios $(\mathrm{Cs} / \mathrm{Eu})$ for rocks collected higher in the cavity and chimney (Thompson, 1996).

In tests conducted beneath the water table, the condensed water will mix with groundwater invading from the periphery and will occupy the interstitial voids of the rubble and glass matrices. This will allow the "rubble-", "water-", as well as some of the "gas-based" fractions of the inventory to become incorporated in and mobilized by the groundwater, and for the "glassbound" fractions to slowly dissolve into the groundwater over the long term.

The decay chain dynamics for ${ }^{90} \mathrm{Sr}$ and ${ }^{137} \mathrm{Cs}$ are of particular interest because they have noblegas precursors that can be transported away from the detonation point before decaying to their respective daughter products (e.g., ${ }^{137} \mathrm{Xe}$ decays to ${ }^{137} \mathrm{Cs}$ in $3.84 \mathrm{~min}$ ). Noncondensible gases, such as $\mathrm{CO}_{2}$ and $\mathrm{H}_{2}$, may act as carrier gases and may move these fission products away from the explosion point (Thompson, 1996). Smith et al. (1996) reported substantial amounts of ${ }^{90} \mathrm{Sr}$ and ${ }^{137} \mathrm{Cs}$ in the fracture zone $10 \mathrm{~m}$ or more away from the cavity wall of a 20 - to 150 -kt explosion. From isotopic ratio data, it was concluded that the gases are not directly injected into the surrounding rock by the explosion, but rather that they penetrate into reactivated preexisting and shot-induced fissures. 
Table 1. Percentage distribution of radionuclides among the glass, rubble, gas, and groundwater following a typical underground nuclear test. (Data are from IAEA, 1998)

\begin{tabular}{ccccc}
\hline Radionuclide & Glass & Rubble & Gas & Water \\
\hline${ }^{3} \mathrm{H}$ & & & 2 & 98 \\
${ }^{36} \mathrm{Cl}$ & 50 & 40 & & 10 \\
${ }^{60} \mathrm{Co}$ & 90 & 10 & & \\
${ }^{90} \mathrm{Sr}$ & 25 & 75 & & \\
${ }^{129} \mathrm{I}$ & 50 & 40 & & 10 \\
${ }^{137} \mathrm{Cs}$ & 10 & 90 & & \\
${ }^{155} \mathrm{Eu}$ & 95 & 5 & \\
${ }^{239} \mathrm{Pu}$ & 95 & 5 & \\
${ }^{241} \mathrm{Am}$ & 95 & 5 & \\
\hline
\end{tabular}

Zones around a nuclear cavity

The propagation of the shock wave from a nuclear explosion produces different spherical zones around the explosion point (Figure 4). Outside the cavity zone exists a fracture zone, which is created from shear failure of the formation. This zone normally extends out to a radius of 4-5 times the cavity radius. Further out is the crack zone, where radial cracks can be observed at a decreasing intensity out to a maximum distance of about $10 \pm 2$ cavity radii. Beyond the outer limit, the rock is essentially undamaged. Because the stress is greater laterally and downward than upward, the fracturing is more extensive upward than in other directions. The inducedfracture systems surrounding the cavities are influenced by such preexisting discontinuities in the rock as bedding, jointing, and faults. The shock wave and the elastic wave from the explosion tend to open and enlarge such discontinuities in the rock (Crow, 1976).

A high-permeability zone marks the distance where rock permeability has significantly increased because of the explosion. High-permeability zones occur on average at a radius of 2-2.5 times the cavity radius inside the fracture zone. These zones are observed from the disappearance of water, released during reentry drilling, into the cavity (IAEA, 1998).

Studies of nuclear tests fired above the water table indicate that material may be transported by prompt injection through explosion-induced fractures arranged radially away from ground zero (Nimz and Thompson, 1992; Smith et al., 1996; Rose et al., 2000c). This prompt injection process may deposit radionuclides outside the immediate vicinity of the cavity and chimney system. By this mechanism, gaseous species (tritium and ${ }^{137} \mathrm{Cs}$ ) may be deposited several cavity radii away from the working point. 


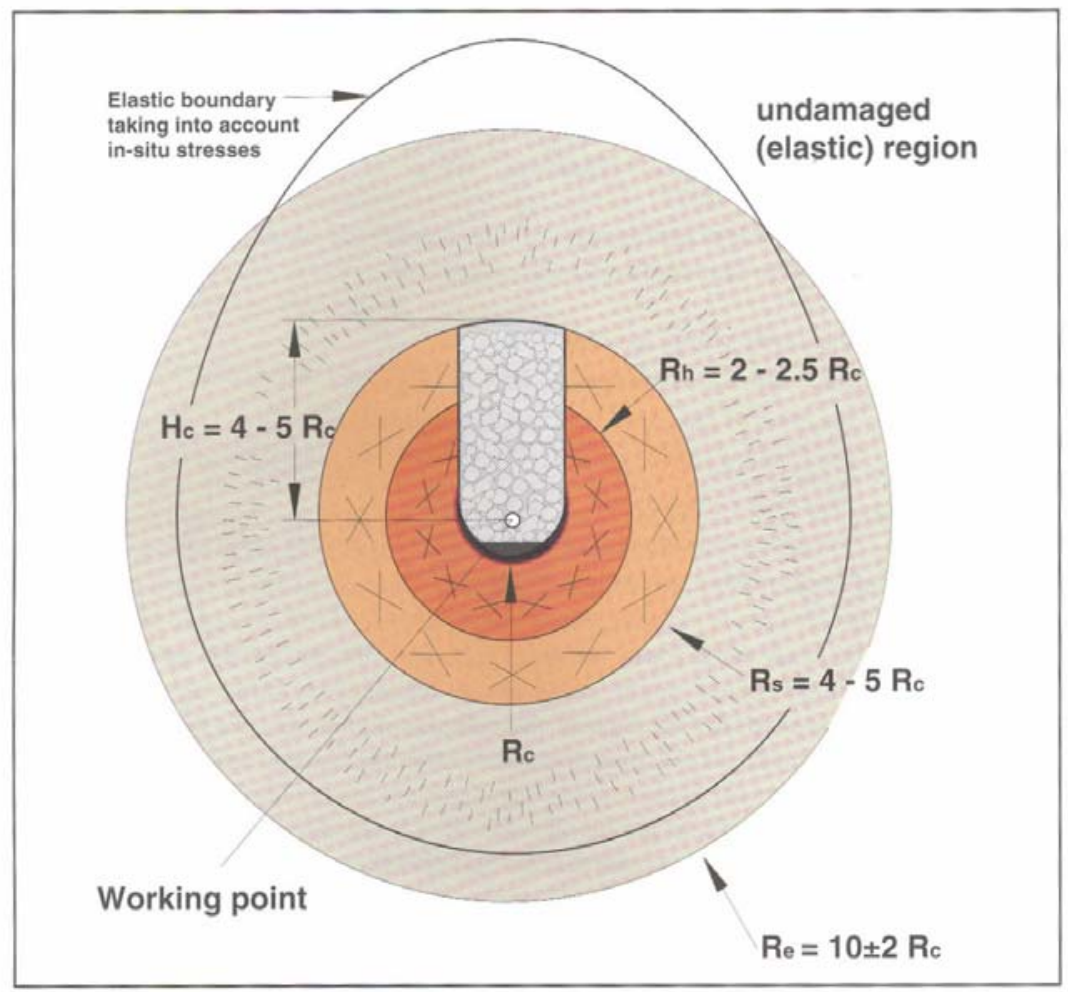

Figure 4. Different spherical zones around the explosion point. $R_{\mathrm{c}}$ : cavity radius; $H_{\mathrm{c}}$ : chimney height; $R_{\mathrm{h}}$ : radius for the zone of increased permeability; $R_{\mathrm{s}}$ : fracture zone radius; $R_{\mathrm{e}}$ : crack zone radius. (Reproduced from IAEA, 1998.)

Two forced-gradient-radionuclide-migration experiments, related to the CAMBRIC and CHESHIRE tests, are briefly summarized below. They are the two underground weapons tests that have been most thoroughly characterized by the DOE/NV RNM Program. Data from these two radionuclide migration studies contribute significantly to the knowledge base of which radionuclides are soluble, ranges in observed concentrations, and factors that affect radionuclide mobility. CAMBRIC and CHESHIRE also represent two major NTS hydrogeologic settings (alluvium and fractured volcanic rock), which are closely relevant to the TSPA of the potential repository at Yucca Mountain. Yucca Mountain consists of a group of north-south-trending block-faulted ridges composed of tertiary volcanic rocks. Approximately $12-13 \mathrm{~km}$ from the site, the water table transitions from volcanic tuffs to alluvium (Eddebbarh et al., 2003).

\section{The CAMBRIC test}

Frenchman Flat is located in the southeast corner of NTS (Figure 1). As discussed in Bryant (1992), Frenchman Flat is an intermountain basin formed by tertiary-age faulting typical of the basin and range physiographic province. To the north and west, the basin is rimmed by tertiary volcanic rocks derived from volcanic centers west and northwest of Frenchman Flat. Highlands to the south and east, as well as the underlying basement rock, are composed of Paleozoic carbonate rocks. Most of the basin is covered by tertiary volcanic rocks and volcanic-derived sedimentary rocks. The central part of the Frenchman Flat basin is filled with quaternary/tertiary alluvium. 


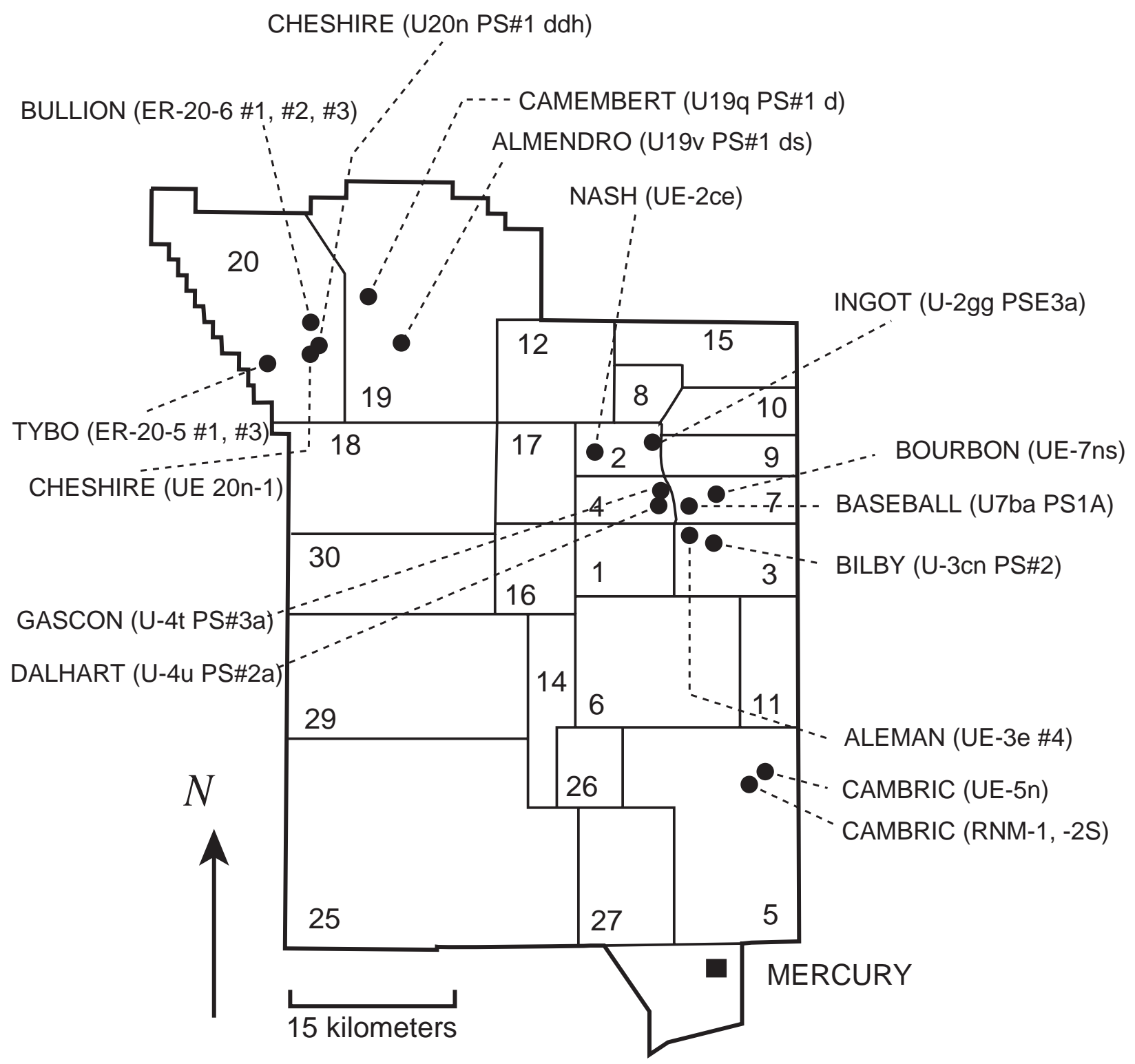

Figure 5. Map of the Nevada Test Site showing the near-field sampling sites. Both test name and affiliated near-field well (in parentheses) are provided.

The CAMBRIC test was conducted in the central portion (alluvium) of Frenchman Flat in 1965 at a depth of $295 \mathrm{~m}, 77 \mathrm{~m}$ below the water table (see Figures 1 and 5). The device was deployed in emplacement hole U5e, with a yield of $0.75 \mathrm{kt}$. The CAMBRIC test produced a blast cavity with a diameter of $22 \mathrm{~m}$. The chimney extends above the water table but does not reach the ground surface. The height of the chimney is uncertain but is expected to be in the range of 100$140 \mathrm{~m}$ (Borg et al., 1976; Guell and Hunt, 2003). The calculated volume of melt glass produced at the bottom of the cavity is between 525 and $975 \mathrm{t}$. Outside the cavity-chimney region lies relatively undisturbed alluvium. The composition of the melt glass, chimney, and cavity rubble reflects the composition of the original and undisturbed alluvium. 


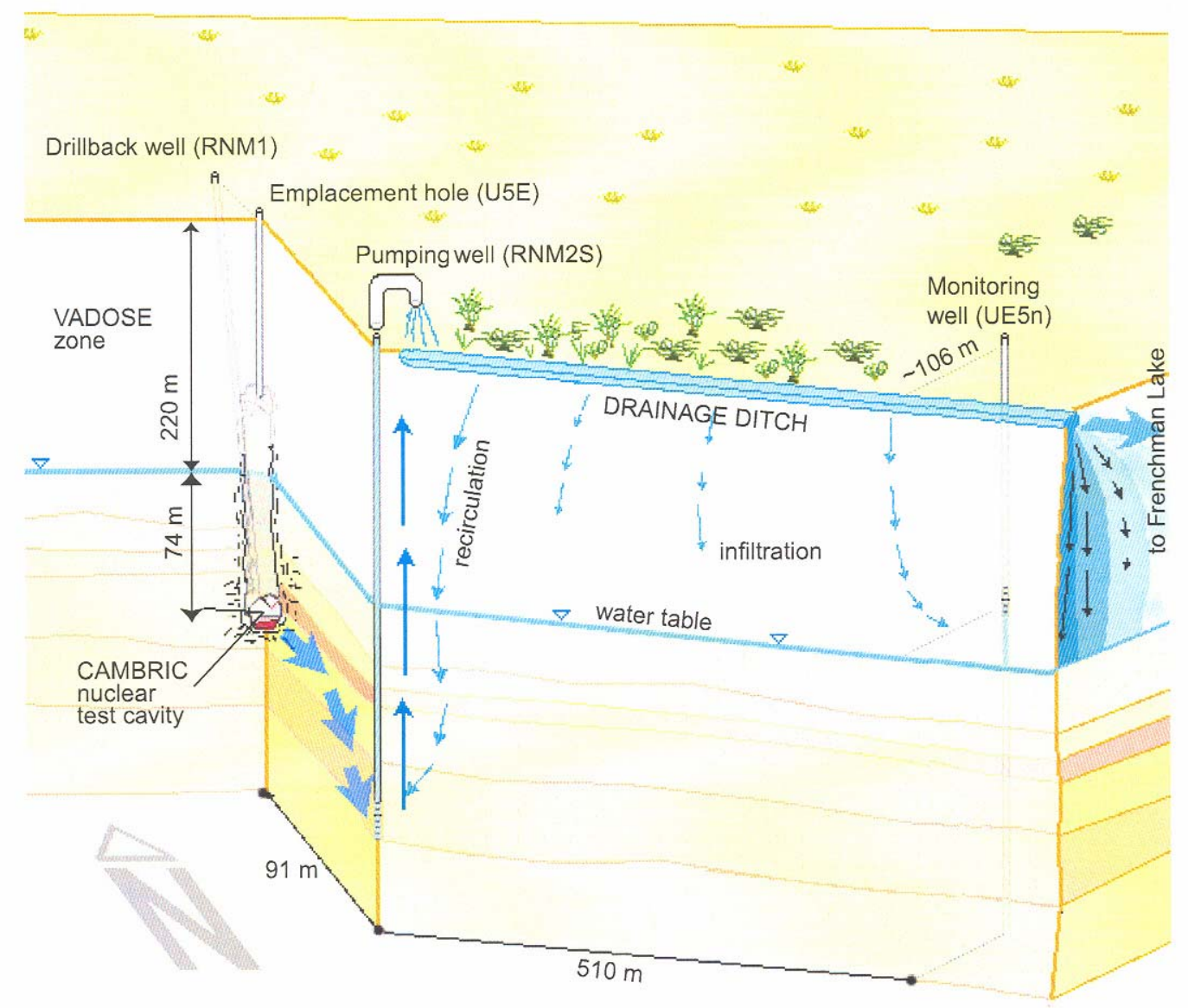

Figure 6. Schematic of the CAMBRIC experiment. (Reproduced from Tompson et al., 2002.)

In 1975, the RNM-1 hole was drilled into and through the cavity, and numerous rock and water samples were collected (Figure 6). Nearly all of the radioactive material associated with the test was found still in the cavity region (Hoffman et al., 1977; Bryant, 1992). A satellite well (RNM2s) was drilled $91 \mathrm{~m}$ from the cavity, and pumping began in 1975 to observe the groundwater transport of radionuclides. Water from both the RNM-1 and RNM-2s holes has been periodically sampled ever since. Continuous pumping at RNM-2s was terminated in 1991 after approximately $1.7 \times 10^{7} \mathrm{~m}^{3}$ of water had been pumped out and discharged into the drainage ditch. A monitoring well, UE-5n, was drilled to a depth of $514 \mathrm{~m}$ in March 1976 and completed with a 27-cm casing to a depth of $464 \mathrm{~m}$. It is approximately $560 \mathrm{~m}$ southeast of RNM-1 and $510 \mathrm{~m}$ away from RNM$2 \mathrm{~s}$.

Over the duration of the 16-year pumping experiment, the effluent produced relatively complete breakthrough profiles of the mobile radionuclides ${ }^{3} \mathrm{H},{ }^{36} \mathrm{Cl},{ }^{85} \mathrm{Kr}$, and ${ }^{129} \mathrm{I}$ and sporadic observations of ${ }^{99} \mathrm{Tc}$ and ${ }^{106} \mathrm{Ru}$ arrivals. Immobile species such as ${ }^{90} \mathrm{Sr},{ }^{137} \mathrm{Cs}$, and $\mathrm{Pu}\left({ }^{238} \mathrm{Pu}\right.$, ${ }^{239} \mathrm{Pu}$ ) were looked for but never detected (Bryant, 1992). In general, the first arrival times of ${ }^{36} \mathrm{Cl},{ }^{106} \mathrm{Ru}$, and ${ }^{129} \mathrm{I}$ were similar to that of tritium. The peak concentration of ${ }^{36} \mathrm{Cl}$ occurred somewhat earlier than that of tritium, while those of ${ }^{85} \mathrm{Kr}$ and ${ }^{129} \mathrm{I}$ were somewhat delayed. However, measurements for ${ }^{106} \mathrm{Ru}$ and ${ }^{129} \mathrm{I}$ were not made at frequent intervals. In general, differences in the shapes of these profiles can be attributed to early-time phenomenologic (detonation) effects that affect initial radionuclide distributions (Bryant, 1992; Tompson et al., 
2002; Guell and Hunt, 2003), as well as to slight differences in the overall mobility of radionuclides in groundwater.

\section{The CHESHIRE test}

The CHESHIRE device was fired in early 1976 in the fractured volcanic rocks of Pahute Mesa at a depth of $1174 \mathrm{~m}$, some $544 \mathrm{~m}$ below the water table (see Figures 1 and 5). The CHESHIRE test was detonated in the U-20n emplacement hole with a reported yield of 200-500 kt. At

CHESHIRE, the saturated zone consists of the Calico Hills rhyolite lava that is among the most transmissive volcanic rock aquifers at the NTS because of the lava's widespread and laterally continuous fracture network. The CHESHIRE site is also significant because it is located in western Pahute Mesa and is representative of the other large, below-the-water-table tests that are close to potential off-site points of public water use.

In 1987, a hole (UE 20n-1) was drilled $300 \mathrm{~m}$ away from the CHESHIRE site (Figure 7a). This hole was $100 \mathrm{~m}$ in depth and penetrated several permeable zones thought to serve as pathways for water flow away from the cavity region. Sawyer et al. (1999) summarized historical interpretations of radionuclide migration associated with the CHESHIRE test. Monitoring of water samples from U-20n PS\#1 ddh and UE 20n-1 wells indicates that the concentration of ${ }^{3} \mathrm{H}$, ${ }^{85} \mathrm{Kr},{ }^{125} \mathrm{Sb}$, and ${ }^{137} \mathrm{Cs}$ in the cavity has decreased with time and that these radionuclides appear at UE 20n-1. In addition, $\mathrm{Mn}, \mathrm{Co}, \mathrm{Ce}$, and Eu isotopes (and even appreciable fractions of Cs) are observed to be in associated with colloidal material (Buddemeier and Hunt, 1988). Studies of solid and fluid samples from CHESHIRE indicate that the test cavity filled in quickly with water containing high concentrations of tritium $\left(10^{7} \mathrm{~Bq} / \mathrm{L}\right)$ and other soluble radionuclides including ${ }^{90} \mathrm{Sr},{ }^{106} \mathrm{Ru}$, and ${ }^{125} \mathrm{Sb} .{ }^{137} \mathrm{Cs}$ and refractory radionuclides (e.g., ${ }^{144} \mathrm{Ce}$ ) were found in low concentrations. A comparison of the predicted versus observed hydrologic source term for the CHESHIRE cavity indicates that the effective volume in which the tritium was distributed was approximately 2 times that of the cavity; tritium was most likely well mixed throughout the collapsed chimney, which extends upward to the level of the static water table.

The data from the CHESHIRE test are exceptional because they document both the prompt $(<1$ year) radiologic-source-term residual as well as the resulting hydrologic source term. This data set is also unique because it permits an analysis of the transition between the immediate dispersal of radioactive materials and the subsequent migration involving physicochemical interactions with the regional aquifer system. These data provide information about the controls on radionuclide migration associated with high-yield ( $>200-\mathrm{kt})$, below-the-water-table tests conducted in fracture-flow volcanic aquifers at the NTS. 


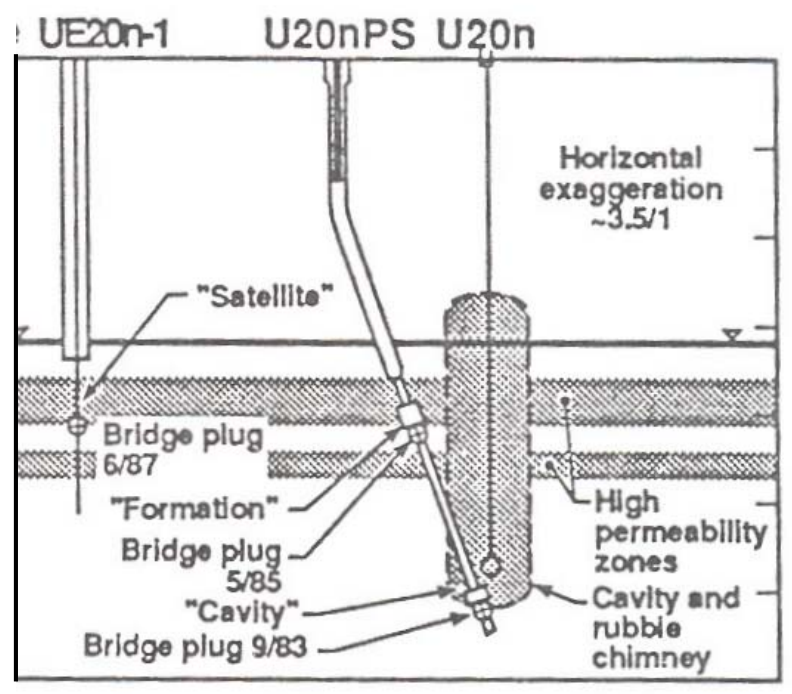

(a)

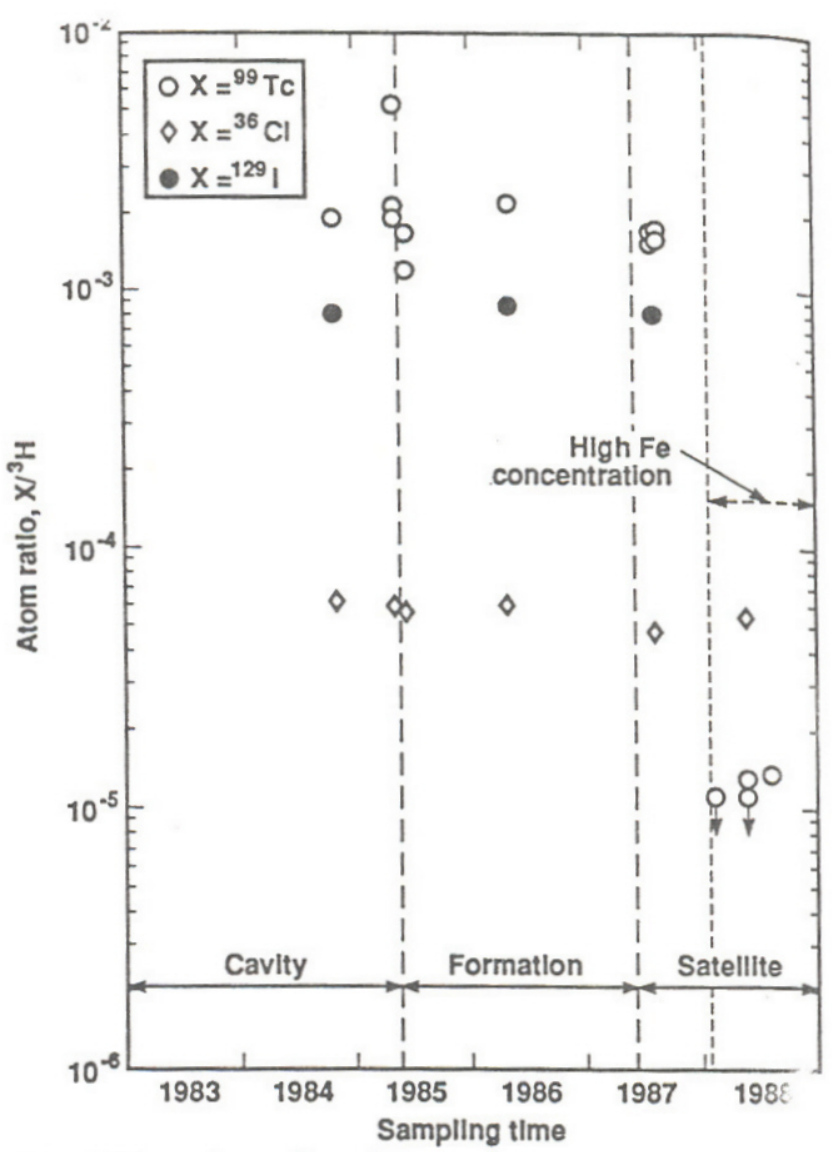

(b)

Figure 7. (a) Vertical section of the CHESHIRE study area, showing the relationship between the UE 20n-1 satellite well and the cavity and formation sampling points in the U-20n PS hole. (b) The ratios of ${ }^{36} \mathrm{Cl},{ }^{129} \mathrm{I}$, and ${ }^{99} \mathrm{Tc}$ to ${ }^{3} \mathrm{H}$ in the CHESHIRE test at various sampling times and locations. (Reproduced from Buddemeier et al., 1991.) 


\section{Migration of mobile radionuclides}

We now proceed to present the results obtained from the synthesis of available radionuclide concentration data at the NTS, with a focus on radionuclides inferred to exhibit conservative migration behavior $\left({ }^{3} \mathrm{H},{ }^{14} \mathrm{C},{ }^{36} \mathrm{Cl},{ }^{85} \mathrm{Kr},{ }^{99} \mathrm{Tc}\right.$, and $\left.{ }^{129} \mathrm{I}\right)$. Radionuclides that behave nonconservatively (e.g., $\mathrm{Sr}$ and $\mathrm{Cs}$ ) are not specifically included in this report. Furthermore, colloid-facilitated transport for otherwise strongly sorbing radionuclides such as $\mathrm{Pu}$ (Kersting et al., 1999) is not examined here either.

\section{Compilation of "hot” well data}

"Hot" (near-field) wells refer to sampling wells where the samples contain radionuclides above the Nevada safe-drinking-water standards. A number of hot wells were completed opportunistically in postshot reentry borings into a nuclear test cavity or chimney. These borings were originally drilled to return solid samples for diagnosing device performance. The near field includes the area extending radially $\sim 300 \mathrm{~m}$ from surface ground zero, the firing point of an underground nuclear test projected upwards on ground surface (Smith, 2002). Due to cavity collapses and well plugging, fewer than 20 of approximately 300 saturated nuclear event cavities are available for sampling (Kersting, 1996). Only 15 near-field study sites regularly produce water (Smith, 2002). Although the original near-field sampling program was not designed to detect the arrival or movement of radionuclides, a body of data accumulated over 30 years from these wells can be used to establish bounds on the radionuclides in solution and to deduce controls on their solubility and mobility.

From archival technical reports of LLNL, LANL, and NNSA/NV, we have compiled a database that contains radionuclide concentration data from 18 monitoring wells for 14 nuclear tests at the NTS, with a total of 201 sampling events (Table 2). The database includes information, if available, about the sampling well, depth, date, measured $\mathrm{pH}$, dissolved oxygen (DO), and concentrations for inorganic carbon, anions, cations, stable isotopes, and radionuclides. Relevant information, such as filtration and data reference source, is also included. The database is composed of 13 Excel files, which are associated with each individual nuclear test. (The TYBO and BENHAM tests are combined in one file.) In the file, the activity of radionuclides is decaycorrected to the test date of each nuclear detonation. The files have been submitted with this report.

We further focus on the measured activity for ${ }^{3} \mathrm{H},{ }^{14} \mathrm{C},{ }^{36} \mathrm{Cl},{ }^{85} \mathrm{Kr},{ }^{99} \mathrm{Tc}$, and ${ }^{129} \mathrm{I}$, as available. These activities were decay-corrected to September 23, 1992, the date of the last underground nuclear test at the NTS. By this decay correction, we can directly compare the radionuclide inventory for the five principal geographic test centers reported by Bowen et al. (2001) and Smith et al. (2003). These reports contain a compilation of the residual radionuclide inventory remaining from 828 underground nuclear tests conducted from 1951 to 1992. This inventory is available to the general public, but the test-specific inventory is classified. The source-term inventory does not represent the total radioactivity dissolved in the groundwater. The radioactive inventory was subdivided into five principal geographic test centers (Figure 1) by summing the radionuclide totals for individual tests into regional areas. This process may minimize the contribution from any one test, particularly for higher-yield tests. Because the radionuclide source term is device-dependent, a better method would consider each test individually, relative to both yield and specific radionuclide production. Yet such information is classified. 
Table 2. List of hot wells and sample collection times.

\begin{tabular}{|c|c|c|c|c|}
\hline Test name & Test date & $\begin{array}{l}\text { Emplacement } \\
\text { hole }\end{array}$ & Well name(s) & Hot well sample collection times \\
\hline ALEMAN & $9-11-1986$ & $\mathrm{U}-3 \mathrm{kz}$ & UE-3e \#4 & $8 / 93$ \\
\hline ALEMENDRO & $6-6-1973$ & $\mathrm{U}-19 \mathrm{v}$ & U-19v PS\#1 ds & $9 / 93,6 / 96,9 / 98,8 / 99,9 / 00,5 / 01$ \\
\hline \multirow[t]{2}{*}{ BILBY } & $9-13-1963$ & $\mathrm{U}-3 \mathrm{cn}$ & U-3en PS\#2 & 9/77 (8 times), 10/81, 7/82, 7/83, 6/85, 1/97, 12/01 \\
\hline & & & $\mathrm{U}-3 \mathrm{cn} \# 5$ & $1 / 97,10 / 81,10 / 80$ \\
\hline BOURBON & $1-20-1967$ & U-7n & UE-7ns & 6/83, 1984 (7 times), 8/93, 8/01 \\
\hline \multirow[t]{2}{*}{ BULLION } & $6-13-1990$ & U-20bd & ER-20-6 \#1 & 12/96, 6/1997 (2 times), 8/97, 5/98 \\
\hline & & & ER-20-6 \#2 & 11/96, 6/1997 (2 times), 6/97 \\
\hline \multirow[t]{3}{*}{ CAMBRIC } & $5-14-1965$ & $\mathrm{U}-5 \mathrm{e}$ & RNM-1 & $9 / 79,10 / 81,4 / 82,4 / 85,5 / 86,9 / 93,6 / 00$ \\
\hline & & & RNM-2s & $\begin{array}{l}11 / 78,2 / 79,3 / 79,8 / 79,4 / 80,7 / 80,7 / 81,11 / 82,4 / 84 \\
9 / 93,10 / 99,6 / 00\end{array}$ \\
\hline & & & UE-5n & $10 / 99,4 / 01$ \\
\hline CAMEMBERT & $6-26-1975$ & $\mathrm{U}-19 \mathrm{q}$ & U-19q PS\#1 d & $10 / 98$ \\
\hline \multirow[t]{2}{*}{ CHESHIRE } & 2-14-1976 & U-20n & $\begin{array}{l}\text { U-20n PS\#1 } \\
\text { ddh }\end{array}$ & $\begin{array}{l}\text { 1976, 9/83, 10/84, } 1985 \text { (5 times), 9/94, 6/96, 7/97, 7/98, } \\
\text { 9/98, 10/99 }\end{array}$ \\
\hline & & & UE 20n-1 & 1987 (98 times), 1988 (2 times) \\
\hline DALHART & $10-13-1988$ & $\mathrm{U}-4 \mathrm{u}$ & U-4u PS\#2a & $8 / 93,7 / 97,8 / 99$ \\
\hline GASCON & $11-14-1986$ & $\mathrm{U}-4 \mathrm{t}$ & U-4t PS\#3a & $8 / 93$ \\
\hline INGOT & $3-9-1989$ & U-2gg PSE3a & U-2gg PSE3a & $9 / 94$ \\
\hline NASH & $1-19-1967$ & U-2ce & UE-2ce & $3 / 78,10 / 80,2 / 82,7 / 82,8 / 83,4 / 84,8 / 93,8 / 01$ \\
\hline \multirow[t]{2}{*}{ TYBO / BENHAM } & 5-14-1975 (ТYBO) & $\mathrm{U}-20 \mathrm{y} / \mathrm{U}-20 \mathrm{c}$ & ER-20-5 \#1 ${ }^{\text {a }}$ & $1 / 96,6 / 96,4 / 97,7 / 98$ \\
\hline & \multicolumn{2}{|c|}{ 12-19-1968 (BENHAM) } & ER-20-5 \#3 ${ }^{\text {a }}$ & $2 / 96,7 / 96,4 / 97,4 / 98,11 / 01$ \\
\hline
\end{tabular}

${ }^{a}$ The ER-20-5 well cluster was drilled in the near-field ( $\sim 300 \mathrm{~m}$ from the surface ground zero) environment of the TYBO test. However, Pu isotopic signatures indicate the radionuclides in water samples from ER-20-5 wells are derived from the BENHAM test detonated $\sim 1300 \mathrm{~m}$ up-gradient (Kersting et al., 1999). 
As discussed by Kersting (1996), significant differences in sampling protocols have existed over the years. Some samples were collected from the static water column using 2-L bailers, while other wells were pumped prior to sampling. Some samples were filtered before analysis, and some were not. In addition, not all radionuclides of interest were analyzed for each fluid sample. Yet, having recognized these limitations, important information can still be obtained from the various cavity waters and satellite wells regarding the occurrence of specific radionuclides, concentrations, and change in activity over time.

Because tritium is probably the best tracer for tracking water flow and solute transport, we used a ratio approach with tritium as the reference nuclide (i.e., ${ }^{99} \mathrm{Tc} /{ }^{3} \mathrm{H}$ and ${ }^{129} \mathrm{I} /{ }^{3} \mathrm{H}$ ) to assess the migration of other radionuclides. The resulting ratio for each nuclear test was further normalized by dividing with the corresponding ratio value of the source-term inventory, available from Bowen et al. (2001) and Smith et al. (2003), for the principal geographic test center where the nuclear test is located. This normalization, scaling proportionally to the concentration of tritium, provides us with an estimate of the distribution and migration behavior of these radionuclides compared to that of tritium. In other words, if a radionuclide behaves (distribute in the cavitychimney and migrate in the groundwater) as tritium, the normalized concentration ratio will be 1 . As listed in Table 3, some near-field wells sample the cavity-chimney region, and the normalized ratio value of radionuclides will shed light on their distribution in the aqueous, as compared to the nonsoluble, phase; a ratio significantly lower than 1 indicates that this radionuclide exists predominantly in nonsoluble phase. Some are satellite wells located a certain distance away from the cavity-chimney region, and ratio values will help us understand the migration behavior of radionuclides away from the cavity-chimney region; a ratio of 1 signifying the radionuclide migrates conservatively as tritium. Therefore, the discussion that follows will center on the comparison between ratios among samples in cavity-chimney and the satellite wells.

\section{Migration behavior of radionuclides at the NTS}

\section{Tritium-3}

Tritium (half-life [ $t_{1 / 2}$ ] is 12.26 years) is the most abundant radionuclide produced by underground testing. Following a nuclear detonation, tritium occurs mainly in the forms of hydrogen gas (HT) and tritiated water (HTO). Tritium is probably present in free-radical form at early times after the nuclear explosion. The high temperature caused by the explosion, which is greater than the temperatures at which the hydrated forms of many minerals are stable, liberates interstitial water in both the zone of vaporization and the zone of melting, the bound water in the vaporized zone, and much of the bound water in the melted rock. The tritium free radicals are mixed intimately with the vaporized water at temperatures sufficiently high to cause dissociation of the water molecules and to allow incorporation of the tritium in some of them. The tritiated water remains a vapor until the condensation from cooling (Crow, 1976). In the oxidizing environment, $98 \%$ of the tritium becomes associated with water vapor shortly after detonation and then condenses into the liquid phase, leaving only $2 \%$ in the form of HT (Smith, 1998). 
Table 3. Compilation of hot wells and sampling locations.

\begin{tabular}{|c|c|c|c|c|c|}
\hline Test name & $\begin{array}{c}\text { Depth } \\
\text { of } \\
\text { burial } \\
\text { from } \\
\text { surface } \\
\text { (m) }\end{array}$ & $\begin{array}{l}\text { Depth to } \\
\text { water } \\
\text { from } \\
\text { surface } \\
\text { (m) }\end{array}$ & Yield (kt) & Sampling well & $\begin{array}{c}\text { Sampling location with } \\
\text { respect to the test }\end{array}$ \\
\hline ALEMAN & 503 & 475 & $<20$ & UE-3e \#4 & $58 \mathrm{~m}$ north \\
\hline ALEMENDRO & 1067 & 707 & $200-1000$ & U-19v PS\#1 ds & Cavity-chimney region \\
\hline \multirow{2}{*}{ BILBY } & \multirow{2}{*}{715} & \multirow{2}{*}{509} & \multirow{2}{*}{249} & U-3cn PS\#2 & Chimney region \\
\hline & & & & $\mathrm{U}-3 \mathrm{cn} \# 5$ & $122 \mathrm{~m}$ from cavity \\
\hline BOURBON & 560 & 601 & $20-200$ & UE-7ns & 137 m away \\
\hline \multirow{2}{*}{ BULLION } & \multirow{2}{*}{674} & \multirow{2}{*}{621} & \multirow{2}{*}{$20-150$} & ER-20-6 \#1 & $166 \mathrm{~m}$ southwest \\
\hline & & & & ER-20-6 \#2 & 207 m southwest \\
\hline \multirow{3}{*}{ CAMBRIC } & \multirow{3}{*}{295} & \multirow{3}{*}{218} & \multirow{3}{*}{0.75} & RNM-1 & Cavity \\
\hline & & & & RNM-2s & $91 \mathrm{~m}$ from cavity \\
\hline & & & & UE-5n & $510 \mathrm{~m}$ from RNM-2s \\
\hline CAMEMBERT & 1312 & 666 & $200-1000$ & U-19q PS\#1 d & Chimney region \\
\hline \multirow{2}{*}{ CHESHIRE } & \multirow{2}{*}{1167} & \multirow{2}{*}{631} & \multirow{2}{*}{$200-500$} & U-20n PS\#1 ddh & Cavity \\
\hline & & & & UE 20n-1 & 300 m from cavity \\
\hline DALHART & 640 & 477 & $<150$ & U-4u PS\#2a & Chimney region \\
\hline GASCON & 593 & 490 & $20-150$ & U-4t PS\#3a & $\sim 170$ m away \\
\hline INGOT & 500 & 563 & $20-150$ & U-2gg PSE3a & $65 \mathrm{~m}$ from working point \\
\hline NASH & 364 & 527 & 39 & UE-2ce & $183 \mathrm{~m}$ from working point \\
\hline \multirow{2}{*}{ TYBO } & \multirow{2}{*}{765} & \multirow{2}{*}{630} & \multirow[t]{2}{*}{$200-1000$} & ER-20-5 \#1 & $280 \mathrm{~m}$ southwest \\
\hline & & & & ER-20-5 \#3 & $280 \mathrm{~m}$ southwest \\
\hline \multirow{2}{*}{ BENHAM $^{a}$} & \multirow{2}{*}{1402} & \multirow{2}{*}{630} & \multirow{2}{*}{1150} & ER-20-5 \#1 & $1300 \mathrm{~m}$ south \\
\hline & & & & ER-20-5 \#3 & $1300 \mathrm{~m}$ south \\
\hline
\end{tabular}

${ }^{a}$ Data from Kersting et al. (1999). ER-20-5 \#3 is 30 m south of well ER-20-5 \#1.

Tritium has been considered an ideal water tracer (Davis et al., 1980). However, a slight retardation of tritium in transport studies has been reported in numerous publications (e.g., Wierenga et al., 1975; van Genuchten and Wierenga, 1977; Gaber et al., 1995; Hu and Brusseau, 1996). The retardation factor for tritium was measured to be 1.17 in an aggregated tropical soil (Seyfried and Rao, 1987) and 1.2 in a column packed with glass beads and porous kaolinite 
spheres (Hu and Brusseau, 1996). Seyfried and Rao (1987) also reported a significantly larger tritium sorption from batch adsorption experiments than column transport studies. A linear sorption isotherm of tritium was observed, with a $K_{d}$ (sorption distribution coefficient) value of $0.133 \pm 0.0046 \mathrm{~mL} / \mathrm{g}$ from batch experiments, compared to a $K_{d}$ value of $0.0653 \pm 0.0044 \mathrm{~mL} / \mathrm{g}$ from column studies.

The interaction of tritium with solid surface has been postulated to occur via hydroxyl exchange with clay lattice hydroxyls (Stewart and Baker, 1973). This process is more pronounced in kaolinite minerals that have available hydroxyl groups at platelet surfaces. In contrast, montmorillonite and illite minerals undergo exchange only at the edges of the plates (where the hydroxyl groups are available), and thus isotopic exchange is almost negligible (Gvirtzman and Magaritz, 1986). Stewart (1970) suggested that the interaction between tritium and solid surfaces depends upon moisture content and will be greater during the flow of tritiated water into initially dry soil than during miscible displacement flow in saturated soils. Because of the low mass numbers of hydrogen isotopes, the differences in their atomic masses and zero-point vibrational energy bonds are large, and there is a high potential for an isotopic effect (Stewart, 1972). Tritium offers the greatest potential for an isotopic effect because, compared to protium, it has the greatest relative difference in atomic weight. The magnitude of the isotopic effect depends upon the energy required to break and re-form hydrogen bonds. During the evaporation of tritiated and deuterated water, an isotopic effect was observed by Stewart (1972), with the vapor phase containing about $10 \%$ less tritium and $6 \%$ less deuterium than the liquid phase.

An appreciable sorption of tritium is not expected at NTS because the geological media at NTS do not contain the high amount of clays needed for tritium retardation, except for highly zeolitized rocks (Rose et al., 2000c). However, Burbey and Wheatcraft (1986) reported that using tritium sorption was necessary to match the tritium elution curve at the CAMBRIC test. Bryant (1992) cautioned that (1) the fit with no tritium sorption was quite good and (2) the magnitude of the reported $K_{d}$ value $(0.8 \mathrm{~mL} / \mathrm{g})$ by Burbey and Wheatcraft (1986) is unusually large. Nevertheless, Bryant (1992) speculated that although the retardation effect is relatively small, it may not be zero.

\section{Carbon-14}

${ }^{14} \mathrm{C}$ is expected to exist as bicarbonate anions in the NTS groundwater. Before $1998,{ }^{14} \mathrm{C}$ was measured by liquid scintillation counting; more recently, ${ }^{94} \mathrm{C}$ has been measured by accelerator mass spectrometry (AMS). Most normalized ${ }^{14} \mathrm{C} /{ }^{3} \mathrm{H}$ ratios are about 1 at the cavity-chimney region, indicating that ${ }^{14} \mathrm{C}$ exists predominantly in the aqueous phase (Figure 8 ). The normalized ratios at satellite wells are similar to, although a bit lower than, those at cavity-chimney wells. This suggests that dissolved ${ }^{14} \mathrm{C}$ migrates similarly as tritium in saturated groundwater. However, ${ }^{14} \mathrm{C}$ data has exhibited variability among samples collected at different durations or depths from the same well, as shown for the DALHART and ALMENDRO tests (Figure 8). Furthermore, the ${ }^{14} \mathrm{C}$ ratio at the far field (UE-5n) is 10 times lower than its discharge source (RNM-2s) at the CAMBRIC vadose zone test (Figures 7-8). The delayed transport of ${ }^{14} \mathrm{C}$ from retardation is most likely related to its isotopic exchange with nonmobile carbon atoms, such as those of carbonate; such exchanges may be more pronounced in the vadose zone. 


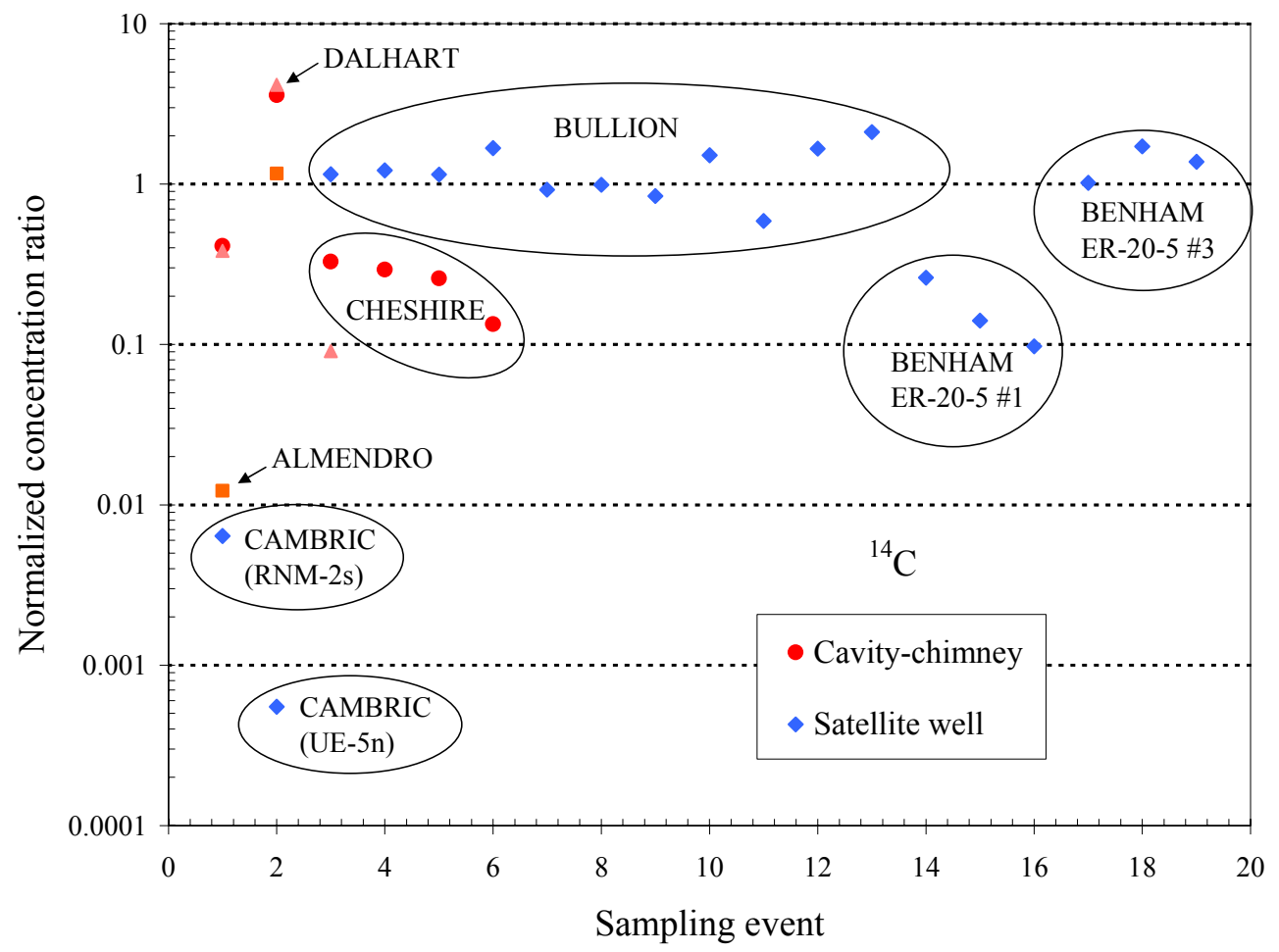

Figure 8. Normalized concentration ratio for ${ }^{14} \mathrm{C}$ in the hot wells.

According to Stead (1963), the amount of ${ }^{14} \mathrm{C}$ induced by neutron reaction with ${ }^{14} \mathrm{~N}$ is at least 4 orders of magnitude lower in an underground nuclear explosion than in an atmospheric explosion. For a nominal 1-Mt fusion explosion underground, the production of ${ }^{14} \mathrm{C}$ is only about $15 \mathrm{Ci}$. The overwhelming activity of ${ }^{14} \mathrm{C}$ resulting from the atmospheric nuclear testing at the NTS need to be taken into account when studying the migration behavior of ${ }^{14} \mathrm{C}$ produced from the underground tests.

\section{Chlorine-36}

For the groundwater samples collected at the NTS, the atom ratio of ${ }^{36} \mathrm{Cl} /{ }^{35} \mathrm{Cl}$ is measured by AMS, and the concentration of ${ }^{36} \mathrm{Cl}$ is calculated by determining the stable chloride concentration from ion chromatography.

${ }^{36} \mathrm{Cl}$ is expected to exist as chloride anions in the NTS groundwater. The surface charge for many clay minerals of the geologic media is predominantly negative and repels the negative charge carried by anions. As a result, chloride is not expected to sorb onto many geologic media. On the contrary, anion exclusion could occur when anions are partially or totally excluded from some water-carrying passageways, resulting in a greater average velocity for chloride than for water molecules. For a soil that contained 40\% clay, Thomas and Swoboda (1970) found that the rate of chloride movement was 1.37 times faster than deuterium. During the CAMBRIC pumping experiment, the breakthrough and the maximum concentration of ${ }^{36} \mathrm{Cl}$ appear slightly ahead of tritium in alluvium. Ogard et al. (1988) suggested that this was caused by the anion exclusion effect that effectively prevented ${ }^{36} \mathrm{Cl}^{-}$from entering the intragranular porosity of the soil particle. 
The calculated anion exclusion volume of the alluvium at the NTS was $7.0 \mathrm{~mL}$ of liquid for 100 g of soil (Ogard et al., 1988).

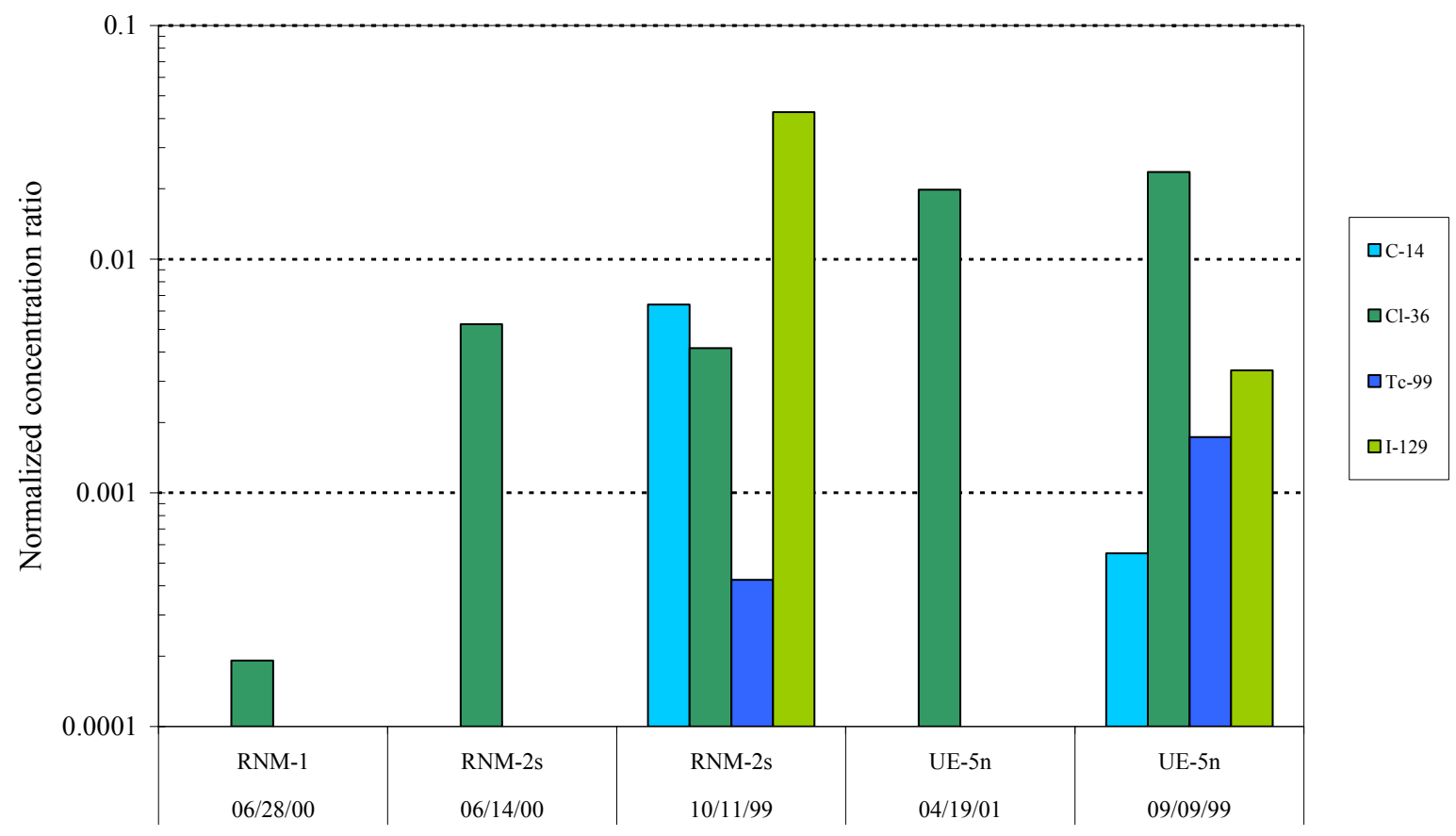

Sample collection location and date

Figure 9. Concentration ratios of selected radionuclides relative to tritium for wells associated with the CAMBRIC site.

We would like to point out that both early (anion exclusion) and delayed (anion sorption) transport of anions have been reported in various geologic media (McMahon and Thomas, 1974; Chan et al., 1980; Gvirtzman et al., 1986; Toner et al., 1989; Ishiguro et al., 1992; Seaman, 1998). The process and magnitude of anion exclusion are related to the nature of the clay minerals, clay content, liquid saturation, iron oxide content, and anion concentrations (Thomas and Swoboda, 1970; Appelt et al., 1975; James and Rubin, 1986). Bresler (1973) proposed an empirical relationship to evaluate the relative exclusion concentration, as a function of $b \sqrt{C}$ (where $b$ is the water-film thickness in $\AA$ and $C$ is the total anion concentration in eq/L). Without information about clay content, clay mineralogy, iron oxide content, and cation/anion exchange capacity to evaluate the proportion of cation/anion sorption capacity, it is difficult to ascertain if either anion exclusion or anion sorption is operative. For example, McMahon and Thomas (1974) observed an anion exclusion effect for chloride transport, compared to tritium, in two of three soils investigated and observed chloride sorption in another soil. The difference is ascribed to the amount of positively charged iron oxides and to anion exchange capacity.

In the CHESHIRE experiment, ${ }^{36} \mathrm{Cl}$, together with ${ }^{99} \mathrm{Tc}$ and ${ }^{129} \mathrm{I}$, showed very constant concentration ratios to tritium in the cavity, formation, and early satellite measurements (Figure $7 b$ ), indicating that these three nuclides were moving in concert with tritium at CHESHIRE. However, it is puzzling that the ${ }^{36} \mathrm{Cl}$ data exhibit a higher normalized ratio for the far-field well (UE-5n) than the cavity source (RNM-1) at CAMBRIC test (see Figure 9), suggesting that there 
are additional sources or some processes that have not been taken into account. Figure 10 compiled the available ${ }^{36} \mathrm{Cl} /{ }^{3} \mathrm{H}$ ratios in the hot wells. It is clear that the satellite wells consistently have higher ratios than the cavity-chimney samples, similar to the observation at CAMBRIC. One possible explanation for this consistent behavior is that the radiologic source term of ${ }^{36} \mathrm{Cl}$ at the NTS is underestimated. However, we would also like to point out that most satellite-well ratios are from the BULLION test, as shown in Table 4 and Figure 9.

Table 4. Ratio of ${ }^{36} \mathrm{Cl} /{ }^{3} \mathrm{H}$ in hot-well samples.

\begin{tabular}{llccc}
\hline \multicolumn{1}{c}{ Test name } & \multicolumn{1}{c}{ Well name } & $\begin{array}{c}\text { Depth interval } \\
(\mathbf{m})\end{array}$ & $\begin{array}{c}\text { Collection } \\
\text { date }\end{array}$ & ${ }^{36} \mathbf{C l} /{ }^{3} \mathbf{H}$ \\
\hline $\begin{array}{c}\text { Cavity-chimney } \\
\text { CAMBRIC }\end{array}$ & RNM-1 & $324-328$ & $6 / 28 / 2000$ & $1.91 \times 10^{-4}$ \\
BILBY & U-3cn PS\#2 & $512-527$ & $1 / 22 / 1997$ & $2.61 \times 10^{-3}$ \\
DALHART & U-4u PS\#2a & $472-501$ & $8 / 16 / 1999$ & $5.19 \times 10^{-2}$ \\
CAMEMBERT & U-19q PS\#1d & $1402-1445$ & $10 / 21 / 1998$ & $1.20 \times 10^{-4}$ \\
CHESHIRE & U-20n PS\#1ddh & $1250-1253(\mathrm{~s})$ & $10 / 12 / 1999$ & $2.12 \times 10^{-3}$ \\
CHESHIRE & U-20n PS\#1ddh & $1250-1253(\mathrm{~s})$ & $9 / 21 / 1998$ & $1.68 \times 10^{-3}$ \\
CHESHIRE & U-20n PS\#1ddh & $812-913(\mathrm{~s})$ & $7 / 28 / 1998$ & $1.71 \times 10^{-3}$ \\
ALMENDRO & U-19v PS\#1 ds & 1005.8 & $5 / 31 / 2001$ & $2.36 \times 10^{-3}$ \\
ALMENDRO & U-19v PS\#1 ds & 1005.8 & $9 / 26 / 2000$ & $3.03 \times 10^{-3}$ \\
ALMENDRO & U-19v PS\#1 ds & 976.5 & $8 / 18 / 1999$ & $1.77 \times 10^{-3}$ \\
\hline
\end{tabular}

\section{Satellite well}

$\begin{array}{llccc}\text { CAMBRIC } & \text { RNM-2s } & 316-340 & 6 / 14 / 2000 & 5.27 \times 10^{-3} \\ \text { CAMBRIC } & \text { RNM-2s } & 316-340 & 10 / 11 / 1999 & 4.17 \times 10^{-3} \\ \text { CAMBRIC } & \text { UE-5n } & 219.5-222.5 & 4 / 19 / 2001 & 1.98 \times 10^{-2} \\ \text { CAMBRIC } & \text { UE-5n } & 219.5-222.5 & 9 / 9 / 1999 & 2.36 \times 10^{-2} \\ \text { BULLION } & \text { ER-20-6\#1 } & 742.8-898.2 & 5 / 14 / 1998 & 5.04 \times 10^{-2} \\ \text { BULLION } & \text { ER-20-6\#1 } & 742.8-898.2 & 8 / 27 / 1997 & 4.84 \times 10^{-2} \\ \text { BULLION } & \text { ER-20-6\#1 } & 742.8-898.2 & 6 / 3 / 1997 & 3.70 \times 10^{-2} \\ \text { BULLION } & \text { ER-20-6\#1 } & 742.8-898.2 & 12 / 17 / 1996 & 3.75 \times 10^{-2} \\ \text { BULLION } & \text { ER-20-6\#2 } & 742.8-898.2 & 7 / 17 / 1997 & 2.76 \times 10^{-2} \\ \text { BULLION } & \text { ER-20-6\#2 } & 742.8-898.2 & 6 / 3 / 1997 & 2.52 \times 10^{-2} \\ \text { BULLION } & \text { ER-20-6\#2 } & 742.8-898.2 & 11 / 27 / 1996 & 3.03 \times 10^{-2} \\ \text { BULLION } & \text { ER-20-6\#3 } & 755.9-854.7 & 5 / 13 / 1998 & 7.98 \times 10^{-2} \\ \text { BULLION } & \text { ER-20-6\#3 } & 755.9-854.7 & 7 / 17 / 1997 & 1.81 \times 10^{-2} \\ \text { BULLION } & \text { ER-20-6\#3 } & 755.9-854.7 & 6 / 2 / 1997 & 5.97 \times 10^{-3} \\ \text { BULLION } & \text { ER-20-6\#3 } & 755.9-854.7 & 12 / 16 / 1996 & 2.07 \times 10^{-3} \\ \text { BENHAM } & \text { ER-20-5\#3 } & 1046-1183 & 4 / 30 / 1998 & 1.94 \times 10^{-2} \\ \text { BENHAM } & \text { ER-20-5\#3 } & 1046-1183 & 4 / 22 / 1997 & 2.56 \times 10^{-2}\end{array}$




\begin{tabular}{lllll} 
BENHAM & ER-20-5 \#3 & $1046-1183$ & $7 / 31 / 1996$ & $2.21 \times 10^{-2}$ \\
\hline
\end{tabular}

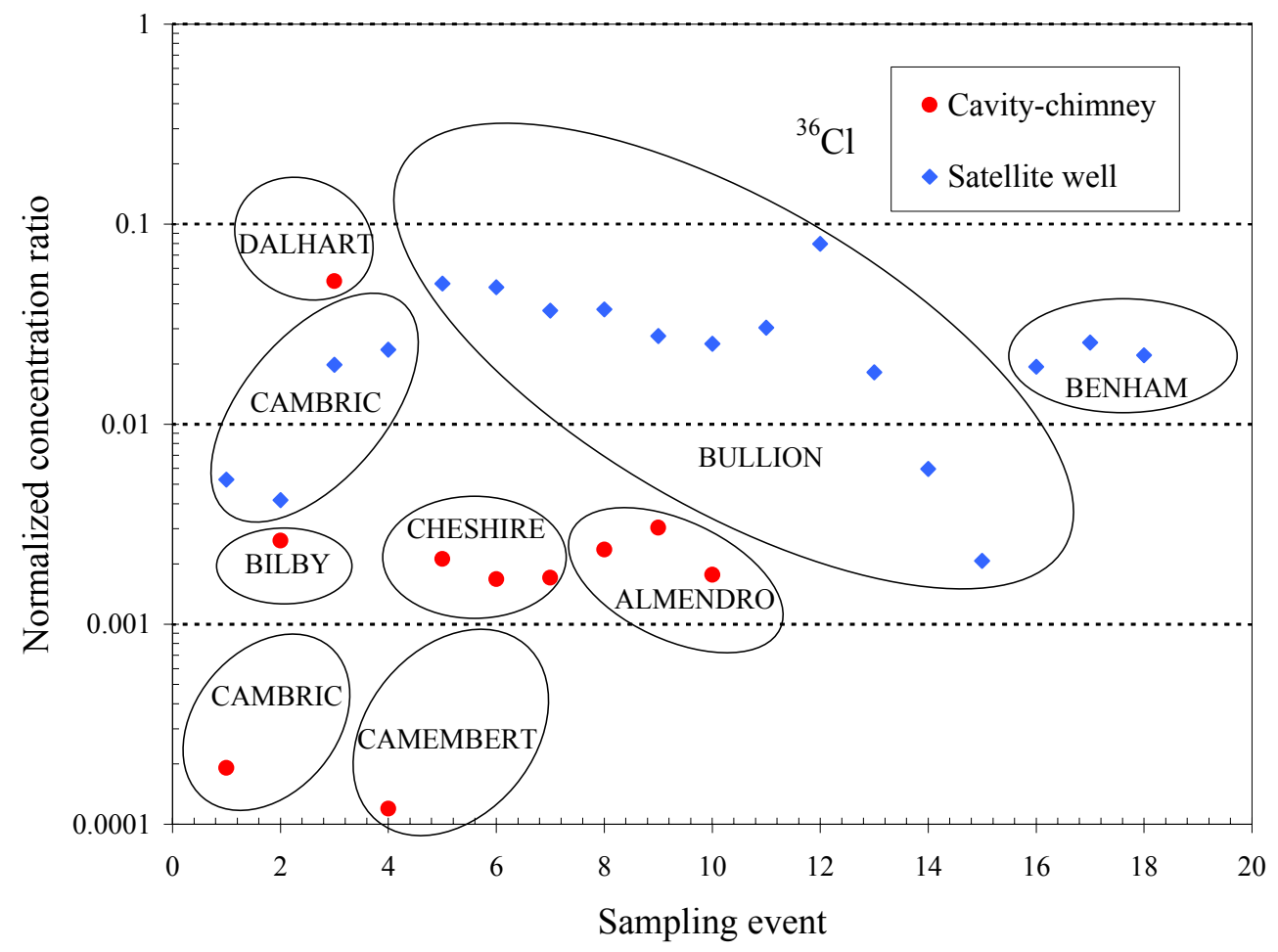

Figure 10. Normalized concentration ratio for ${ }^{36} \mathrm{Cl}$ in the hot wells.

\section{Krypton-85}

The noble gas ${ }^{85} \mathrm{Kr}$ is a highly volatile radionuclide with a half-life of 10.74 years, and is formed from the short-lived fission products ${ }^{85} \mathrm{Se}$ and ${ }^{85} \mathrm{Br}$ on the mass- 85 chain (Guell and Hunt, 2003). For detonations below the water table, groundwater will flow back into the cavity. As water reenters the region occupied by a rubble-filled cavity and chimney, the water will physically displace most of the gas; some ${ }^{85} \mathrm{Kr}$ gas will be dissolved in the flowing water and transported as a neutral species.

At the CAMBRIC experiment, the pumped well RNM-2s $91 \mathrm{~m}$ from the detonation cavity was sampled regularly over 16 years (1975-1991) and recovered $94 \%$ of the tritium but only $42 \%$ of the ${ }^{85} \mathrm{Kr}$. Guell and Hunt (2003) employed a numerical model to simulate tritium and ${ }^{85} \mathrm{Kr}$ transport from the cavity to the pumped well using tritium data to determine regional hydrogeology. The calibrated model reproduced the ${ }^{85} \mathrm{Kr}$ breakthrough data quite well when the emplacement of ${ }^{85} \mathrm{Kr}$ by the upward migration of $\mathrm{CO}_{2}$ is included. Guell and Hunt suggested that about $50 \%$ of ${ }^{85} \mathrm{Kr}$ was transported rapidly upward by $\mathrm{CO}_{2}$ gas produced from carbonate minerals into the vadose zone, where ${ }^{85} \mathrm{Kr}$ escapes more readily to the accessible environment, while tritium became associated with condensed steam within the cavity. Therefore, the initial 
distributions of radionuclides are determined by phenomena occurring on time scales of seconds to days following detonation.

Although numerous ${ }^{85} \mathrm{Kr}$ analyses have been carried out during the CAMBRIC project, the results for ${ }^{85} \mathrm{Kr}$ and its ratio to tritium have been disturbingly variable (Bryant, 1992). The analytical results for sequential samples from the same source have sometimes differed by as much as a factor of 2 . The source of the variability has not been identified and may be related to sampling and analytical procedures (Bryant, 1992). If this concern is true, the lower mass for ${ }^{85} \mathrm{Kr}(42 \%$ vs. $94 \%$ for tritium) may also be partly caused by analytical variability.

From other samples across the NTS, we observe that the ${ }^{85} \mathrm{Kr} /{ }^{3} \mathrm{H}$ ratios from cavity-chimney wells are nearly 1 (except for the BILBY sample), indicating that nearly all of the ${ }^{85} \mathrm{Kr}$ produced is likely in the same aqueous form as tritium (Figure 11). This is consistent with the observation at the CAMBRIC test. The ratio of ${ }^{85} \mathrm{Kr}$ to tritium in core water varied from 0.4 to 5 times the expected ratio for the device as a whole, suggesting that a substantial fraction of the ${ }^{85} \mathrm{Kr}$ was found in water (Bryant, 1992). However, the ratios from the satellite wells are consistently lower than those of the cavity-chimney samples, suggesting that there are some process(es) contributing to the mass loss or delayed transport of ${ }^{85} \mathrm{Kr}$ in the groundwater. These processes could include retardation, degassing, and analytical variability.

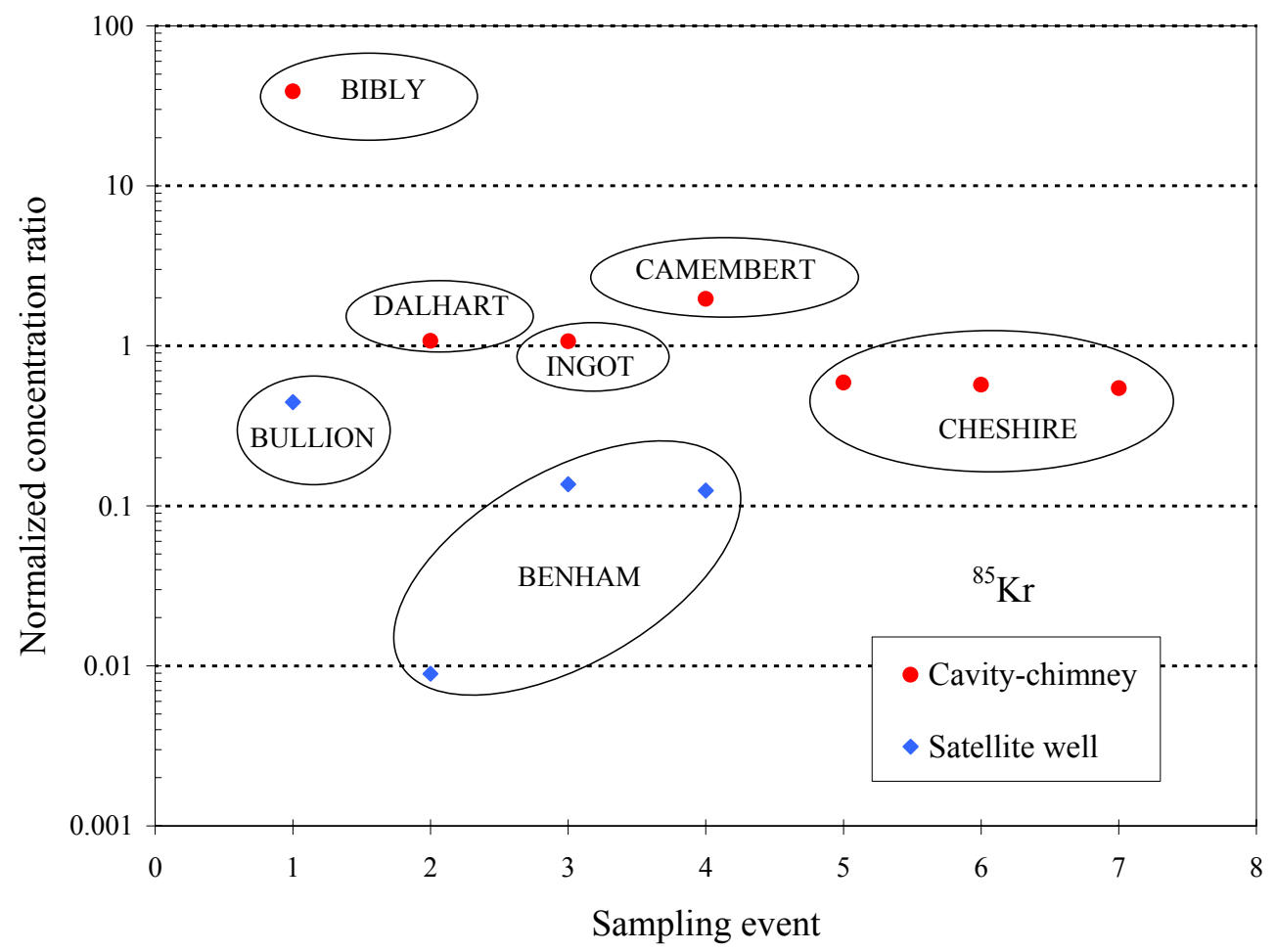

Figure 11. Normalized concentration ratio for ${ }^{85} \mathrm{Kr}$ in the hot wells. 


\section{Technetium-99}

${ }^{99} \mathrm{Tc}$ is a long-lived $\left(\mathrm{t}_{1 / 2}=2.13 \times 10^{5}\right.$ years $)$, abundant ( $6 \%$ yield $)$ fission product of ${ }^{235} \mathrm{U}$ and ${ }^{239} \mathrm{Pu}$. The NTS hot-well water samples have been measured for ${ }^{99} \mathrm{Tc}$ by radiochemical counting (Silva et al., 1988). Recently, analysis of ${ }^{99} \mathrm{Tc}$ has been done using LLNL's tandem accelerator mass spectrometer (TAMS), which provides detection sensitivity and precision that are not available through conventional radiochemical counting (McAninch et al., 2000).

Under oxidizing and near-neutral $\mathrm{pH}$ conditions, ${ }^{99} \mathrm{Tc}$ occurs predominantly as the pertechnetate ion $\left(\mathrm{TcO}_{4}{ }^{-}\right)$, which is not expected to be readily sorbed and which has the potential to migrate as conservatively as tritium. This seemed to be the case at CHESHIRE: ${ }^{99} \mathrm{Tc}$ showed very constant concentration ratios to tritium in the cavity, formation, and early satellite measurements (Figures $7 \mathrm{~b}$ and 12). However, when iron precipitates were observed in the satellite, the ${ }^{99} \mathrm{Tc} /{ }^{3} \mathrm{H}$ ratio dropped precipitously; presumably, ${ }^{99} \mathrm{Tc}$ speciation had changed (this presumption will be discussed in more detail below).

Schroeder et al. (1993) reported that ${ }^{99} \mathrm{Tc}$ in solution appears to migrate more slowly than ${ }^{36} \mathrm{Cl}$. The initial breakthrough for ${ }^{99} \mathrm{Tc}$ is similar to tritium; the migration rate, evaluated from the center of mass, of the ${ }^{99} \mathrm{Tc}$ appears to slightly exceed that of the ${ }^{3} \mathrm{H}$, perhaps as a result of anion exclusion effects. Schroeder et al. reported a ${ }^{99} \mathrm{Tc} /{ }^{3} \mathrm{H}$ ratio of $2.8 \times 10^{-7}$ for the CAMBRIC source term and an activity ratio of $3.4 \times 10^{-11}$ measured in the cavity water. This indicates that only $0.01 \%$ of the ${ }^{99} \mathrm{Tc}$ source term was in the aqueous form and available for transport; the remainder is presumably contained in the melt glass. The parent chain of ${ }^{99} \mathrm{Tc}$ includes ${ }^{99} \mathrm{Zr}\left(t_{1 / 2}\right.$ $=2.2 \mathrm{~s}),{ }^{99} \mathrm{Nb}\left(t_{1 / 2}=15.0 \mathrm{~s}\right)$, and ${ }^{99} \mathrm{Mo}\left(t_{1 / 2}=2.75\right.$ days $)$, which are all relatively refractory and could be incorporated into the melt glass. The ratio of ${ }^{99} \mathrm{Tc}$ to tritium is similar for wells RNM-1 and RNM-2s, suggesting that the soluble ${ }^{99}$ Tc migrated as rapidly as the tritiated water (Bryant, 1992).

However, as seen in Figure 13, all ${ }^{99} \mathrm{Tc} /{ }^{3} \mathrm{H}$ ratios at the cavity-chimney wells are consistently higher than those reported for CAMBRIC. The exception is the ALMENDRO test, which is an anomaly with an environmentally isolated nuclear test cavity-chimney system (Rose et al., 2000a). The low ${ }^{99} \mathrm{Tc} /{ }^{3} \mathrm{H}$ ratio - and hence large proportion of ${ }^{99} \mathrm{Tc}$ being incorporated into the melt glass - of CAMBRIC may be characteristic of this particular test, which has a much smaller nuclear yield than the other nuclear tests (see Table 3 ).

The cavity Tc ratio at CHESHIRE from the six samples collected between 1984 and 1999 is $0.100 \pm 0.016$, and the ratio is a bit lower $(0.064$ from a sole measurement at 1987) at satellite well UE 20n-1 300 m away (Figure 12). Apart from the CHESHIRE data, the ${ }^{99} \mathrm{Tc} /{ }^{3} \mathrm{H}$ ratios at the three other available satellite wells are about 2 orders of magnitude lower than the cavitychimney values (Figure 13). This indicates that field-scale migration of ${ }^{99} \mathrm{Tc}$ at the NTS has an apparent retardation factor of about 100 . To evaluate the nonconservative transport of ${ }^{99} \mathrm{Tc}$, we need to consider the redox chemistry of both cavity water and local groundwater.

Many radionuclides of environmental concern, including ${ }^{99} \mathrm{Tc}$ and ${ }^{129} \mathrm{I}$, have more than one oxidation state, and these species may exhibit greatly different chemical behavior and mobility. Generally, the reduced forms have low water solubilities. The effect of oxidation state on mobility is especially important for ${ }^{99} \mathrm{Tc}$ and ${ }^{129} \mathrm{I}$, which are assumed to behave conservatively in the TSPA of YMP. 


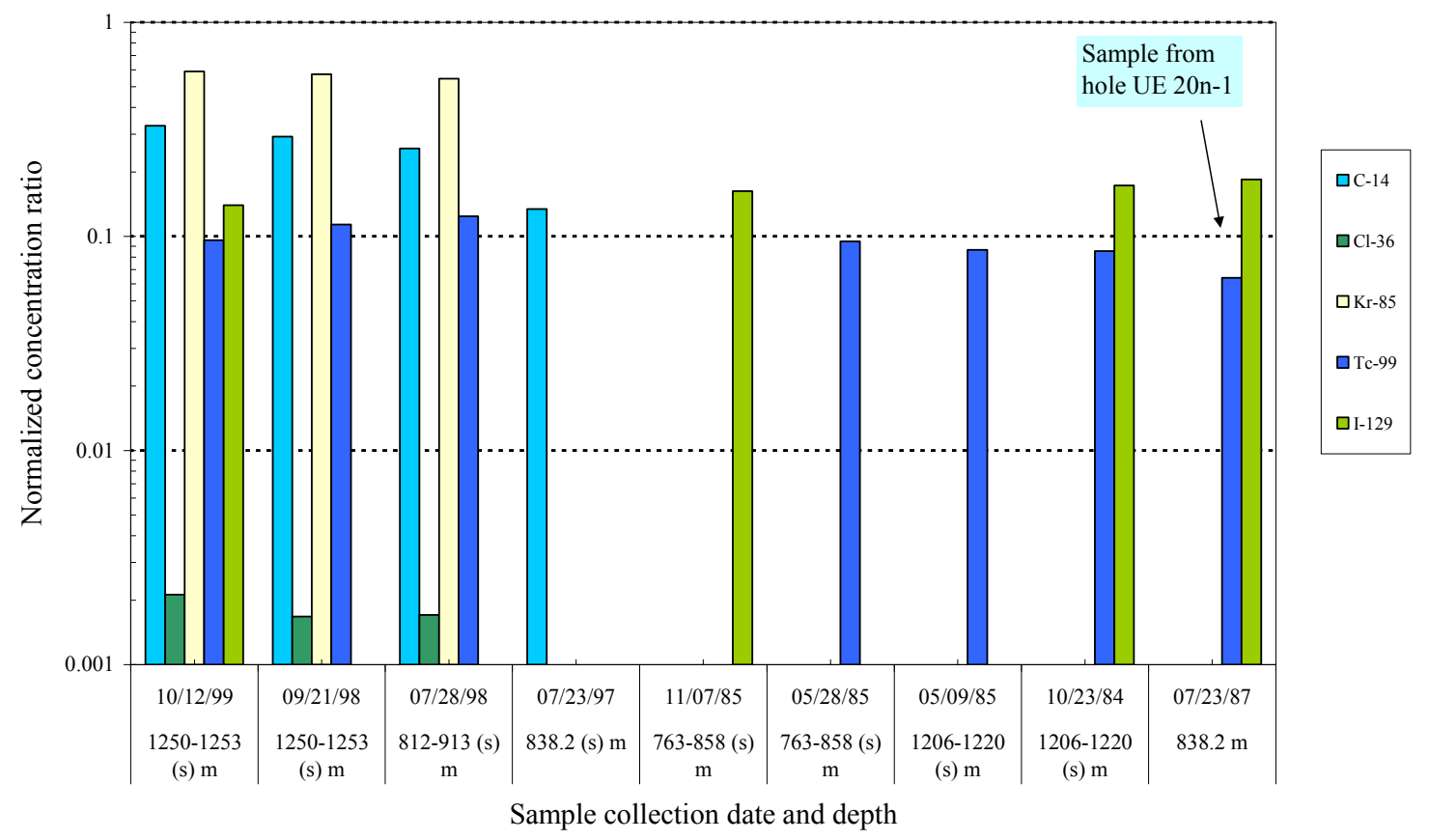

Figure 12. Concentration ratios of selected radionuclides relative to tritium for wells associated with the CHESHIRE site. Results shown are for liquid samples collected over time at the cavity (depth range $\sim 1200 \mathrm{~m}$ slanted) and at formation (depth range $\sim 800 \mathrm{~m}$ ). Also shown is the result for a sample from well UE 20n-1, 300 m away.

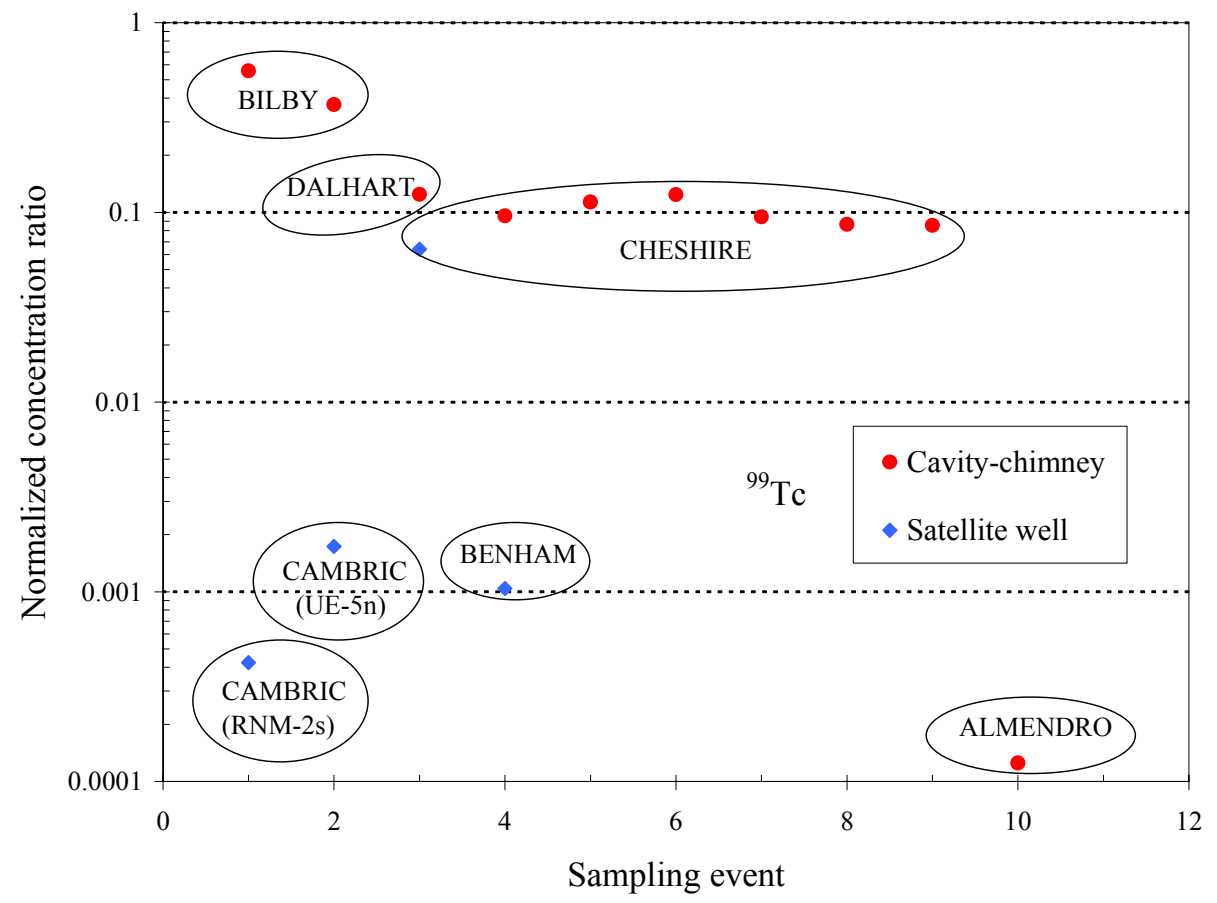

Figure 13. Normalized concentration ratio for ${ }^{99} \mathrm{Tc}$ in the hot wells. 
Depending upon the redox conditions, Tc primarily exists in two stable oxidation states. It forms a reduced species [predominantly Tc(IV)] at redox potential (Eh) values below about $220 \mathrm{mV}$ in neutral $\mathrm{pH}$ conditions. At higher Eh, it occurs as $\mathrm{Tc}(\mathrm{VII})$, which forms $\mathrm{TcO}_{4}{ }^{-}$(Figure 14). Due to its weak interaction with mineral surfaces, $\mathrm{TcO}_{4}{ }^{-}$is deemed one of the most mobile radionuclides in the environment. In contrast, transport of Tc(IV) species are expected to be strongly retarded from their interactions with minerals and/or precipitation due to their low solubility.

The environmental redox chemistry of Tc is, therefore, very important in governing its mobility. From experiments conducted at five sediments and groundwaters in Germany, Lieser and Bauscher (1987) obtained a different sorption coefficient for Tc under aerobic and anaerobic conditions (Figure 14). By varying the redox potential, they observed a drastic drop in the $K_{d}$ value for Tc by about 3 orders of magnitude within a small range of Eh (at $170 \pm 60 \mathrm{mV}$ for a $\mathrm{pH}$ of $7 \pm 0.5)$.

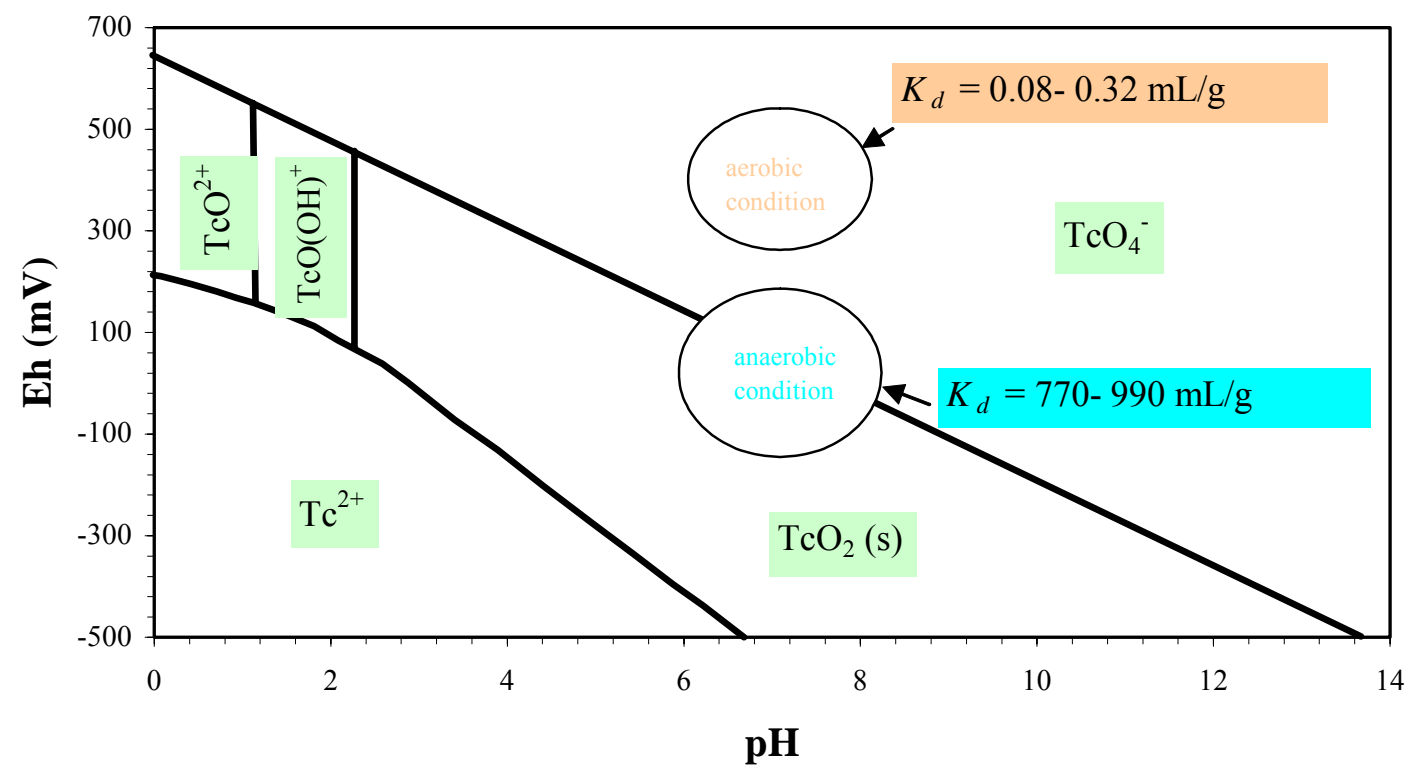

Figure 14. The relationship between the sorption distribution coefficient $\left(K_{d}\right)$ and the speciation of Tc. (Adapted from Lieser and Bauscher, 1987.)

We expect the migration behavior of ${ }^{99} \mathrm{Tc}$ to be significantly dictated by the redox conditions of the cavity and surrounding groundwater. Under saturated conditions in the absence of air, the cavity environment is likely to be of a reducing nature, as assumed by IAEA (1998) with no supporting evidence. Several lines of evidence from this work strongly suggest that the cavity environment is likely reducing, or that the cavity environment at least was reducing during the early time after nuclear explosions and may last for some duration of time. A study by Borg (1975) directly pointed to a reducing cavity environment, at least at the time when melt glasses are formed. Chemical analyses of the 1966 PILEDRIVER test (fired in granodiorite rock) in Area 15 and the 1957 RAINIER test (tuff) in Area 2 of the NTS resulted in compositions of the 
major constituents of the glasses that closely resemble those of the preshot rock except for the conversion of original ferric iron $\left(\mathrm{Fe}^{3+}\right)$ to ferrous $\left(\mathrm{Fe}^{2+}\right)$ ion and decreasing amount of water (Borg, 1975). From the analyses of a total of seven melt glass samples, the $\mathrm{Fe}^{2+} / \mathrm{Fe}^{3+}$ ratio increased by a factor of 2.6 to 4.8 for PILEDRIVER and 9.1 to 15.0 times for RAINIER debris relative to the $\mathrm{Fe}^{2+} / \mathrm{Fe}^{3+}$ ratio of the preshot rock. There is no substantial change in the total iron content, although the device canister and hardware are expected to add a few tenths of a weight percent to the total iron content of the melt (Borg, 1975). The weapons canister, diagnostics canister, and supporting rack lowered down the hole contain appreciable amounts of steel used in the construction; the weight of the steel in the device component alone often exceeds $15 \mathrm{~kg}$.

The reduction of ferric iron indicates that a reducing atmosphere prevailed in the cavities at the time of quenching. However, the mass balance analyses show that the reduction of ferric iron cannot be accounted for by the reaction $\mathrm{Fe}_{2} \mathrm{O}_{3}+\mathrm{H}_{2} \rightarrow 2 \mathrm{FeO}+\mathrm{H}_{2} \mathrm{O}$ because this reaction requires a greater source of hydrogen (Borg, 1975). The reaction of steam with the steel of the device canister and structural supports can only produce about $10 \%$ of the requisite $\mathrm{H}_{2}$ for iron conversion. A more thorough understanding of high-temperature chemistry at early times in the cavity history was suggested by Borg (1975).

Studies of ALMENDRO and CAMEMBERT tests also indicated a reducing cavity environment. Anomalously enriched $\delta^{13} \mathrm{C}$ values in ALMENDRO samples suggest that methanogenesis process is occurring (Rose et al., 2000a). The reduction of $\mathrm{CO}_{2}$ to $\mathrm{CH}_{4}$ is associated with progressively enriched ${ }^{13} \mathrm{C}$ over time in a closed system. In 1998, a gas sample was collected 107 $\mathrm{m}$ below the surface in the CAMEMBERT postshot hole, and the sample was representative of the vapor that remained undisturbed in the capped borehole (Rose et al., 2000a). The analysis showed that the gas, relative to normal atmosphere, is significantly depleted in oxygen $(0.12 \pm$ $0.01 \%)$ and enriched in hydrogen gas $(8.28 \pm 0.01 \%)$, which is characteristic of the anoxic, reducing condition favorable to methanogenesis. The gas contains $1 \%$ methane and no $\mathrm{CO}_{2}$. For methanogenesis to occur, the redox potential is expected to be lower than $-244 \mathrm{mV}$ (at $\mathrm{pH} 7$ ), which would indicate a strongly reducing environment at these tests.

We now discuss the available information of the redox condition of the groundwater at the NTS. Below the water table, where gas exchange with the atmosphere diminishes, DO is gradually consumed by microbial uptake, biodegradation of organic matter, and retention with reduced mineral phases in the aquifer. It has often been assumed that deep aquifers $(>250 \mathrm{~m})$ are reducing since they are isolated from the atmosphere. Although the water table at the NTS ranges from 400 to $700 \mathrm{~m}$ deep, the groundwater has been considered to be oxygenated (Winograd and Robertson, 1982; Coles and Ramspott, 1982; Buddemeier and Hunt, 1988). Nevertheless, this is based on limited information. Winograd and Robertson (1982) reported that even very old groundwaters ( $>10,000$ years), along an approximately $80-\mathrm{km}$ flow path from recharge areas in the Paleozoic carbonate-rock aquifer of the Ash Meadows groundwater basin (southcentral Nevada) near the NTS, contain DO concentrations close to air saturation. Wolfsberg (1978) measured Eh with a platinum electrode at the RNM-2s well of the CAMBRIC and observed mildly oxidizing conditions $(+330 \mathrm{mV})$. However, little detailed information about the measurement was presented, which raises the possibility that air exposure may have compromised the measurement's integrity. Wolfsberg did state that the measurement was conducted by using freshwater in the field, before the water had contacted the atmosphere. 
Starting in September 2000, LANL employed a Hydrolab Minisonde 4a multiprobe to measure several geochemical parameters (temperature, $\mathrm{pH}$, specific conductivity, $\mathrm{DO}$, and Eh) in situ in uncontaminated wells at the NTS. From a total of 19 wells, a wide range of Eh and DO values were observed at NTS (Finnegan and Thompson, 2001; 2002; 2003). The measured Eh indicates that water in seven wells is mildly oxidizing (Eh ranges from about 200 to $400 \mathrm{mV}$ ), water in six wells is mildly reducing (about -100 to $200 \mathrm{mV}$ ), and water in six wells is strongly reducing (from -300 to $-100 \mathrm{mV}$ ); some examples are shown in Figure 15. Based on these in situ measurements, it is very likely that Tc will not always exist as $\mathrm{TcO}_{4}{ }^{-}$and act as a mobile radionuclide in the groundwater of the NTS. The assumption of oxidizing groundwaters at the NTS is partly based on the scarcity of in situ geochemistry data in the subsurface.

Furthermore, the presence of $\mathrm{Fe}(\mathrm{II})$ and $\mathrm{S}^{2-}$ as reductants can also contribute to the reduction of $\mathrm{Tc}(\mathrm{VII})$ to $\mathrm{Tc}(\mathrm{IV})$. $\mathrm{Fe}(\mathrm{II})$ minerals in igneous rocks can reduce $\mathrm{TcO}_{4}{ }^{-}$and lead to sorption on mineral surfaces (Bondietti and Francis, 1979). Under reducing conditions, Cui and Eriksen $(1996 \mathrm{~b}, 1998)$ discovered that $\mathrm{TcO}_{4}{ }^{-}$was reduced to sparingly soluble $\mathrm{TcO}_{2} \cdot \mathrm{nH}_{2} \mathrm{O}(\mathrm{s})$ by the $\mathrm{Fe}(\mathrm{II})$-containing fracture-filling material and that $\mathrm{Tc}(\mathrm{IV})_{\text {aq }}$ was rapidly sorbed by the material. Reduction of $\mathrm{Tc}(\mathrm{VII})$ to the sparingly soluble $\mathrm{Tc}(\mathrm{IV})$ occurs with $\mathrm{Fe}(\mathrm{II})$-containing solid phases but not by aqueous $\mathrm{Fe}(\mathrm{II})$ species (Cui and Eriksen, 1996a). The solubility of the reduced form of $\mathrm{TcO}_{2} \cdot \mathrm{nH}_{2} \mathrm{O}(\mathrm{s})$ in carbonate-containing groundwater is about $10^{-8} \mathrm{M}$ (Eriksen et al., 1992).

During the CHESHIRE migration test, ${ }^{99} \mathrm{Tc}$ concentration was observed to drop precipitously for groundwater samples with high iron content, while ${ }^{36} \mathrm{Cl}$ was not affected (Buddemeier et al., 1991). No explanation was offered, and it seems probable that, in this case, the reduction of $\mathrm{Tc}(\mathrm{VII})$ to $\mathrm{Tc}(\mathrm{IV})$ and the formation of an insoluble precipitate constitute the likely mechanisms for the much slower mobility of ${ }^{99} \mathrm{Tc}$.

(a)

Well WW-5a (measured pH range 8.1 - 8.2)

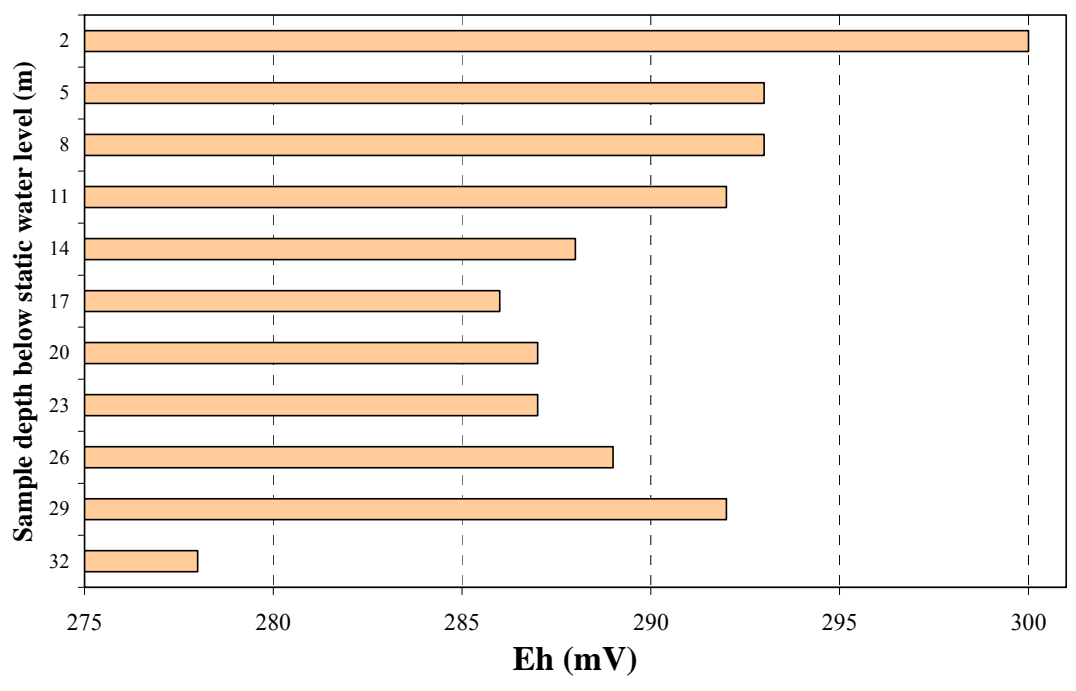


(b)

Well TW-7 (measured pH range 8.0 - 8.7)

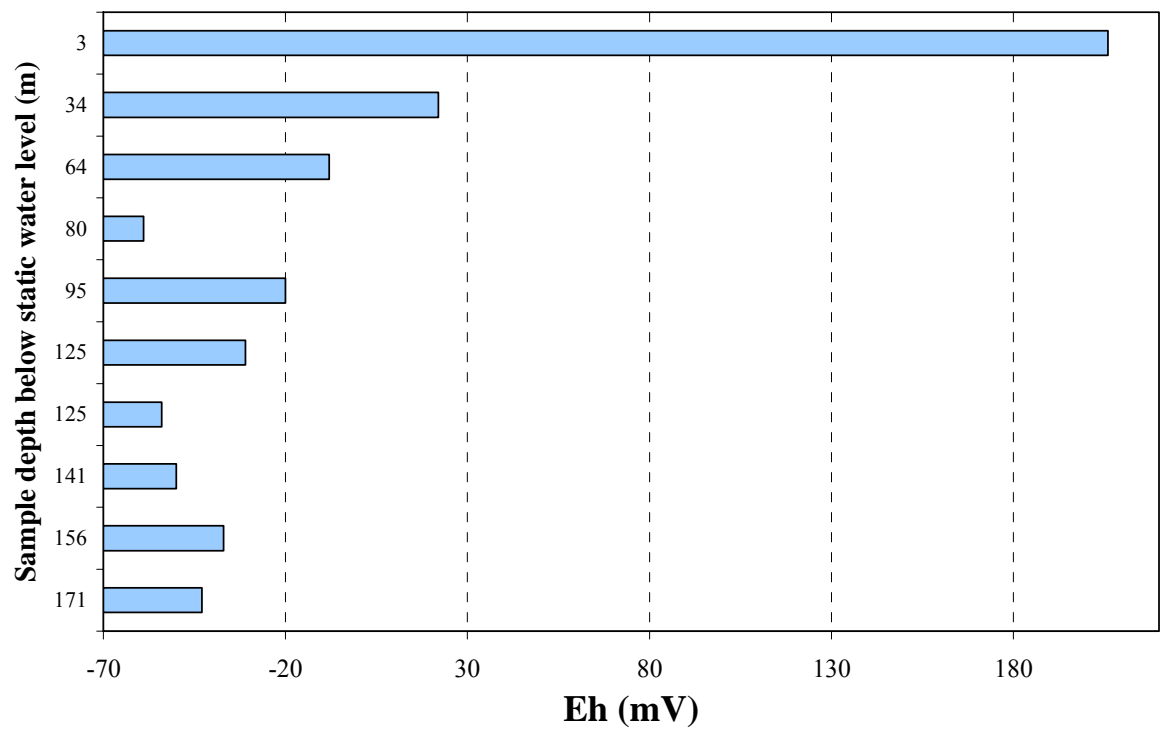

(c)

Well WW-2 (measured pH range 7.9 - 8.4)

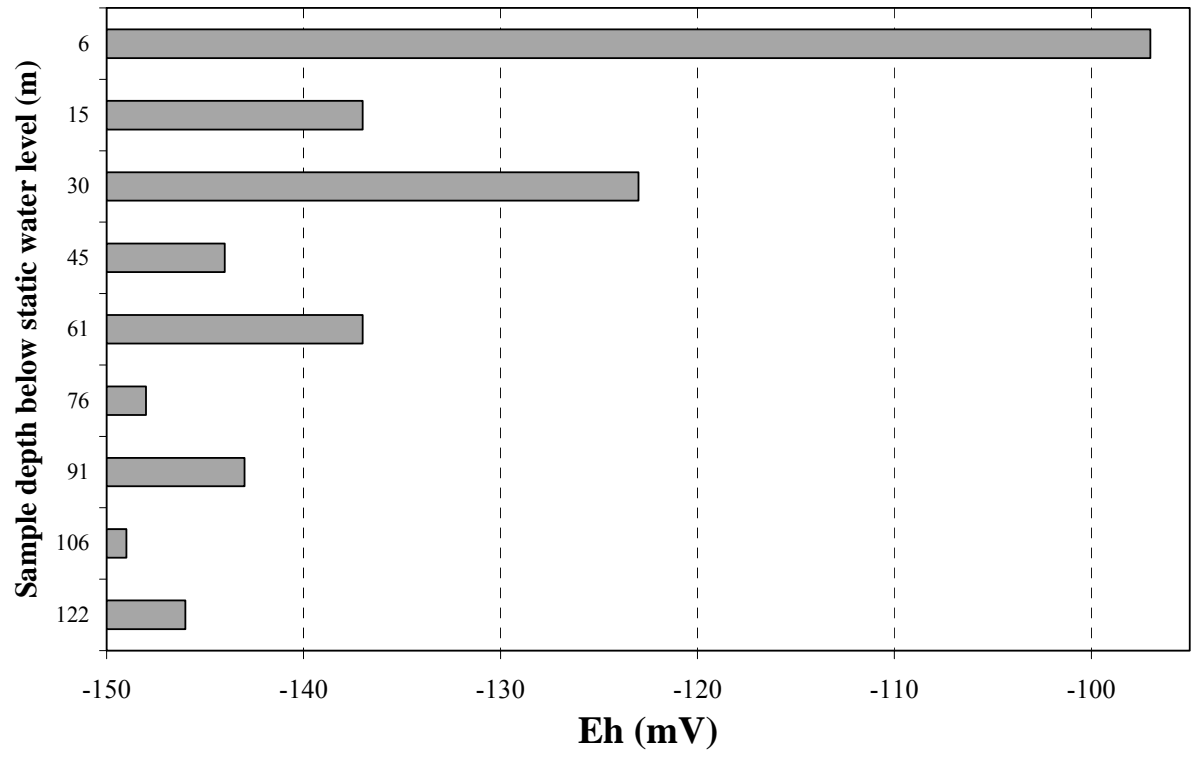

Figure 15. Measured in situ redox potentials at three representative wells at the Nevada Test Site: (a) oxidizing, (b) mildly reducing, and (c) strongly reducing. (Data from Finnegan and Thompson, 2001; 2002.)

We would like to point out that anions can also be sorbed into geological media, although most ionic sorption studies have focused on cations. The adsorption of charged ionic species from the 
aqueous phase onto minerals is likely to occur whenever the mineral surface exhibits a net surface charge. Most rock-forming alumino-silicate minerals under typical, ambient, shallow groundwater conditions, whether in phreatic or vadose zones, have negatively charged surfaces. These surfaces can become positively charged in the presence of acids or if the surfaces dry out and only residual oligolayers of water remain. The transition from negatively to positively charged surface occurs at the point of zero charge (PZC), where the surface charge is zero; PZC is usually expressed in terms of $\mathrm{pH}$. PZC differs from one mineral to another, but for most rockforming minerals the value is less than $\mathrm{pH}=4$. However, in some materials, such as iron oxides, sulfides, and some organic matter, $\mathrm{PZC}$ is as high as a $\mathrm{pH}$ of 8 to 9 . These minerals can display a tendency to adsorb anionic species such as $\mathrm{I}^{-}$and $\mathrm{TcO}_{4}{ }^{-}$under ambient groundwater conditions. For example, the extent of $\mathrm{AsO}_{4}{ }^{3-}$ sorption on hydrous ferric oxide is related to a function of $\mathrm{pH}$ (Dzombak and Morel, 1990). The edge sites on clays are also reported to contain positive sites. In addition, significant sorption has been reported for anionic tracers in systems with high concentrations of iron oxides and kaolinite (Boggs and Adams, 1992; Seaman, 1998).

Therefore, the clay content and mineralogy of geologic media can contribute to the local presence of positively-charged sites and will likely affect the sorption behavior of anions (e.g., $\mathrm{TcO}_{4}{ }^{-}$). We are not aware of any reports concerning the occurrence and significance of localized positively charged sorption sites on Yucca Mountain tuff, yet the existence of localized positively charged sorption sites cannot be ruled out. As stated above, clays and oxides may potentially contribute to positively charged sites. Smectite is a significant constituent of some unwelded tuff horizons at Yucca Mountain, while hematite and illite are present in minor or trace amounts. Hematite is widely distributed, particularly in the matrix of devitrified units. Smectite and hematite also coat the fracture walls in Yucca Mountain tuffs.

From flow-through column experiments using Eleana argillite sampled from drill hole UE17e at the NTS, Treher and Raybold (1982) observed that Tc (applied as $\mathrm{TcO}_{4}^{-}$) was significantly retarded, while tritium and $\mathrm{I}^{-}$were not retarded. The argillite sample was reported to contain an appreciable amount of clay minerals (10-20\% montmorillonite, 5-10\% pyrophyllite, $20-40 \%$ smectite, and $15-30 \%$ chlorite), along with 30-50\% quartz. Sorption was found to be strongly affected by kinetics, as evidenced from the apparent $K_{d}$ values under different flow rates. At flow rates of $\sim 2000 \mathrm{~m} / \mathrm{yr}$, either in air or in a controlled atmosphere of nitrogen with $\leq 0.2 \mathrm{ppm} \mathrm{O}_{2}$ and $\leq 20 \mathrm{ppm} \mathrm{CO}$, the $K_{d}$ values were 0.29 to $0.43 \mathrm{~mL} / \mathrm{g}$. When the flow rate was slowed to $20 \mathrm{~m} / \mathrm{yr}$, allowing more time for reaction, the Tc $K_{d}$ value increased to $72 \mathrm{~mL} / \mathrm{g}$. The retardation mechanism of Tc probably occurs by reducing $\mathrm{TcO}_{4}{ }^{-}$to $\mathrm{Tc}(\mathrm{IV})$, perhaps as $\mathrm{TcO}_{2}$, rather than by ion exchange (Treher and Raybold, 1982).

\section{Iodine-129}

Similar to ${ }^{99} \mathrm{Tc},{ }^{129} \mathrm{I}$ has a long half-life $\left(t_{1 / 2}=1.57 \times 10^{7}\right.$ years $)$ as well as a unique and complex chemistry in the environment, and the fate and transport of ${ }^{129} \mathrm{I}$ in groundwater are dictated by chemical speciation. In normal environments, aqueous iodine usually occurs as the highly mobile iodide anion $\left(\mathrm{I}^{-}\right)$(Figure 16). Under more oxidizing conditions, iodine may be present as the more reactive iodate anion $\left(\mathrm{IO}_{3}{ }^{-}\right)$; the interaction of $\mathrm{IO}_{3}{ }^{-}$with clays and organic matter leads to the retarded transport of $\mathrm{IO}_{3}^{-}$(Couture and Seitz, 1983; Sheppard and Thibault, 1992). The coexistence of several iodine species has been reported in the soil-soil solution syetem. From incubation experiments with different water saturations, Yuita (1994) reported that, under upland field conditions, $\mathrm{IO}_{3}{ }^{-}$is the dominant species (89.0\%), when compared to $\mathrm{I}^{-}(6.5 \%)$, elemental $\mathrm{I}_{2}$ 
(4.5\%), and organoiodine (1.6\%). In contrast, under flooded conditions, the relative proportions of iodine species are $\mathrm{I}^{-}(90.3 \%), \mathrm{IO}_{3}^{-}(9.7 \%), \mathrm{I}_{2}(0.07 \%)$, and no organoiodine.

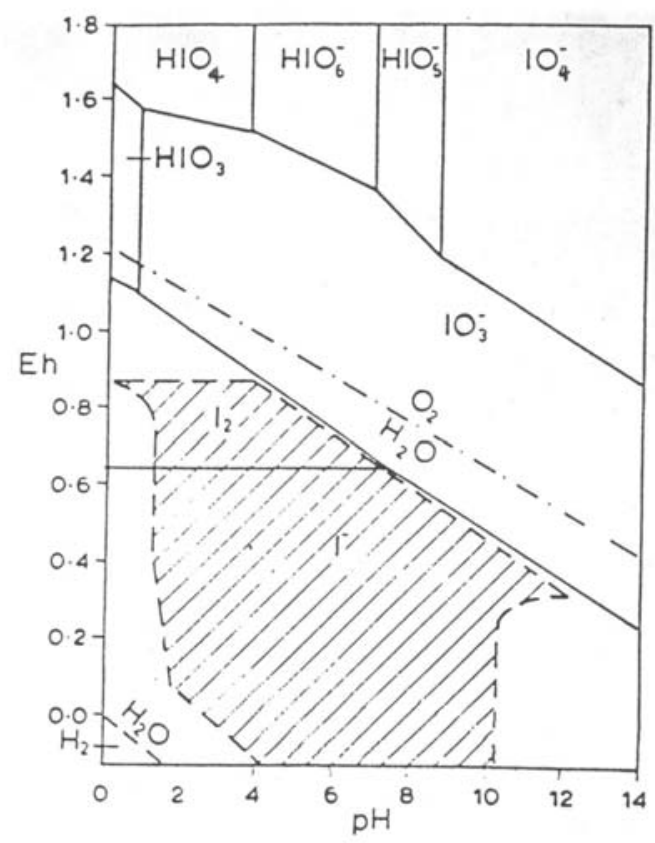

Figure 16. Fields of stability for the various iodine species. The $\mathrm{Eh}-\mathrm{pH}$ conditions for most natural waters are shown as a shaded field. (Reproduced from Fuge and Johnson, 1986.)

The fission product ${ }^{129}$ I in the NTS samples has been measured by neutron activation, thermalionization mass spectrometry (TIMS), and AMS (Daniels, 1982; Finkel et al., 1992). From the CAMBRIC nuclear test at the NTS, $39 \pm 11 \%$ of the ${ }^{129} \mathrm{I}$ and about $60 \%$ of the tritium inventory were eluted at pumping well RNM-2s. The lower recovery of ${ }^{129} \mathrm{I}$ suggests that not all of the ${ }^{129} \mathrm{I}$ produced from the nuclear test was dissolved in the groundwater, and the remainder presumably was contained either in fused materials or in insoluble forms (Thompson, 1985). After acknowledging the large amount of scatter in the data, Bryant (1992) reported that the atom ratio of ${ }^{127}$ I to tritium in the RNM-2s sample was $\sim 0.0003$ near the tritium peak. The measured ratio at RNM-1 was $\sim 0.005$, and the expected ratio for the CAMBRIC source is 0.0012. Although a substantial fraction of the ${ }^{129}$ I migrated from RNM-1 to RNM-2s, some of the ${ }^{129} \mathrm{I}$ is immobile or its migration is retarded to some extent (Bryant, 1992). Bryant (1992) postulated that reactive $\mathrm{HIO}$, a weak acid, is the predominant species and that it may interact with matrix materials, thereby retarding its migration relative to tritium. At the $\mathrm{pH}-\mathrm{Eh}$ conditions prevalent at CAMBRIC, some of the iodine could exist as HIO (Bryant, 1992).

Measurements from other hot wells exhibit no difference between cavity and satellite well samples (Figure 17). CHESHIRE is the only test for which both cavity and satellite well samples are available, and its results show nearly the same values among these samples (Figure 12). The normalized ratio value for ${ }^{129}$ I to tritium is abnormally large for the BOURBON (ratio 28.3) and NASH (ratio 8.32) tests; these abnormalities may be related to using the nonspecific radiological 
source term for calculations. Overall, it is likely that iodine is migrating conservatively at the NTS.

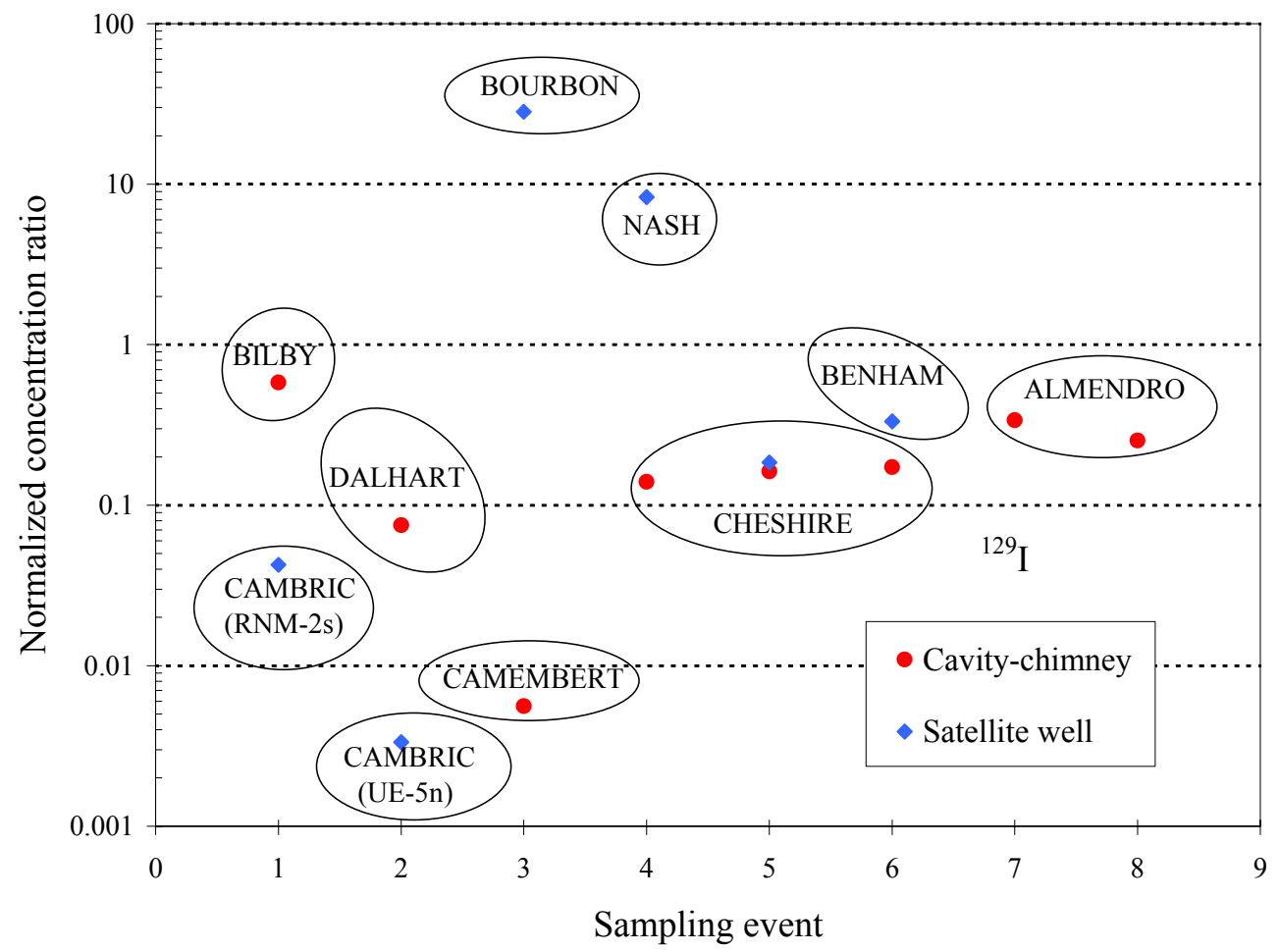

Figure 17. Normalized concentration ratio for ${ }^{129} \mathrm{I}$ in the hot wells.

However, it would not be surprising if the sorption of iodine were to be observed under strongly oxidizing condition at the NTS, as the presence of high-valence-state iodine species leads to their interactions with geological media. In a leachate of a tuff sample collected from an underground nuclear explosion in hole U7ajs, Wolfsberg (1978) reported the existence of at least three iodine species: $\mathrm{IO}_{4}^{-}, \mathrm{IO}_{3}^{-}$, and $\mathrm{I}^{-}$, with proportions of 10,40 , and $50 \%$, respectively. This leachate was further used for batch sorption-desorption studies in alluvium samples at the CAMBRIC site. For sorption study, a value of $K_{d}=24.5 \pm 0.7 \mathrm{~mL} / \mathrm{g}$ is obtained for iodine, and the $K_{d}$ for desorption is as large as $400-900 \mathrm{~mL} / \mathrm{g}$. A recommended $K_{d}$ value for iodine in alluvium is 640 $\pm 300 \mathrm{~mL} / \mathrm{g}$ (Wolfsberg, 1978).

\section{Laboratory column studies}

We conducted complementary laboratory column experiments as a part of this study to directly compare the transport behavior of the several species discussed above. The solid samples used in the column studies included alluvium and volcanic tuff. The alluvium was collected from the exposed section of the U-1a.102 drift (Yucca Flat) in the U-1a tunnel complex of NTS, and the petrographic analysis of the sample was reported in Rose et al. (2000b). The tuff sample was crushed from a sample block collected from the Topopah Spring welded volcanic tuff, the potential repository geologic unit, in the underground tunnel at Yucca Mountain. Tuff samples from the same block have been used in other studies (Hu et al., 2001). Both the alluvium and 
crushed tuff samples were passed through a 2-mm sieve before being packed into the columns. A stainless-steel column (2.2-cm inner diameter, 7.0-cm length, Alltech Associates, Inc.) was incrementally packed with the air-dry sample to obtain uniform bulk densities. After the column was packed, synthetic J-13 water was injected into the column to achieve full saturation. Water from the J-13 well at Fortymile Wash, east of Yucca Mountain, is considered to be the reference water for the proposed emplacement area (CRWMS M\&O, 2000). This well water is low in ionic strength, and its composition is shown in Table 5. According to the thermodynamic database, a solution composed of J-13 water should be supersaturated with respect to a number of phases, including calcite (Viani, 2002). Synthetic J-13 water was prepared using a recipe from Viani (2002) that is predicted to be stable at $25{ }^{\circ} \mathrm{C}$ and atmospheric $p \mathrm{CO}_{2}$, and the measured concentrations of some constituents of the prepared synthetic J-13 water are also presented in Table 5.

The apparatus and methods employed for the miscible displacement column studies were similar to those used in previous experiments (c.f. Hu and Brusseau, 1996). A high-performance liquid chromatography pump (Model 301, Alltech Associates, Inc.) was connected to the column, with a three-way switching valve placed in-line to facilitate switching between solutions with and without the solute of interest. The tracers dissolved in the synthetic J-13 water included $3 \times 10^{-3}$ $\mathrm{M} \mathrm{Cl}^{-}, 1 \times 10^{-4} \mathrm{M} \mathrm{I}^{-}, 1 \times 10^{-4} \mathrm{M} \mathrm{IO}_{3}{ }^{-}, 1 \times 10^{-4} \mathrm{M} \mathrm{Br}^{-}, 1 \times 10^{-4} \mathrm{M} \mathrm{MoO}_{4}{ }^{2-}$, and $1 \times 10^{-6} \mathrm{M}$ $\mathrm{ReO}^{-}$, as well as tritium $(3.3 \mathrm{kBq} / \mathrm{L})$. Stable chloride and iodine species (iodide and iodate) were used as substitutes for their radioactive counterparts. As a conservative tracer, bromide has been used in several field-scale transport studies at Yucca Mountain (Hu et al., 2001; Turin et al., 2002; Liu et al., 2003) and was included in our study as a comparison for other tracers. Perrhenate $\left(\mathrm{ReO}_{4}{ }^{-}\right)$and molybdate $\left(\mathrm{MoO}_{4}{ }^{-}\right)$serve as analogs for pertechnetate $\left(\mathrm{TcO}_{4}{ }^{-}\right)$, because of their chemical similarity (Brookins, 1986; Harvey et al., 1992; Wharton et al., 2000). The use of Re as an analog for Tc is based on their similar crystal chemistry, electronic configuration, and thermodynamic data. In addition, the crystal chemical behavior of Tc and Re in solutions and in solids is almost identical. Eh-pH diagrams are useful in predicting long-term behavior of elements under equilibrium conditions. The $\mathrm{Eh}-\mathrm{pH}$ diagrams for $\mathrm{Tc}$ and $\mathrm{Re}$ show that nearly identical Eh-pH fields are occupied by aqueous species $\left(\mathrm{TcO}_{4}{ }^{-}\right.$and $\left.\mathrm{ReO}_{4}{ }^{-}\right)$and by solids of Tc and Re.

A flow rate of $0.08 \mathrm{~mL} / \mathrm{min}$ was used for the column transport studies, which corresponds to a pore-water velocity of about $10 \mathrm{~cm} / \mathrm{hr}$ and a residence time of 0.6 hour. Column effluent was collected with an automated fraction collector (Retriever 500, ISCO, Inc.) for concentration determination. Tritium concentration was determined by liquid scintillation counting. The concentrations of $\mathrm{Br}^{-}, \mathrm{Cl}^{-}, \mathrm{I}^{-}, \mathrm{IO}_{3}{ }^{-}$, and $\mathrm{MoO}_{4}{ }^{2-}$ were measured in a single run by using an ion chromatography method that we developed, which employed an AS17 anion exchange column (Model DX-600, Dionex Corp.). The concentration of perrhenate was analyzed by an inductively coupled plasma-mass spectrometer (ICP-MS, Model 4500 series, Hewlett Packard), that used rhodium as the internal standard. Measurement of $\mathrm{pH}$ for the column effluent was conducted using an IQ240 $\mathrm{pH}$ measurement system with an ISFET sensor probe (IQ Scientific Instruments) calibrated to $\mathrm{pH}$ buffer standards. The redox potential, relative to the standard hydrogen electrode, was measured by using platinum as a sensing electrode and silver-silver chloride as a reference electrode (Platinum Redox Electrodes, Thermo Orion) filled with saturated potassium chloride. Zobell's solution (a solution of potassium ferric-ferrocyanide of known Eh) was used to verify the working operation of the measurement system. 
Table 5. Measured and synthetic J-13 well water compositions.

\begin{tabular}{|c|c|c|c|c|c|}
\hline \multirow[t]{2}{*}{ Constituent } & Unit & \multicolumn{2}{|c|}{$\mathrm{J}-13$ well water ${ }^{\mathrm{a}}$} & $\begin{array}{c}\text { Equilibrium } \\
\mathbf{J}^{-13}{ }^{\mathbf{b}} \\
\end{array}$ & $\begin{array}{c}\text { Synthetic } \\
\mathrm{J}-13^{\mathrm{C}} \\
\end{array}$ \\
\hline & & Mean & $\begin{array}{l}\text { Standard } \\
\text { deviation }\end{array}$ & & \\
\hline $\mathrm{pH}$ & $\begin{array}{l}\text { (standard } \\
\text { unit) }\end{array}$ & 7.41 & 0.44 & 8.54 & 8.35 \\
\hline $\begin{array}{l}\text { Alkalinity } \\
\text { (as } \\
\text { bicarbonate) }\end{array}$ & $(\mathrm{mg} / \mathrm{L})$ & 128.9 & 8.6 & 111.6 & n.m. \\
\hline Chloride & $(\mathrm{mg} / \mathrm{L})$ & 7.14 & 0.61 & 7.14 & 7.13 \\
\hline Fluoride & $(\mathrm{mg} / \mathrm{L})$ & 2.18 & 0.29 & 2.18 & 2.44 \\
\hline Nitrate & $(\mathrm{mg} / \mathrm{L})$ & 8.78 & 1.03 & 8.78 & 9.21 \\
\hline Sulfate & $(\mathrm{mg} / \mathrm{L})$ & 18.4 & 1.03 & 18.4 & 18.2 \\
\hline Calcium & $(\mathrm{mg} / \mathrm{L})$ & 12.9 & 0.99 & 6.76 & 6.15 \\
\hline Magnesium & $(\mathrm{mg} / \mathrm{L})$ & 2.01 & 0.21 & 2.01 & 1.51 \\
\hline Potassium & $(\mathrm{mg} / \mathrm{L})$ & 5.04 & 0.61 & 5.04 & 5.11 \\
\hline Sodium & $(\mathrm{mg} / \mathrm{L})$ & 45.8 & 2.29 & 48.7 & 49.3 \\
\hline Silicon & $(\mathrm{mg} / \mathrm{L})$ & 28.5 & 1.85 & 28.5 & n.m. \\
\hline
\end{tabular}

${ }^{\mathrm{a}}$ Data from CRWMS M\&O (2000).

${ }^{\mathrm{b}}$ From Viani (2002).

${ }^{c}$ Measured values of the water prepared according to the recipe. n.m.: not measured.

Figure 18 shows the simultaneous transport of multiple tracers in the alluvium column. Nearly identical breakthrough curves were obtained for bromide, chloride, iodide, $\mathrm{MoO}_{4}{ }^{2-}$, and $\mathrm{ReO}_{4}{ }^{-}$; all breakthrough curves exhibited symmetrical behavior with negligible tailing. By using a numerical simulation program (c.f. Jessup et al., 1989), we found that the retardation factors for these tracers were 1.0, which indicates that no sorption occurred in the alluvium. A slight sorption of iodate, with a retardation factor of 1.44 , was noticed with the alluvium. This finding is consistent with observations by numerous researchers that iodate has a stronger interaction with geological media than does iodide (Couture and Seitz, 1983; Ticknor and Cho, 1990; Sheppard and Thibault, 1992; Yoshida et al., 1992). We do not know why tritium behaved unusually with a retardation factor of only 0.9 . However, we suspect that our attempts to use less radioactivity, which resulted in our tracer solution exhibiting tritium activity that was 10 times lower than typical, might have had some effect. 


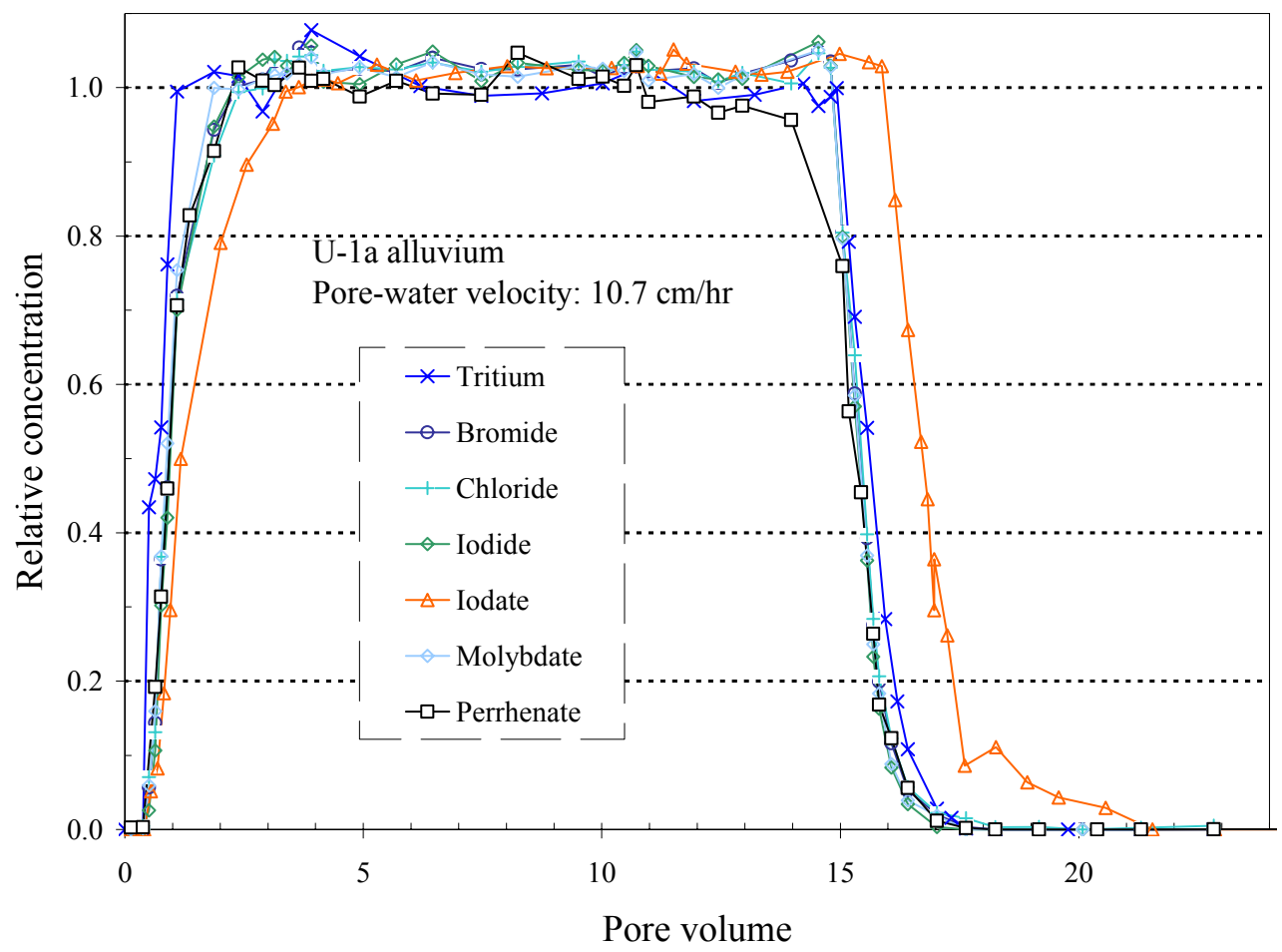

Figure 18. Breakthrough curves of various tracers in the column packed with alluvium. The $y$ axis shows the measured tracer concentration in the collected effluent sample divided by the input concentration, while the $x$-axis represents the volume of fluid introduced through the porous medium divided by the fluid capacity of the porous medium.

Figure 19 shows the simultaneous transport of multiple tracers in the column packed with the crushed tuff. The breakthrough curves for all tracers were nonsymmetrical with gradual tailing to approach the input concentration; such nonideal transport behavior is related to the physical heterogeneity of the tuff used (Hu and Brusseau, 1996). The intragrain porosity of the tuff was measured to be about $9 \%$, and water contained in these pores may be immobile when compared to mobile intergrain water. The tailing in the breakthrough is caused from the diffusive mass transfer among inter- and intra-granular waters. A dual-continuum modeling approach is needed to describe such nonideal transport, compared to the conventional advection-dispersion equation to describe the breakthrough in the alluvium column. Figure 20 shows the data and simulation for perrhenate $\left(\mathrm{ReO}_{4}{ }^{-}\right)$in two columns. Although $\mathrm{ReO}_{4}{ }^{-}$exhibits nonideal transport in the crushed tuff column, there is no chemical interaction with the tuff medium to cause the retardation, with a fitted retardation factor of 0.93 . This conservative behavior of Re is consistent with the measured redox potential and $\mathrm{pH}$ values in the column effluent samples, as shown in Figure 21. According to the Eh- $\mathrm{pH}$ diagram shown in Figure 14, $\mathrm{ReO}_{4}^{-}$is the dominant rhenium species under the experimental conditions. 
Hu et al. Radionuclide mobility ...

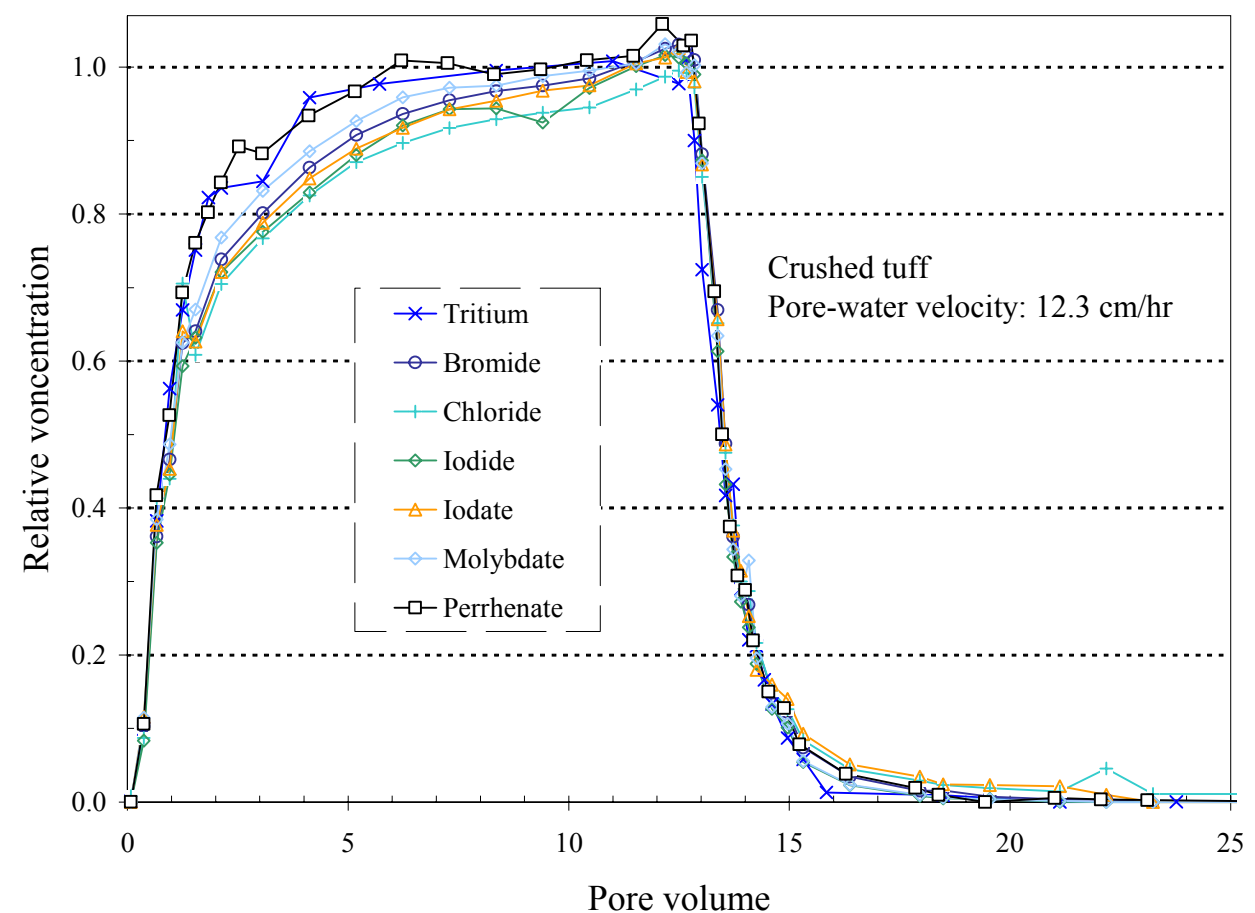

Figure 19. Breakthrough curves of various tracers in the column packed with crushed tuff.

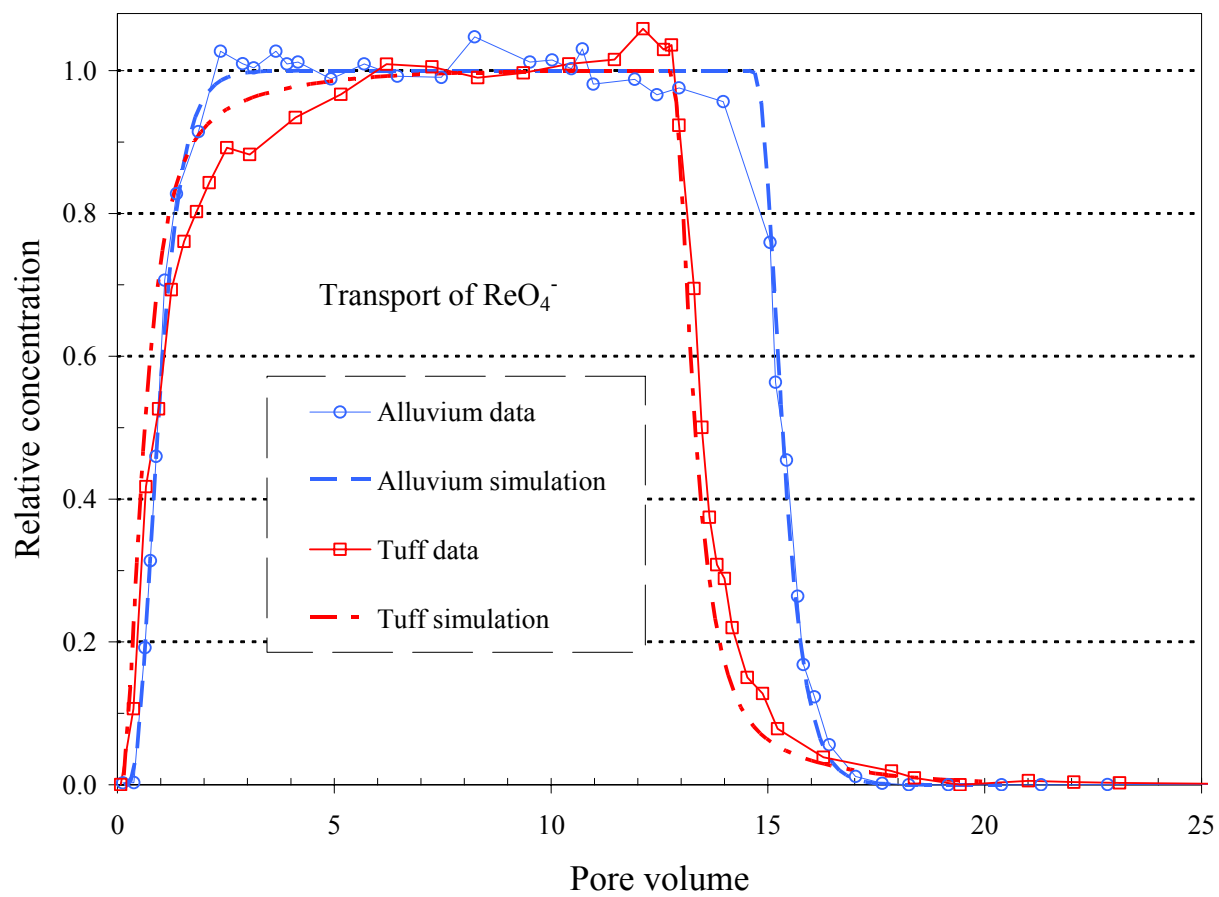

Figure 20. Breakthrough curves of perrhenate $\left(\mathrm{ReO}_{4}{ }^{-}\right)$in the columns packed with alluvium and crushed tuff. The input pulse is 14.6 and 12.7 pore volumes for the alluvium and tuff columns, respectively. 
(a)

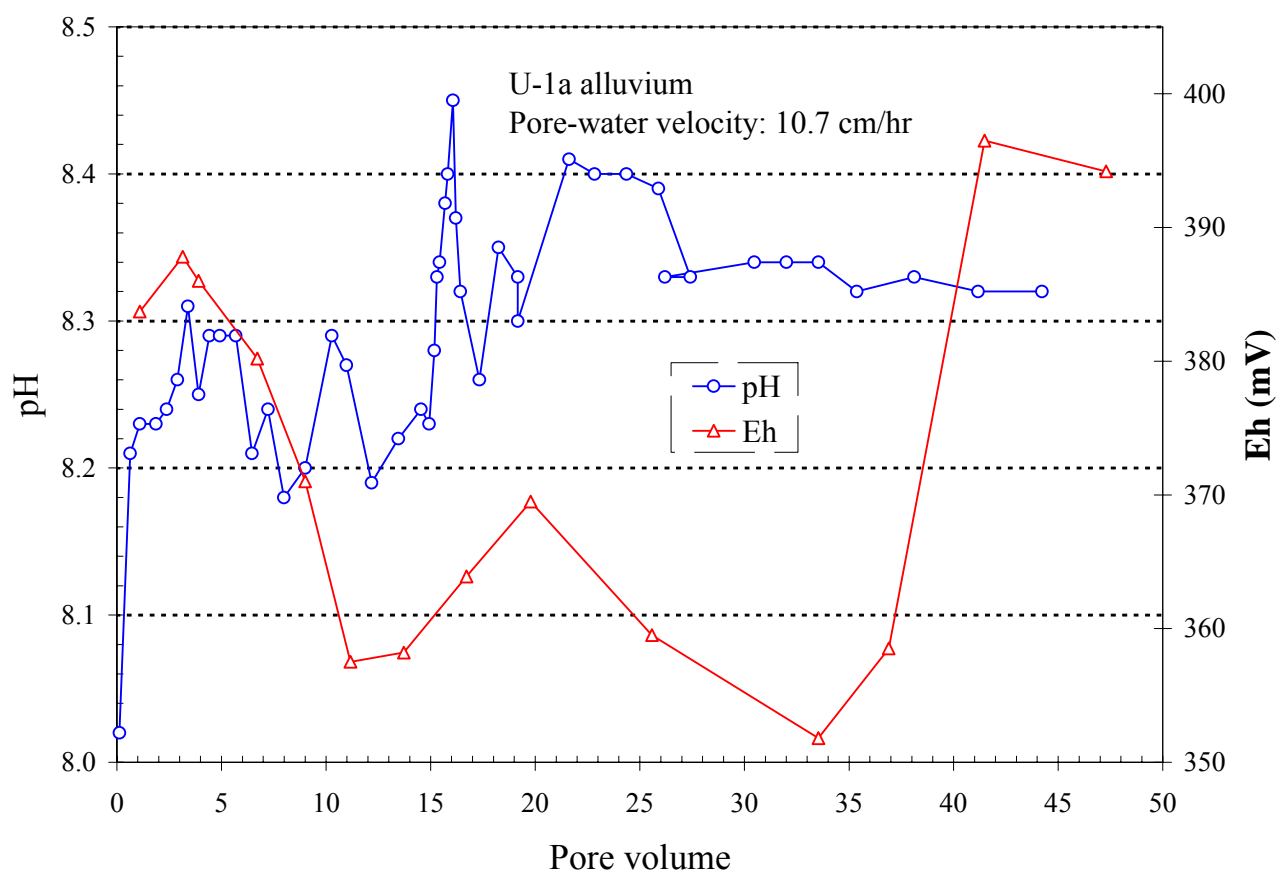

(b)

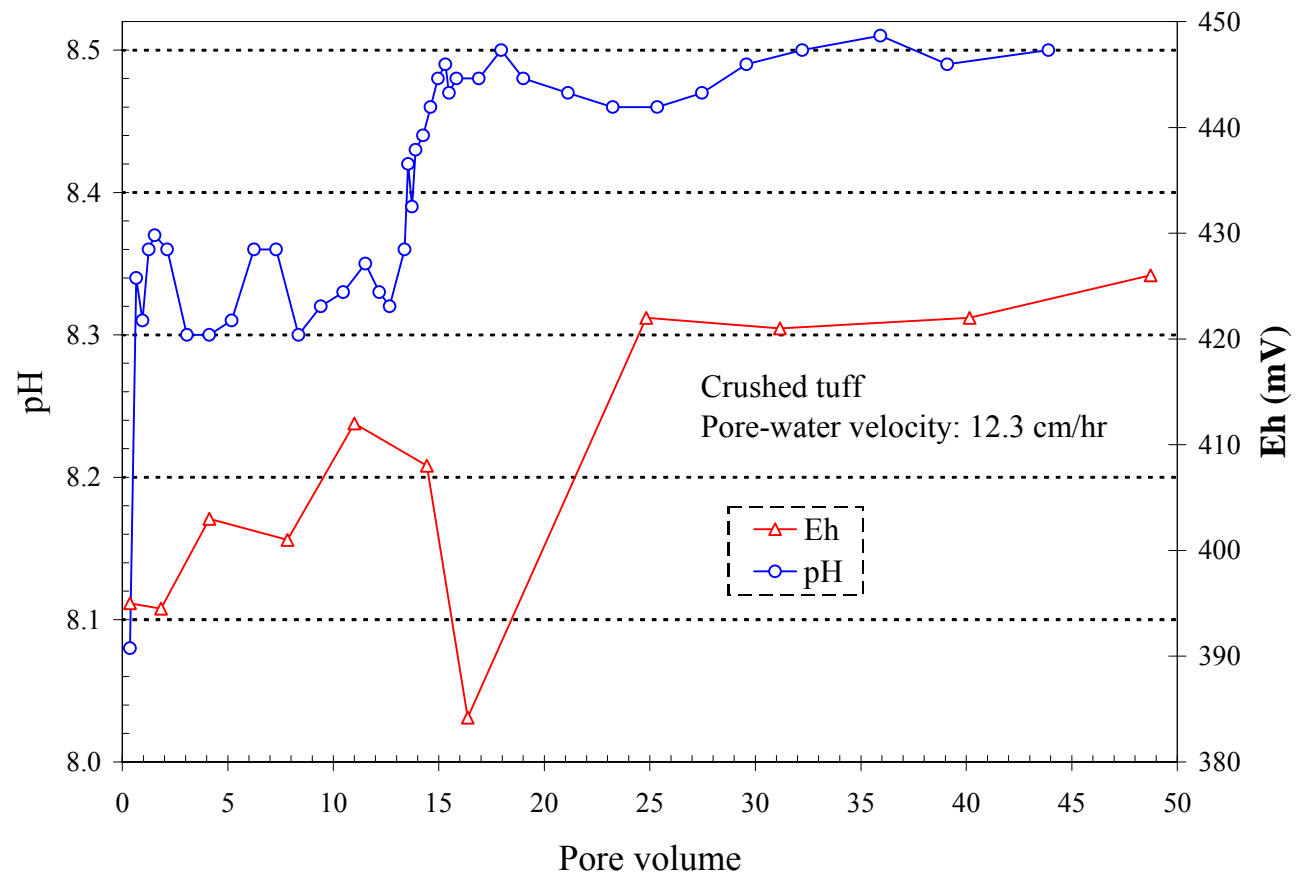

Figure 21. Measured $\mathrm{pH}$ and Eh values of column effluents: (a) U-1a alluvium and (b) crushed tuff. 


\section{Radionuclide transport modeling}

In parallel with the RNM/HRMP projects, the UGTA project has been evaluating the extent of groundwater contamination due to underground nuclear testing at the NTS. The UGTA project strategy includes drilling, groundwater analysis/monitoring, and three-dimensional (3-D) flow and transport modeling with a 1000-year contaminant boundary. The modeling effort consists of a three-tiered approach in which detailed near-field models (scale: $\sim 1 \mathrm{~km}^{2}$ ) provide input to subregional scale models (scale: $\sim 10^{2} \mathrm{~km}^{2}$ ), which are set within the limits of a regional scale model (scale: $\sim 10^{4} \mathrm{~km}^{2}$ ). The near field of an underground nuclear test consists of a radiological source term that is distributed, in general, roughly in a spherical manner with the device working point at its center. Near-field models generally evaluate the nonisothermal transport of sourceterm radionuclides hundreds of meters downstream from the initial sphere of contamination; the subregional and regional models evaluate the isothermal transport of radionuclides away from the near field for distances of several kilometers through heterogeneous rock. To date, simulations have been performed for the Frenchman Flat alluvium (e.g., the CAMBRIC test) and for Pahute Mesa fractured lava (e.g., the CHESHIRE and BENHAM tests).

UGTA simulations include investigations of the effect of residual test heat on flow and transport, geostatistical approaches to mineral distribution and the effects of mineral distribution on radionuclide adsorption, fully coupled reactive-transport models of radionuclide migration from the near field, and generalized models of radionuclide surface complexation and ion exchange to various minerals. The insight gained from these simulations can be employed when modeling of radionuclide migration at the proposed Yucca Mountain repository.

\section{Radionuclide transport in alluvium (Frenchman Flat simulations)}

The radionuclide release from the CAMBRIC test, located in the saturated alluvium of Frenchman Flat, was simulated to define the release and transport of radionuclides away from a nuclear explosion (Tompson et al., 1999). The flow was simulated on a nonuniform field of hydraulic conductivity chosen from an idealized random-field model, which assumed steadystate flow. Mineral spatial heterogeneity was considered for radionuclide transport. The radionuclide release from nuclear melt glass was based on the transition-state model of mineral dissolution, while the radionuclide sorption was based on nonelectrostatic surface complexation and Vanselow ion exchange models. The effect of spatially heterogeneous mineral distribution on radionuclide transport was examined in a rudimentary fashion by isolating radionuclidesorbing minerals to zones of low permeability. Simulations were performed by employing a streamline approach in which 3-D flow is deconvolved to a large number of one-dimensional streamlines. The reactive transport of $\mathrm{Cs}, \mathrm{Sr}$, and $\mathrm{Pu}$ was examined in these simulations, while all other radionuclides were treated as tracers. The simulations of radionuclide transport considered mechanistic surface complexation, ion exchange, and mineral dissolution models.

\section{Radionuclide transport in fractured lava (Pahute Mesa simulations)}

The Pahute Mesa tests are more directly relevant to Yucca Mountain due to similarity in the geologic setting; Pahute Mesa testing occurred in the fractured volcanic tuffs and lavas that are analogous to the proposed repository setting. A nonisothermal model using the NUFT code (Nitao, 1998) was developed for the CHESHIRE test (Pawloski et al., 2001) at LLNL, while a similar effort at LANL employed the FEHM code (Zyvoloski et al., 1997) to model the 
BENHAM test (Wolfsberg et al., 2001). Both the CHESHIRE and BENHAM tests were located in fractured lava deep below the water table. A temperature history from the CHESHIRE cavity indicates the persistence of temperatures far above background (referred to as "residual heat" or "residual thermal response"). A separate study by Kersting et al. (1999) discovered trace quantities of $\mathrm{Pu}$ fingerprinted to the BENHAM test nearly $1.3 \mathrm{~km}$ downstream of the test location and $500 \mathrm{~m}$ above the working point, the depth at which the testing device was placed. Simulations of both CHESHIRE and BENHAM indicate that the residual thermal response resulted in substantial vertical transport of radionuclides. Improvements to UGTA modeling of radionuclide transport at the NTS for the CHESHIRE and BENHAM tests include the following:

- Development of a surface complexation and ion exchange model for $\mathrm{Pu}, \mathrm{Np}, \mathrm{Cs}, \mathrm{Sr}, \mathrm{Am}$, $\mathrm{Eu}, \mathrm{Sm}, \mathrm{U}$, and ${ }^{41} \mathrm{Ca}$.

- Refinement of the reactive surface area of nuclear melt glass.

- Accounting for the decay and ingrowth of radionuclides.

- Development of a geostatistical model of heterogeneous hydraulic permeability in the near field.

- Development of a geostatistical model of radionuclide-sorbing mineral distribution in the near field.

- Accounting for early-time, transient-flow fields resulting from residual test-derived heat.

- Use of a streamline approach for steady-state to near-steady-state flow fields when modeling radionuclide reactive transport.

- Use of a particle transport approach for highly transient flow fields when modeling radionuclide reactive transport.

Conclusions resulting from the CHESHIRE and BENHAM simulations include the following (excerpted from Pawloski et al. [2001] and Wolfsberg et al. [2001]):

- Residual heat from the test, manifested as high initial temperatures in the melt glass, has numerous important effects on flow, transport, and reaction phenomena in the near-field system. Fast, initial upward migration of the more mobile radionuclides is possible under such conditions, but it has less of an impact on the more retarded or strongly sorbing radionuclides (Figures 22-23).

- The dissipation of elevated temperatures near the source is dominated by the convection in groundwater of thermal energy away from the glass.

- Melt-glass dissolution rates are highly sensitive to variations in temperature, surface area, silica concentration and $\mathrm{pH}$, and the secondary minerals that precipitate in the glass zone. 
- Monte Carlo simulations spanning a range of plausible and conditioned permeability and mineralogy realizations indicate a significant degree of variability — or uncertainty — with regard to the flux of radionuclides both vertically and horizontally. This variability ultimately represents a balance of competing forces related to thermal buoyancy effects, horizontal hydraulic gradients, nonuniform permeability distributions, radionuclidedependent reactivities and release times, and nonuniform reactive mineral distributions (Figure 24). A sample set of Monte Carlo simulations from the BENHAM cavity is illustrated in Figure 25.

- Simple conceptualizations of the heterogeneous permeability distribution involving layered or uniform structures cannot be fully calibrated to available data and must be considered unrealistic. Geostatistical variation in the permeability distribution, as guided by geophysical logs and other related observations, is necessary to develop reasonable representations of the hydrogeology.

- Numerical results suggest that if Pu-colloid reactive transport is modeled simply as a nonsorbing tracer, Pu-colloid material can be transported $1.3 \mathrm{~km}$ downstream from the BENHAM site in less than 30 years (i.e., hydrologic transport is a plausible mechanism that explains the downstream Pu observations by Kersting et al. [1999]).

- The effects of decay and ingrowth can influence the abundance and migration behavior of the source term radionuclides. Although all of the 37 radionuclides included in this model will undergo decay, only those in the chain ${ }^{241} \mathrm{Pu} \rightarrow{ }^{241} \mathrm{Am} \rightarrow{ }^{237} \mathrm{~Np}$ need to be considered from a coupled decay and ingrowth perspective.

- The sensitivity of model results to the addition of local dispersion is small. Only when dispersion was set to very high values (dispersivity $\alpha_{L}=100 \mathrm{~m}$ and $\alpha_{T}=10 \mathrm{~m}$ ) did breakthrough at the downstream plane noticeably depart from the base-case simulations.

- Use of both streamline and particle simulations proved to be a useful and successful marriage of two competing numerical techniques. The collective advantages of these techniques could then be mutually exploited for a complete analysis of reactive transport of radionuclides away from the test source. For example, the stochastically generated stream-tube simulations of Figure 25 can be combined with the radionuclide efflux from the BENHAM source (Figure 23 and left-hand plots of Figure 26). Assuming steady-state flow at the subregional scale, a convolution integration method can be employed to yield radionuclide breakthrough curves at observation wells and at the NTS boundary (righthand plots of Figure 26). Both conservative and nonconservative radionuclides can be considered in this manner. 

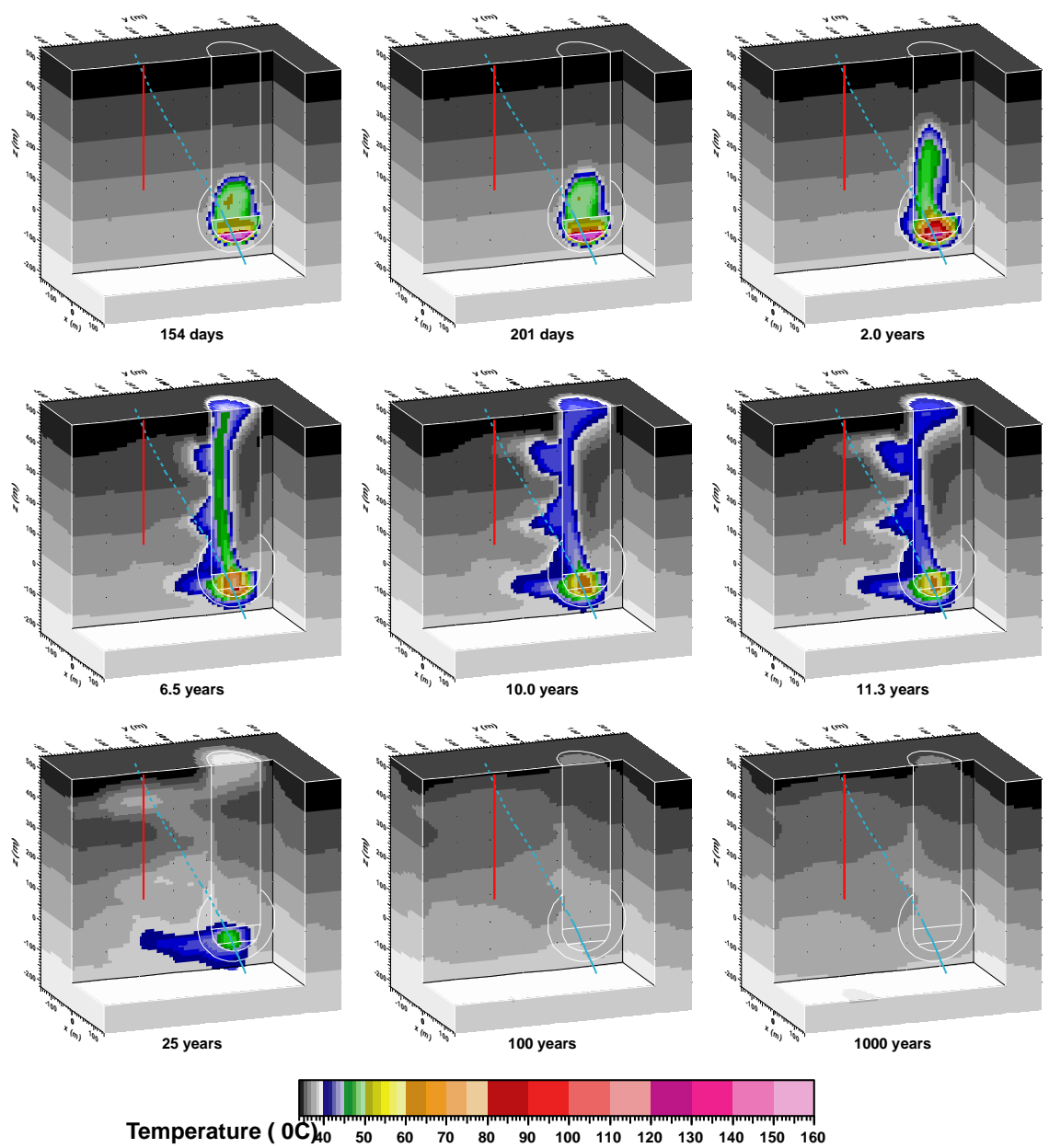

Figure 22. Perspective views of temperature fields at different times from nonisothermal flow simulation for one realization of the LLNL CHESHIRE simulations (Pawloski et al., 2001). 

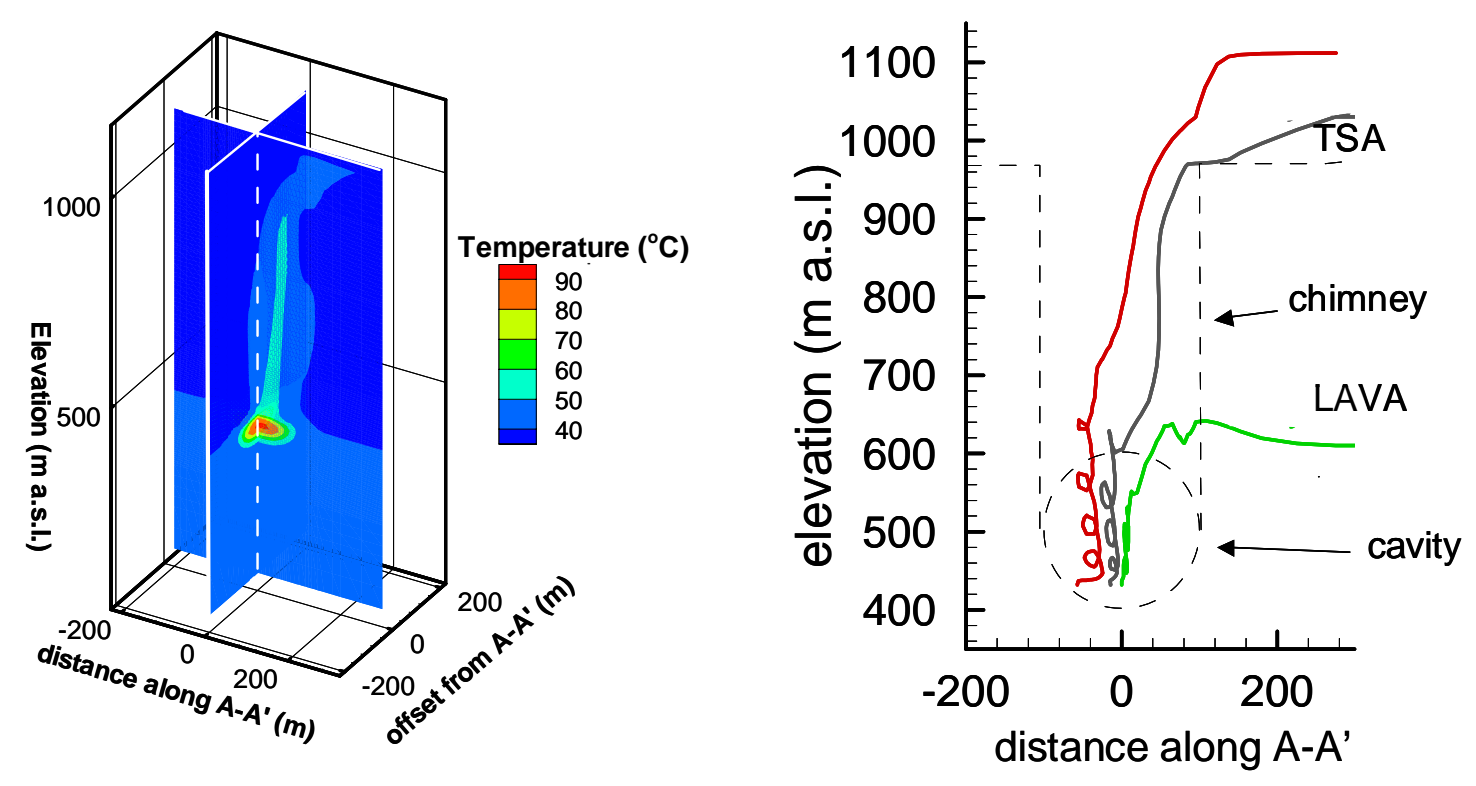

Figure 23. A flow and transport simulation by LANL of the BENHAM test 20 years after the testing event: (left plot) a buoyant plume of water convects vertically from the deep source; (right plot) particle path-lines indicate the convective path of conservative tracers in the nonisothermal flow (Wolfsberg et al., 2001). TSA: Topopah Springs aquifer.

\section{Rock Zones}

$\begin{array}{lll}1 & \text { Bedded } & \text { Orange } \\ 2 & \text { NonWelded } & \text { Green } \\ 3 & \text { Welded } & \text { Blue } \\ 4 & \text { Lava } & \text { Red } \\ 5 & \text { Zeolitic } & \text { Magenta }\end{array}$
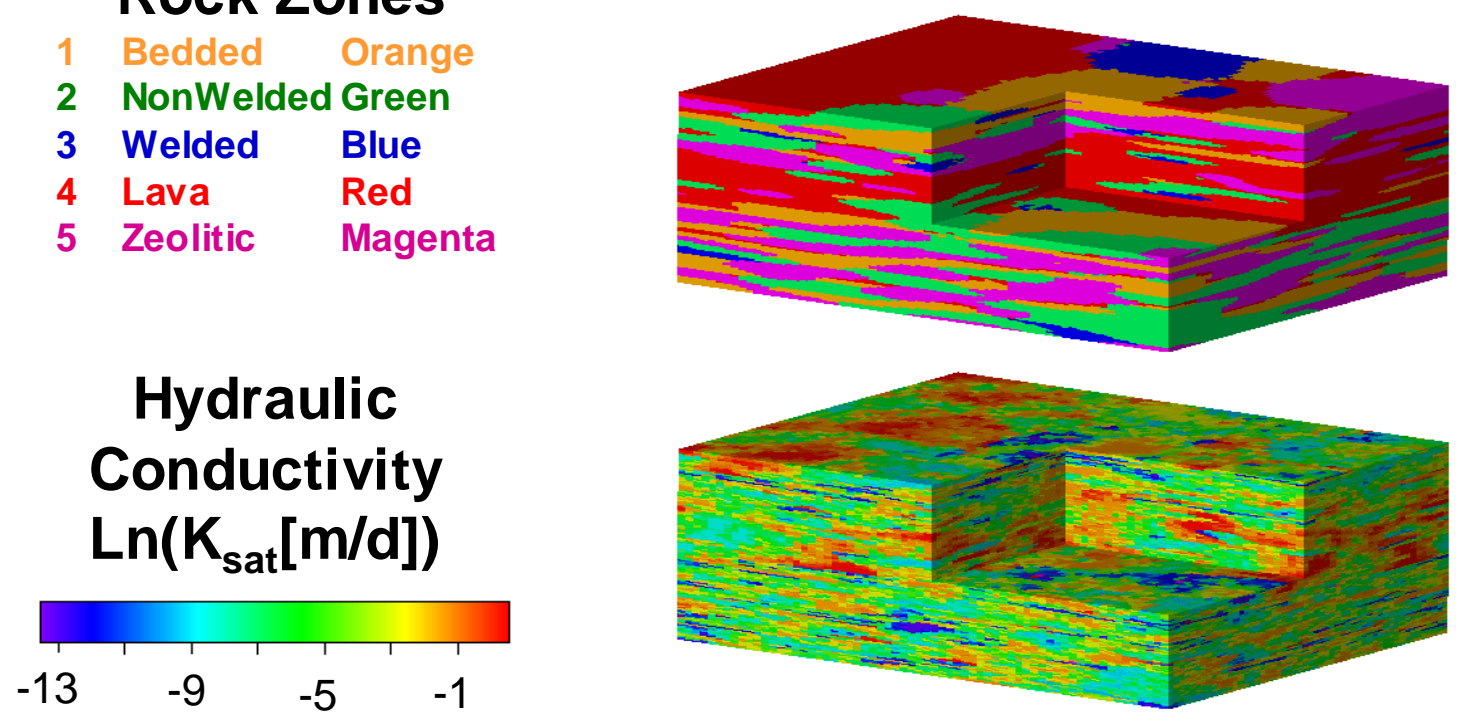

Figure 24. The CHESHIRE and BENHAM simulations considered regional geo-statistically varied volcanic rock very similar in makeup to the Yucca Mountain site (Pawloski et al., 2001; Wolfsberg et al., 2001). 

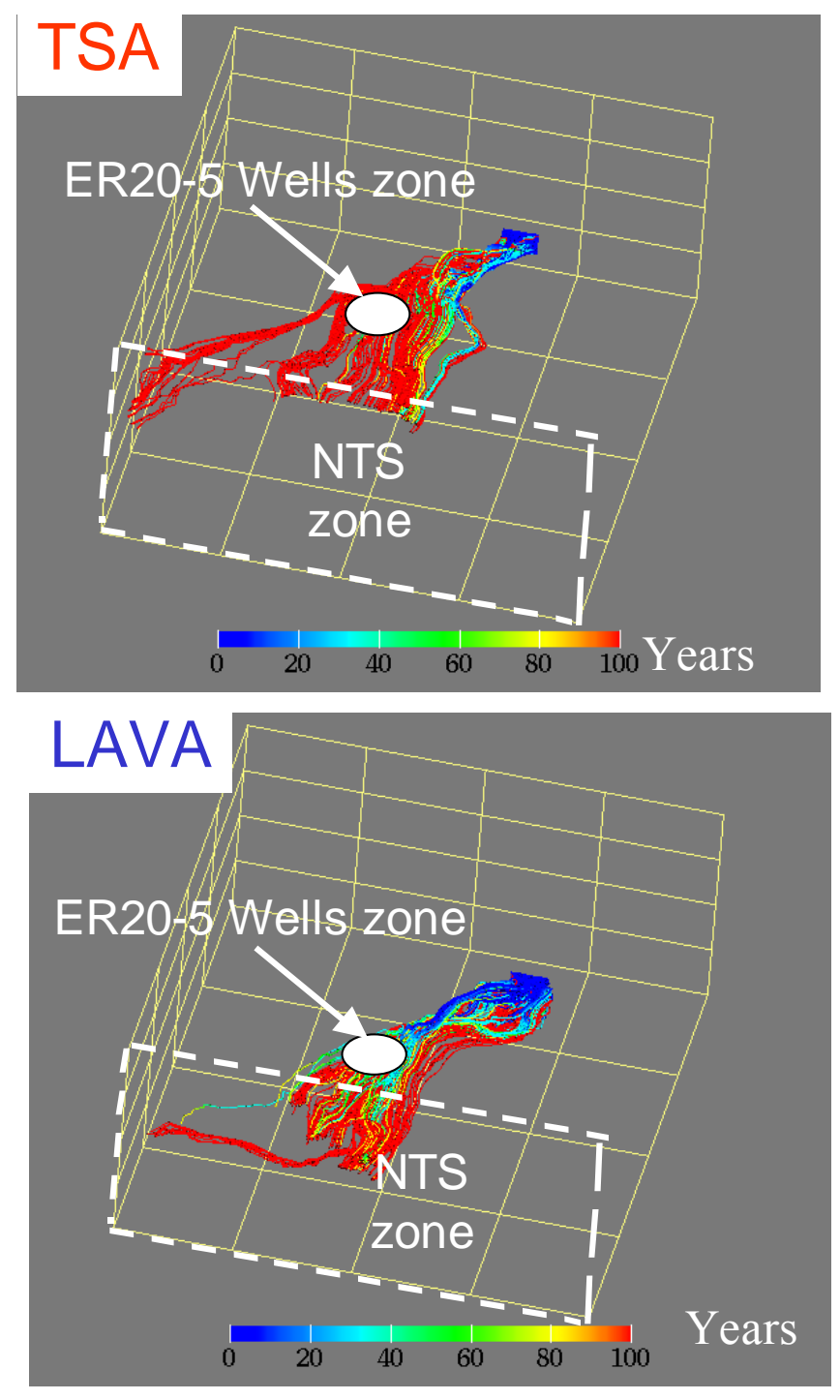

Figure 25. Tracer particle paths in two fractured volcanic rock units: the Topopah Springs Aquifer (top) and the Lava Aquifer (bottom) (Wolfsberg et al., 2001). 

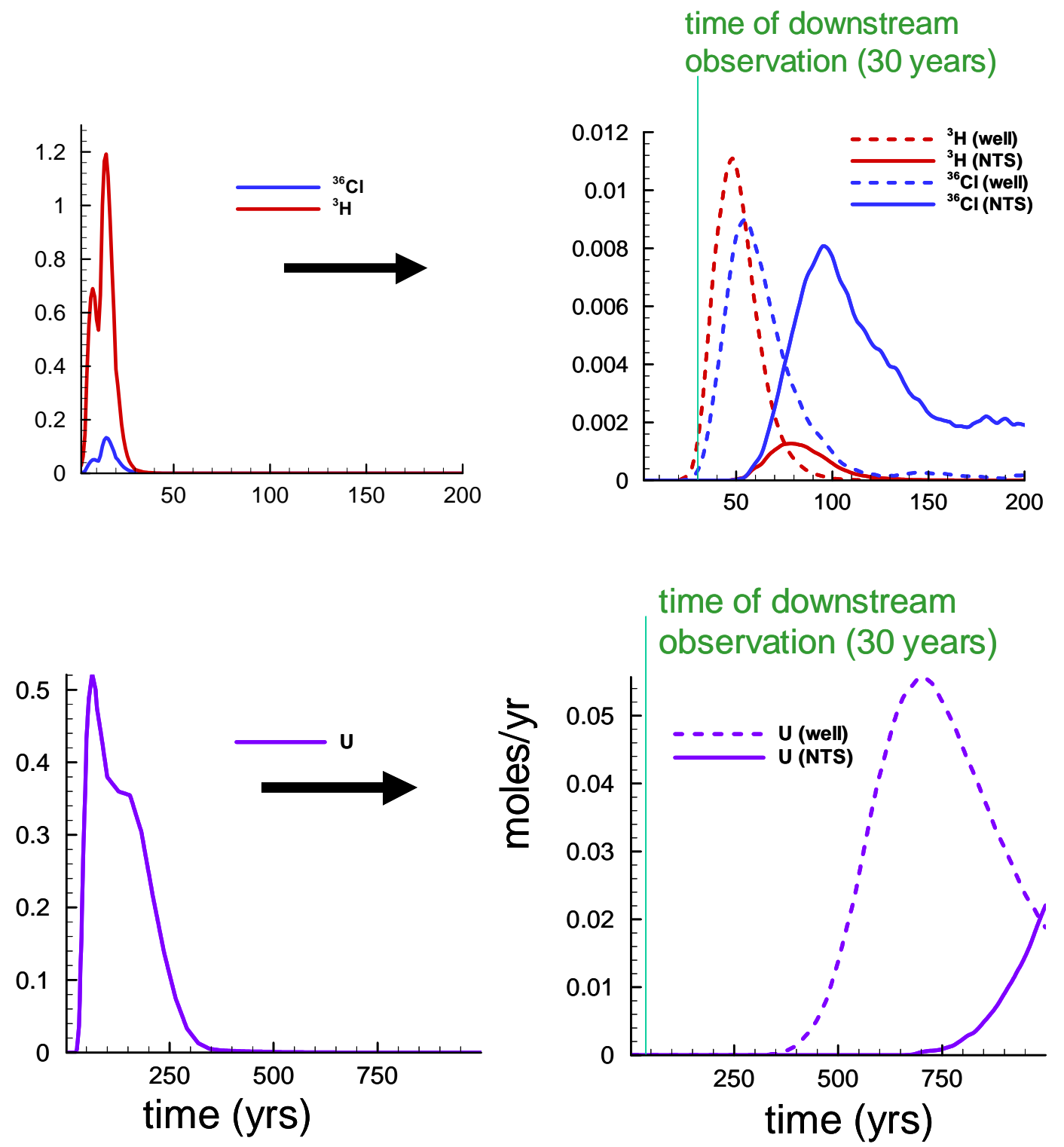

Figure 26. Concentration histories at the BENHAM source (left-hand plots) and downstream at the observation well and NTS boundary for select radionuclides (right-hand plots). The top plots illustrate conservative radionuclides ${ }^{3} \mathrm{H}$ and ${ }^{36} \mathrm{Cl}$, the bottom plots illustrate non-conservatively modeled uranium complexations (Wolfsberg et al., 2001). 


\section{Other issues relevant to the Yucca Mountain Project}

\section{Transport in unsaturated zone}

Nearly one-third (258 out of 828) of the nuclear tests were conducted near (less than $100 \mathrm{~m}$ above the static water table) or beneath the pretest static water level (SWL) (Laczniak et al., 1996; Smith, 2003). A total of 512 tests were detonated more than 5 cavity radii above the water table (Table 6). Although nearly two-thirds of the nuclear tests were conducted above the water table, detailed information is not available about the distribution of radionuclides from these tests. Below is a compilation of studies and results related to the radionuclide distribution at the NTS vadose zone.

The CAMBRIC experiment provides the most insight regarding radionuclide migration through the NTS vadose zone. During the CAMBRIC studies, the effluent from pumping well RNM-2s was monitored and discharged to an unlined ditch that emptied into Frenchman Lake, which was $1 \mathrm{~km}$ away. The effluent contained mostly soluble radionuclides such as tritium, ${ }^{14} \mathrm{C},{ }^{36} \mathrm{Cl},{ }^{85} \mathrm{Kr}$,

${ }^{99} \mathrm{Tc}$, and ${ }^{129} \mathrm{I}$. This discharge infiltrated the ground along the ditch, which created an unexpected and remarkable experiment that provides insight into radionuclide migration through the $220-\mathrm{m}$ vadose zone (Tompson et al., 2002). UE-5n is a groundwater monitoring well located $100 \mathrm{~m}$ away from the ditch (Figure 6). Tritium was first detected in this well about 16 years after its initial discharge into the ditch. Tompson et al. (2002) used the pumping and effluent data, geologic information, isotopic age-dating estimates, and vadose-zone flow-and-transport models to understand the movement of radionuclides through the vadose zone. Modeling and tritium age dating showed a transient time of 3.5 to 5.5 years through the vadose zone.

The radionuclides ${ }^{36} \mathrm{Cl},{ }^{99} \mathrm{Tc}$, and ${ }^{129} \mathrm{I}$ were also detected at UE-5n, indicating that these isotopes move in concert with tritium (Tompson et al., 2002). The relative mobilities of tritium and ${ }^{36} \mathrm{Cl}$, although similar in a saturated environment, differ in the vadose zone because tritium evaporates more readily into the gas phase (Buddemeier et al., 1991; Tompson et al., 2002). In unsaturated transport, if tritiated water moves via vapor phase transport to a significant extent, then solute species may be left behind and cannot act as conservative water tracers. ${ }^{36} \mathrm{Cl}$ is elevated well above the source-term ratio concentration in all lysimeter samples, possibly from some additional sources, such as local and global fallout. ${ }^{129}$ I exhibits a pattern that suggests retardation and buildup in the ditch-margin soils (Buddemeier et al., 1991).

${ }^{14} \mathrm{C}$ and ${ }^{85} \mathrm{Kr}$ were present in the effluent from pumping well RNM-2s, but not in UE-5n (Finnegan and Thompson, 2001). The preferential retention of ${ }^{14} \mathrm{C}$ may be due to its precipitation or other chemical reaction (isotopic exchange with common carbonate minerals) during transit to the water table. In the vadose zone, ${ }^{85} \mathrm{Kr}$ will probably preferentially partition into the gas phase and will not move in water, as it does in the saturated zone. 
Table 6. Distribution of underground tests relative to water table. (Modified from Laczniak et al., 1996.)

\begin{tabular}{|c|c|c|c|}
\hline \multirow[b]{2}{*}{ NTS area } & \multirow{2}{*}{$\begin{array}{l}\text { Below } \\
\text { the water table }\end{array}$} & \multicolumn{2}{|c|}{ Above the water table } \\
\hline & & $\begin{array}{c}\text { Less than } 5 \text { cavity } \\
\text { radii }^{\mathrm{a}}\end{array}$ & $\begin{array}{c}\text { Greater than } 5 \\
\text { cavity radii }\end{array}$ \\
\hline \multicolumn{4}{|c|}{ Yucca Flat } \\
\hline 1 & 0 & 0 & 3 \\
\hline 2 & 19 & 37 & 81 \\
\hline 3 & 9 & 60 & 183 \\
\hline 4 & 16 & 10 & 8 \\
\hline 6 & 0 & 1 & 4 \\
\hline 7 & 30 & 22 & 10 \\
\hline 8 & 0 & 2 & 8 \\
\hline 9 & 1 & 8 & 90 \\
\hline 10 & 1 & 10 & 45 \\
\hline 15 & 0 & 0 & 3 \\
\hline Subtotal & 76 & 150 & 435 \\
\hline \multicolumn{4}{|c|}{ Pahute Mesa } \\
\hline 19 & 14 & 20 & 2 \\
\hline 20 & 20 & 26 & 3 \\
\hline Subtotal & 34 & 46 & 5 \\
\hline \multicolumn{4}{|c|}{ Rainier Mesa } \\
\hline 12 & 0 & 0 & 62 \\
\hline \multicolumn{4}{|c|}{ Frenchman Flat } \\
\hline 5 & 1 & 4 & 0 \\
\hline 11 & 0 & 5 & 0 \\
\hline Subtotal & 1 & 9 & 0 \\
\hline \multicolumn{4}{|c|}{ Shoshone Mesa } \\
\hline 16 & 0 & 0 & 6 \\
\hline \multicolumn{4}{|c|}{ Buckboard Mesa } \\
\hline 18 & 0 & 0 & 3 \\
\hline \multicolumn{4}{|c|}{ Dome Mountain } \\
\hline 30 & 0 & 0 & 1 \\
\hline Total & 111 & 205 & 512 \\
\hline
\end{tabular}

${ }^{\mathrm{a}}$ Widespread fracturing caused by detonation will affect a region of 5 cavity radii. 
Some nuclear tests were conducted above the water table (Table 3), and the results from these tests further assist us in understanding the migration behavior of radionuclides in the vadose zone. At the NASH nuclear test (U-2ce), significant quantities of tritium and low but measurable amounts of ${ }^{85} \mathrm{Kr},{ }^{22} \mathrm{Na}$, and ${ }^{90} \mathrm{Sr}$ have been detected in UE-2ce, a satellite well drilled in the Paleozoic carbonate aquifer $183 \mathrm{~m}$ from the working point (Buddemeier and Isherwood, 1985). Nuclides may have been transported downward to the underlying water table by infiltrating the surface water through the chimney and cavity. Although NASH was detonated $163 \mathrm{~m}$ above SWL, the cavity formed by NASH likely extends to a depth near the water table, or there may be fluctuations in the water levels sufficient to flood the existing cavity and enhance radionuclide transport.

The BOURBON test (U-7n) was detonated in 1967 in Paleozoic carbonate rock approximately $41 \mathrm{~m}$ above SWL (Buddemeier and Isherwood, 1985). It is probable that the cavity intersected the water table. In 1976, satellite well UE-7nS was drilled $137 \mathrm{~m}$ from the U-7n location, and low-volume pumping took place until 1984. Only a low level tritium (maxmiun $\sim 10^{2} \mathrm{~Bq} / \mathrm{L}$ ) was detected in the water samples from well UE-7nS.

Tyler et al. (1992) observed enhanced water infiltration in nuclear subsidence craters at the NTS, and they reported a vertical flux beneath the crater on the order of $0.6 \mathrm{~m}$ per year. They postulated that the surface topography, combined with the coarse-textured soils beneath the crater, allows for the deep infiltration of ephemerally ponded water at the bottom of the crater.

\section{Radionuclide distribution in the subsurface}

Drillbacks into nuclear test cavities have been conducted for many tests to obtain melt glass for diagnostic purposes. Some drillbacks were specifically performed with the objective of acquiring data on the distribution of radionuclides, and useful information on vertical distributions of tritium and fission products at the NTS has been obtained (Thompson, 1996; Smith, 1998).

In 1994, two holes were drilled into the cavity of the 1981 BASEBALL test in Yucca Flat (Thompson, 1996). During drilling, radiation levels in the upper part of the cavity were measured using a high-sensitivity gamma detector. The results showed that extremely heterogeneous radionuclide disposition in the underground environment of the cavity region. There exists an extreme variability of radionuclide content in samples taken from locations close to one another or even at the same depth. Even tritium preserves a distribution pattern such that large concentration differences exist over narrow intervals both vertically and horizontally. Also at this site, the radionuclides have remained where they were deposited during the formation of the cavity and chimney (Thompson, 1996). During a 13-year span from the test firing and drillbacks, there seems to have been little vertical or horizontal migration of tritium.

As discussed in Smith (1998), the 1994 INGOT drillback targeted fractured media adjacent to the edge of the cavity and emphasized the extent of gaseous transport in discrete intervals of enhanced permeability. The INGOT event had a working point of $500 \mathrm{~m}$ in a volcanic rock (Timber Mountain tuff) with an SWL at $563 \mathrm{~m}$ below the land surface. The test was fired in 1989 with an announced yield of 20-150 kt (Table 3). The drillback hole was slant-drilled to pass within $10 \mathrm{~m}$ of the edge of the cavity at the level of the working point at a total depth $46 \mathrm{~m}$ below SWL. The results show that, in addition to tritium, gaseous fission daughter products $\left({ }^{137} \mathrm{Cs}\right.$ and $\left.{ }^{90} \mathrm{Sr}\right)$ are abundant and may be encountered $10 \mathrm{~m}$ or more away from the cavity edge. 
Over $90 \%$ of the ${ }^{137} \mathrm{Cs}$ is produced from $\beta$-decay of a gaseous ${ }^{137} \mathrm{Xe}$ parent with a 3.84 -min halflife. When the cavity collapsed 7.9 min after zero time, much of the ${ }^{137} \mathrm{Cs}$ chain-yield was still in the form of ${ }^{137} \mathrm{Xe}$. Most of the migration probably occurred as the cavity collapsed, the chimney propagated upward, and the radioactive gases in the cavity region were displaced towards the surface. Overall, the late-time gaseous transport of ${ }^{137} \mathrm{Xe}$ and ${ }^{90} \mathrm{Kr}$ is responsible for the dispersion and subsequent deposition of ${ }^{137} \mathrm{Cs}$ and ${ }^{90} \mathrm{Sr}$.

Similar behavior was observed for ${ }^{137} \mathrm{Cs}$ for HYRAX (hole U-3bh) test, which occurred in September 14, 1962, at a working point $272 \mathrm{~m}$ above the static water table (Smith, 1998). Two vertical boreholes (U-3bh \#1 and \#2), separated by $15 \mathrm{~m}$, were drilled in the bottom of the subsidence crater. Drill cores indicate the presence of ${ }^{137} \mathrm{Cs}$ in the collapse chimney at $152 \mathrm{~m}$ above the working point (about 5 cavity radii) in the unsaturated zone. This ${ }^{137} \mathrm{Cs}$ was probably produced from the $\beta$-decay of a gaseous ${ }^{137} \mathrm{Xe}$ parent due to gas movement at the time the cavity and chimney formed. This suggests that significant radionuclide transport can occur in the distributed chimney region of a nuclear test conducted in the vadose zone. A significant amount of carbonate existed at the HYRAX working point, and the vaporization and melting of the carbonate produced an abundance of noncondensible $\mathrm{CO}_{2}$ gas that entrained the radioactive gases (Thompson, 1997). While ${ }^{137} \mathrm{Cs}$ abundances are nearly the same in the two boreholes, the tritium abundances vary by 2 orders of magnitude.

Two neighboring tests, BOBAC and JERBOA, were conducted at similar depths as HYRAX in the same carbonate-rich alluvium with similar phenomenology, but these tests showed no evidence of ${ }^{137} \mathrm{Cs}$ ascent through the chimney (Thompson, 1999; Smith, 2002). The JERBOA test was conducted on March 1, 1963, at a depth of $310 \mathrm{~m}$ in hole U-3at. Cavity collapsed at 35.3 min postshot; the collapse zone extended to the surface and formed a crater about $32 \mathrm{~m}$ deep. In June 1996, a slant hole (U-3at-D1) was drilled under the collapse crater at U-3at, and core samples were obtained from vertical depths as deep as $147 \mathrm{~m}$. No ${ }^{137} \mathrm{Cs}$ was detected in any cores, although there was a slight increase in tritium levels over the ambient levels in the very deepest samples (at about 4 cavity radii above the working point).

The BOBAC test was conducted on August 24, 1962, at a depth of $195 \mathrm{~m}$ at U-3bl. Cavity collapse occurred 8.2 min postshot; the collapse zone extended to the surface and formed a crater about 14 m deep. The slant hole (U-3bl-D2), drilled in February 1996, passed under the collapse zone and through the rubble chimney below the zone. The hole terminated at a vertical depth of approximately $97 \mathrm{~m}$. Twenty-nine cores were collected at 3-m intervals throughout the chimney region. No ${ }^{137} \mathrm{Cs}$ was detected, even in cores taken from about 3.5 to 4.5 cavity radii above the working point, and the tritium content in all cores was quite low.

There are no detailed reports regarding the roles of test-induced fractures on radionuclide migration. Underground nuclear tests ranged in yield from less than $1 \mathrm{kt}$ to detonations in excess of $1 \mathrm{Mt}$ (Kersting, 1996). Rock outward of 1.3 cavity radii was intensively pulverized. Up to a distance of 2 cavity radii, the rock was pervasively fractured. Fractures occurred but were more widely spaced, at distances up to 5 cavity radii. Offsets on preexisting faults at distances up to 11 cavity radii have been observed (Laczniak et al., 1996). Earlier investigations at the NTS indicated "prompt fracture injection" as a mechanism for transporting radionuclides away from the working point. In this conceptual model, a high-temperature and high-pressure plasma produced by the detonation is injected at zero time along newly created and reactivated fractures surrounding the working point. Nimz and Thompson (1992) attributed radionuclide migration in 
the unsaturated zone at U-3cn\#5 (satellite well of BILBY), UE-4g\#2, U-9 ITS U-29, U-3kz (ALEMAN emplacement hole), and UE-2ce (NASH emplacement hole) to prompt injection. However, the absence of a suite of long-lived refractory fission products from many nuclear tests argues against the direct injection of an undifferentiated high-temperature plasma at zero time.

HALFBEAK (U-19b) was fired at a depth of $820 \mathrm{~m}$ on June 30, 1966, in Area 19 at Pahute Mesa. The SWL at this site was $646 \mathrm{~m}$. As part of a moisture infiltration study, samples were collected from auger drilled into the collapsed crater of HALFBEAK. Rock samples were collected at $1.5-\mathrm{m}$ intervals up to a depth of $24.4 \mathrm{~m}$ for a radiochemical survey. No radioactivity associated with the HALFBEAK event was detected at shallow depths below the collapse crater (Thompson, 1999).

\section{Transport affected by thermal processes}

According to Smith et al. (1996), Butkovich (1974) reported on the extent of incremental heating associated with a nuclear test relative to total test yield and working point density. At a distance of $\sim 15 \mathrm{~m}$ (precavity displacement) from the working point, for a rock with a density of 2.6 $\mathrm{g} / \mathrm{cm}^{3}$, a 1-kt explosion results in an incremental temperature increase of $10^{\circ} \mathrm{C}$, while for the same distance and rock density, a 100-kt explosion results in a temperature increase of $1000^{\circ} \mathrm{C}$.

A significant part of the pressure from a nuclear test is due to the expansion of superheated water vapor. A natural water-vapor-reflux condenser in a nuclear explosion chimney results as the residual heat continually vaporizes water near the working point. As long as these rocks remain above the boiling point of water, vapor will form and rise in the chimney until it contacts rocks cooler than the boiling point of water. The vapor will condense on these rocks, and the resulting water will trickle down into the hotter zone, where it will again vaporize and move upward. This type of heat-pipe condition (vapor-liquid counter flow with phase change) is directly relevant to the potential repository at Yucca Mountain (Kneafsey and Pruess, 1998). At the geological repository, heat from radionuclide decay will heat up the rock. For the high-temperature thermal load configuration, the time at which boiling temperatures are predicted to exist will be in about 1000-2000 years (Dobson et al., 2003).

We would like to draw some analogies from these observations to the nuclear testing at the NTS.

A nuclear detonation releases considerable heat within the cavity region that may cause buoyancy-driven groundwater flow once the cavity is filled in. In the CHESHIRE test, tritium was observed in groundwater in the permeable zones above the cavity, which suggests that vertical flow and migration occurred after the test. A small vertical hydraulic gradient was measured and cited as a possible mechanism for driving flow up through the chimney region. Temperature log from the drillback hole (U20n-PS1dd) showed that significant thermal profiles existed across the cavity and chimney horizon as long as 6.5 years after the test. At all times, the highest temperatures were generally confined to the melt glass $\left(150^{\circ} \mathrm{C}\right.$ at 154 days; about $70^{\circ} \mathrm{C}$ after 6.5 years), with cooler, yet above ambient, temperatures in the cavity region $\left(50^{\circ} \mathrm{C}\right.$ at 154 days). Maxwell et al. (2000) developed a two-dimensional model of thermally driven fluid flow to study water movement and heat dissipation in the immediate region surrounding the working point. Results from the model indicate that the high temperature associated with the test will persist on the order of tens of years and may facilitate the transport of conservative species from 
the cavity region to the upper chimney region within time scales of $10-20$ years. A highpermeability zone located in the upper saturated zone, connected with the cavity-chimney system, allows for accelerated transport away from the vicinity of the test location.

After the ALMENDRO test was fired in 1973 at a depth of $1063 \mathrm{~m}$, the temperature in the reentry well was periodically logged, and the results showed that anomalously high temperatures persisted in the test cavity. In 1996, 23 years after the test, the water temperature log showed a modest increase with depth outside the zone impacted by the test shock wave, but water temperature rose sharply near the cavity-chimney region. The maximum temperature of $157^{\circ} \mathrm{C}$ was recorded at a depth of $1147 \mathrm{~m}$ within the test cavity (Rose et al., 2000a). Furthermore, immediately following the test, the water level dropped $\sim 250 \mathrm{~m}$ below the pretest water level. Monitoring revealed that the recovery of the water table took approximately 20 years. The groundwater isotope enrichments imply a prolonged water-rock interaction at elevated temperatures, and anomalous $\delta^{13} \mathrm{C}$-enriched carbon isotope signatures may be the result of methanogenic processes involving the reduction of carbon dioxide (Rose et al., 2000a).

The anomalous temperature, unusual enrichment in oxygen and carbon isotope ratios, and the slow recovery of the water table suggests that the water in the ALMENDRO cavity is only partially in contact with the ambient groundwater flow system in central Pahute Mesa. Thus, the saturated ALMENDRO cavity represents a "quasi-closed" or partially isolated hydrologic system (Rose et al., 2000a; Smith, 2002). The cavity seems to seal itself from extensive communication with the surrounding aquifer. It may be possible for a system to gradually evolve toward a closed condition as fractures are sealed due to secondary mineral deposition (Rose et al., 2000a). From laboratory experiments and numerical simulations conducted on Yucca Mountain tuff, Dobson et al. (2003) indicated that the boiling and concomitant precipitation of amorphous silica could cause significant reductions in fracture porosity and permeability on a local scale.

Other sites with elevated down-hole temperatures include the FAULTLESS test, which was conducted in 1968 at the central NTS. Down-hole temperature measurements in a postshot hole drilled in the collapse crater are in excess of $100{ }^{\circ} \mathrm{C}$ at depths of $800 \mathrm{~m}$ or more (Rose et al., 2000a).

\section{Radionuclides in the melt glass}

The melt glass created by the shock melting from an underground nuclear explosion coalesces in the lower cavity region and forms a puddle where the melt glass sequesters most long-lived radionuclides, including ${ }^{99} \mathrm{Tc}$. During an underground nuclear explosion, an explosive shock wave vaporizes approximately $7 \mathrm{t}$ and melts another $700 \mathrm{t}$ of rock for every kiloton of explosive yield (Smith, 1995). Within this mass, approximately $60 \mathrm{~g}$ of radionuclides are incorporated volumetrically.

As part of the test diagnosis for the nuclear weapons testing program, many puddle glass samples were recovered through reentry drilling after the test to determine which radionuclides were present. These samples provide opportunities to study the characteristics of the melt glass, the radionuclide distribution, and the leaching behavior of melt glass in groundwater. For example, LLNL researchers have conducted radiochemical studies on these glass and debris samples to determine the distribution of radionuclides (Smith, 1993; Smith, 1995; Eaton and Smith, 2001). 
These studies have yielded insight into the distribution of various radionuclides in the melt glass and the subsequent migration from leaching in the groundwater. Such knowledge is relevant to the analogous glass waste-forms proposed for Yucca Mountain.

According to Smith (1995), the following characteristics of melt glasses were summarized by Schwartz et al. (1984):

- Melt glasses are dehydrated relative to their hydrated host tuff.

- Glasses are extremely heterogeneous in major element composition.

- Geochemical heterogeneities occur on the scale of tens of micrometers.

- Iron-rich, darker glasses occur closer to the working point.

- There is no appreciable migration of major elements away from the working point.

Smith (1995) examined the composition, crystallinity, and texture of residual nuclear explosion melt debris and how such debris affects the potential mobility of constituent radionuclide species. Volatile species are likely surface-deposited on the abundant fracture surfaces created in the crystalline matrices while refractory species are volume-incorporated into the melt glass itself. Iron, which is contributed from the steel used in the device component, is enriched in the explosive glasses relative to natural glasses. Nuclear explosive glasses were distinguished from natural glasses by their characteristic darker color and highly vesicular texture. X-ray diffraction results indicated that the nuclear explosive debris was a mixture of variable proportions of glass and crystalline phases. All of the samples contained fission products, including ${ }^{106} \mathrm{Ru}{ }^{125} \mathrm{Sb}$, ${ }^{137} \mathrm{Cs},{ }^{144} \mathrm{Ce}$, and ${ }^{155} \mathrm{Eu}$. A number of activation products, including ${ }^{54} \mathrm{Mn},{ }^{60} \mathrm{Co}$, and ${ }^{154} \mathrm{Eu}$, were also identified in each of the six cores examined by Smith (1995). The remaining fission products, activation products, and actinides occurred singularly. In general, glass samples contained ${ }^{241} \mathrm{Am}$, while crystalline samples did not. A majority of refractory radionuclides are volumetrically well mixed in melt glass. Semivolatile and volatile species are associated with fractured crystalline matrices, where they are likely surface-deposited.

Over time, melt glass that is in contact with groundwater will partially dissolve, release some of the trapped radionuclides, and form both noncrystalline and crystalline secondary solids. Glass dissolution reactions are complex and depend on both the initial glass composition and the groundwater chemistry. As summarized by Kersting (1996), the major processes include (1) water diffusion into the glass, (2) subsequent alkali ion exchange, (3) formation of diffusion and gel layers on the contact surface between the glass and water, and (4) reprecipitation of released elements to form secondary phases (commonly clays and zeolites).

Smith (1993) reviewed literature pertaining to the leaching and sorption of radionuclides associated with nuclear explosion melt glasses. Phenomenology of a nuclear test must be understood in the context of the development, distribution, composition, and texture of melt glasses, as these parameters significantly affect the subsequent leaching and sorption of radionuclides. In general, leaching rates have been found to be uniform for a particular radionuclide dissociated from nuclear melt glass; deviations from uniformity are typically due to 
local alteration of a glass. For the majority of the radionuclides studied, less than $1 \%$ of their initial activity was released during a leaching experiment lasting 420 days at $25^{\circ} \mathrm{C}$ (Failor et al., 1983). The leach rate for most radionuclides decreased regularly throughout the duration of the experiment. The kinetics of leaching observed implies that radionuclide release occurs by a process that is more complex than simple dissolution.

\section{Summary and suggested future work}

Since 1973, various programs have been conducted to study the environmental effects of nuclear testing at the NTS. OCRWM and YMP stand to benefit from the NTS radionuclide migration research, from the perspectives of understanding mechanisms for radionuclide transport and performance confirmation. In this report, we have synthesized a substantial body of data and analyses on the mobility and distribution of soluble radionuclides under hydrogeologic and thermal conditions very similar to the proposed repository at Yucca Mountain. The findings from our syntheses are useful for developing tools to (1) understand the controls of radionuclide mobility at Yucca Mountain, (2) provide insight into repository performance, and (3) bound and calibrate numerical predictions of long-term radionuclide releases and migration.

Our main findings are summarized below:

- Phenomenology is critical in the initial distribution and subsequent migration behavior of radionuclides (both refractory and volatile) from an underground nuclear test.

- Knowledge of the speciation and reactions of presumably mobile radionuclides, such as long-lived ${ }^{99} \mathrm{Tc}$ and ${ }^{129} \mathrm{I}$, is very important to understand the transport behavior of these radionuclides at the NTS.

- Numerous lines of evidence suggest that the cavity environment is likely to have a reducing nature, particularly immediately after a nuclear test.

- Tc does not necessarily exist as the mobile and conservative species $\mathrm{TcO}_{4}{ }^{-}$, as commonly assumed. Recent in situ redox potential measurements have indicated that the groundwaters at the NTS are not uniformly oxidizing, as previously believed. The mobility of Tc is greatly reduced in a nonoxidizing environment.

- The migration behavior of iodine species is complex, and different species have different reactivities and mobilities.

- The interaction of tritium with a solid surface via hydroxyl isotopic exchange with clay lattice hydroxyls may cause a slight delay in the transport of tritium.

- The transport of ${ }^{14} \mathrm{C}$ may be affected by its isotopic exchange with carbonate minerals, and the exchange may be more pronounced in the vadose zone.

- Without information about clay content, clay mineralogy, iron oxide content, and cation/anion exchange capacity, the effect of anion exclusion on the transport of anions such as chloride may be mistakenly ascribed. 
- Laboratory column studies under saturated and oxidizing conditions confirm the conservative transport behavior of tritium, chloride, and iodide, as well as molybdate and perrhenate (which serve as analogs for pertechnetate) in alluvium and tuff samples.

- Numerical simulations are used to examine the effect of residual test heat on flow and transport, geostatistical approaches to mineral distribution and its effects on radionuclide adsorption, and fully coupled reactive-transport models of radionuclide migration at the NTS. The insight gained from these simulations will assist the modeling efforts for radionuclide migration at the proposed Yucca Mountain repository.

- Fractures around the test cavity (an analog to waste emplacement drift) are in some cases sealed by secondary-mineral deposition, which is due to the extended period of residual heat from nuclear tests (or high-level nuclear waste). Such "isolated" systems will contribute to the performance of the potential Yucca Mountain repository because they will limit hydraulic communications with the surroundings.

- The leaching of melt-glass samples indicates that, for a majority of radionuclides studied, only a fraction (less than $1 \%$ ) of their initial activity is released at $25^{\circ} \mathrm{C}$ over 420 days. The leach rate for most radionuclides decreases over time, and the kinetics of leaching implies that radionuclide release occurs by a process that is more complex than simple dissolution.

The following future NTS research activities in the context of supporting YMP are suggested:

- An evaluation of data from in situ measurements of the redox state of the groundwater for possible link to the hydrogeologic environment. This will help us understand if reducing water is associated with a particular type of hydrogeologic setting.

- Laboratory experiments, performed under varying controlled redox states, that evaluate the transport of redox-sensitive radionuclides (especially Tc and I).

- A detailed literature review of information on reactive radionuclides (e.g., $\mathrm{Sr}, \mathrm{Cs}, \mathrm{U}, \mathrm{Pu}$ ) from available hot-well samples and synthesis of relevant data regarding their transport behavior.

- A synthesis of the available information from the NTS work regarding the concentration, characteristics, and role of colloids in the facilitated transport of radionuclides.

- Simulations of the possible radionuclide release from the proposed repository by using the modeling tools (e.g., nonisothermal source model, isothermal streamtube subregional model) that were developed for the NTS studies and by incorporating the reactive kinetics knowledge acquired from these studies. The source uncertainty and hydrogeologic uncertainty methods used for investigating radionuclide migration at the NTS are directly transferable to the geologically similar environment at Yucca Mountain. Such a modeling effort may demonstrate the conservatism of current Yucca Mountain 
performance confirmation efforts and may provide insight into the development of a more certain performance confirmation model.

\section{Acknowledgments}

This work was performed under the auspices of the U.S. Department of Energy by the University of California, Lawrence Livermore National Laboratory under Contract No. W-7405-Eng-48. The work is funded through the Science and Technology Program of the Office of Civilian Radioactive Waste Management of the U.S. Department of Energy. The authors thank Emmeline Chen for many helpful comments. 


\section{References}

Applet, H., K. Holtzclaw, and P. F. Pratt. 1975. Effect of anion exclusion on the movement of chloride through soils. Soil Sci. Soc. Am. Proc., 39:264-267.

Boggs, M. J., and Adams, E. E. 1992. Field study in a heterogeneous aquifer. 4. Investigation of adsorption and sampling bias. Water Resour. Res., 28:3325-3336.

Bondietti, E. A., and C. W. Francis. 1979. Geologic migration potentials of Tc-99 and Np-237. Science, 203:1337-1340.

Borg, I. Y. 1975. Radioactivity trapped in melt produced by a nuclear explosion. Nuclear Technol., 26:88-100.

Borg, I. Y., R. Stone, H. B. Levey, and L. D. Ramspott. 1976. Information pertinent to the migration of radionuclides in ground water at the Nevada Test Site. Part 1: Review and analysis of existing information. Lawrence Livermore National Laboratory, Livermore, CA, UCRL-52078.

Bowen, S. M., D. L. Finnegan, J. L. Thompson, C. M. Miller, P. L. Baca, L. F. Olivas, C. G. Geoffrion, D. K. Smith, W. Goishi, B. K. Esser, J. W. Meadows, N. Namboodiri, and J. F. Wild. 2001. Nevada Test Site radionuclide inventory, 1951-1992. Los Alamos National Laboratory, Los Alamos, NM, LA-13859-MS.

Bresler, E. 1973. Anion exclusion and coupling effects in nonsteady transport through unsaturated soils: 1. Theory. Soil Sci. Soc. Am. Proc., 37:663-669.

Brookins, D. G. 1986. Rhenium as analog for fissiogenic technetium: Eh-pH diagram $\left(25^{\circ} \mathrm{C}, 1\right.$ bar) constraints. Appl. Geol., 1:513-517.

Bryant, E. A. 1992. The CAMBRIC migration experiment-A summary report. Los Alamos National Laboratory, Los Alamos, NM, LA-12335-MS.

Buddemeier, R.W., and D. Isherwood. 1985. Radionuclide Migration Project 1984 Progress Report. Lawrence Livermore National Laboratory, Livermore, CA, UCRL-53628.

Buddemeier, R. W. and J. R. Hunt. 1988. Transport of colloidal contaminants in groundwater: Radionuclide migration at the Nevada Test Site. Appl. Geochem., 3:535-548.

Buddemeier, R. W., R. C. Finkel, K. V. Marsh, M. R. Ruggieri, J. H. Rego, and R. J. Silva. 1991. Hydrology and radionuclide migration at the Nevada Test Site. Radiochim. Acta, 52/53:275282.

Burbey, T. J., and S. W. Wheatcraft. 1986. Tritium and chlorine-36 migration from a nuclear explosion cavity. Desert Research Institute, Water Resources Center Publication 45050, Las Vegas, NV.

Butkovich, T. R. 1974. Melt from an underground nuclear explosion. Lawrence Livermore National Laboratory, Livermore, CA, UCRL-51554. 
Chan, K. Y., H. R. Geering, and B. G. Vavey. 1980. Movement of chloride in a soil with variable charge properties: I. Chloride systems. J. Environ. Qual., 9:579-582.

Coles, D., and L. Ramspott. 1982. Migration of ruthentium-106 in a Nevada Test Site aquifer: Discrepancy between field and laboratory results. Science, 215:1235-1237.

Couture, R. A., and M. G. Seitz. 1983. Sorption of anions of iodine by iron oxides and kaolinite. Nuclear Chem. Waste Management, 4:301-306.

Crow, N. B. 1976. First observations of tritium in ground water outside chimneys of underground nuclear explosions, Yucca Flat, Nevada Test Site. Lawrence Livermore National Laboratory, Livermore, CA, URCL-52073.

Civilian Radioactive Waste Management System Management and Operating Contractor (CRWMS M\&O). 2000. Data qualification report: Composition of J-13 well water for use on the Yucca Mountain Project. Las Vegas, NV, TDR-NBS-HS-000003 REV 00.

Cui, D., and T. E. Eriksen. 1996a. Reduction of pertechnetate by ferrous iron in solution: Influence of sorbed and precipitated Fe(II). Environ. Sci. Technol., 30:2259-2262.

Cui, D., and T. E. Eriksen. 1996b. Reduction of pertechnetate in solution by heterogeneous electron transfer from Fe(II)-containing geological material. Environ. Sci. Technol., 30:2263-2269.

Cui, D., and T. E. Eriksen. 1998. Reactive transport of Sr, Cs and Tc through a column packed with fracture-filling material. Radiochim. Acta, 82:287-292.

Daniels, W. R. (ed.) 1982. Laboratory and field studies related to the radionuclide migration project, October 1, 1980-September 30, 1981. Los Alamos National Laboratory, Los Alamos, NM, LA-9192-PR.

Davis, S. N., G. M. Thompson, H. W. Bentley, and G. Stiles. 1980. Groundwater tracers. Ground Water, 18:14-23.

Dobson, P. F., T. J. Kneafsey, E. L. Sonnenthal, N. Spycher, and J. A. Apps. 2003. Experimental and numerical simulation of dissolution and precipitation: Implications for fracture sealing at Yucca Mountain, Nevada. J. Contam. Hydrol., 62/63:459-476.

Dzombak, D. A., and Morel, F. M. M. 1990. Surface complexation modeling: Hydrous ferric oxide. John Wiley \& Sons, New York, NY.

Eaton, G. F., and D. K. Smith. 2001. Aged nuclear explosive melt glass: Radiography and scanning electron microscope analyses documenting radionuclide distribution and glass alteration. J. Radioanal. Nucl. Chem., 248:543-547.

Eddebbarh, A. A., G. A. Zyvoloski, B. A. Robinson, E. M. Kwicklis, P. W. Reimus, B. W. Arnold, T. Corbet, S. P. Kuzio, and C. Faunt. 2003. The saturated zone at Yucca Mountain: An overview of the characterization and assessment of the saturated zone as a barrier to potential radionuclide migration. J. Contam. Hydrol., 62/63:477-493. 
Eriksen, T. E., P. Ndalamba, J. Bruno, and M. Caceci. 1992. The solubility of $\mathrm{TcO}_{2} \cdot \mathrm{nH}_{2} \mathrm{O}$ in neutral to alkaline solutions under constant $\mathrm{pCO}_{2}$. Radiochim. Acta, 58/59:67-70.

Failor, R. A., D. G. Coles, and J. H. Rego. 1983. A leaching study of nuclear melt glass: Part I. Lawrence Livermore National Laboratory, Livermore, CA, UCID-19729.

Finkel, R. C., M. W. Caffee, K. V. Marsh, and J. H. Rego. 1992. Accelerator mass spectrometry measurements of ${ }^{129} \mathrm{I}$ in CHESHIRE site groundwater. In K. V. Marsh (ed.), Hydrology and Radionuclide Migration Program 1988 progress report. Lawrence Livermore National Laboratory, Livermore, CA, UCRL-53779-88.

Finnegan, D. L., and J. L. Thompson. 2001. Laboratory and field studies related to radionuclide migration at the Nevada Test Site in support of the Underground Test Area Program and Hydrologic Resources Management Project, October 1, 1999-September 30, 2000. Los Alamos National Laboratory, Los Alamos, NM, LA-13787-PR.

Finnegan, D. L., and J. L. Thompson. 2002. Laboratory and field studies related to radionuclide migration at the Nevada Test Site in support of the Underground Test Area Program and Hydrologic Resources Management Project. Los Alamos National Laboratory, Los Alamos, NM, LA-13919-MS.

Finnegan, D. L., and J. L. Thompson. 2003. Laboratory and field studies related to radionuclide migration at the Nevada Test Site in support of the Underground Test Area Program and Hydrologic Resources Management Project. Los Alamos National Laboratory, Los Alamos, NM, LA-14042-MS.

Gaber, H. M., W. P. Inskeep, S. D. Comfort, and J. M. Wraith. 1995. Non-equilibrium transport of atrazine through large intact soil cores. Soil Sci. Soc. Am. J., 59:60-67.

Guell, M. A., and J.R. Hunt. 2003. Groundwater transport of tritium and krypton-85 from a nuclear detonation cavity. Water Resour. Res., Vol. 39, No. 7, 1175, 10.1029/2001WR001249

Gvirtzman, H., and M. Margaritz. 1986. Investigation of water movement in the unsaturated zone under an irrigated area using environmental tritium. Water Resourc. Res., 22:635-642.

Gvirtzman, H., D. Ronen, and M. Margaritz. 1986. Anion exclusion during transport through the unsaturated zone. J. Hydrol., 87:267-283.

Harvey, B. R., K. J. Williams, M. B. Lovett, and R. D. Ibbett. 1992. Determination of technetium-99 in environmental material with rhenium as a yield monitor. J. Radioanal. Nucl. Chem., 158:417-436.

Hoffman, D. C., J. R. Stone, and W. W. Dudley, Jr. 1977. Radioactivity in the underground environment of the CAMBRIC nuclear explosion at the Nevada Test Site. Los Alamos Scientific Laboratory, Los Alamos, NM, LA-6877-MS.

$\mathrm{Hu}$, Q., and M. L. Brusseau. 1996. Transport of rate-limited sorbing solutes in an aggregated porous medium: A multiprocess non-ideality approach. J. Contam. Hydrol., 24:53-73. 
Hu, Q., R. Salve, W. T. Stringfellow, and J. S. Y. Wang. 2001. Field tracer transport tests in unsaturated fractured tuffs. J. Contam. Hydrol., 51:1-12.

International Atomic Energy Agency (IAEA). 1998. The radiological situation at the atolls of Mururoa and Fangataufa: Inventory of radionuclides underground at the atolls. Interim version, Vol. 3, Vienna.

Ishiguro, M., K. C. Song, and K. Yuita. 1992. Ion transport in allophanic andisol under the influence of variable charge. Soil Sci. Soc. Am. J., 56:1789-1793.

James, R. V., and J. Rubin. 1986. Transport of chloride ion in a water-unsaturated soil exhibiting anion exclusion. Soil Sci. Soc. Am. J., 50:1142-1149.

Jessup, R. E., Brusseau, M. L. and Rao, P. S. C. 1989. Modeling solute transport. Fla. Agric. Exp. Stn. Rep., Univ. of Florida.

Kersting, A. B. 1996. The state of the hydrologic source term. Lawrence Livermore National Laboratory, Livermore, CA, UCRL-ID-126557.

Kersting, A. B., D. W. Efurd, D. L. Finnegan, D. J. Rokop, D. K. Smith, and J. L. Thompson. 1999. Migration of plutonium in groundwater at the Nevada Test Site. Nature, 397:56-59.

Kneafsey, T., and K. Pruess. 1998. Laboratory experiments on heat-driven two-phase flows in natural and artificial rock fractures. Water Resour. Res., 34:3349-3367.

Laczniak, R. J., J. C. Cole, D. A. Sawyer, and D. A. Trudeau. 1996. Summary of hydrogeologic controls on groundwater flow at the Nevada Test Site, Nye County, Nevada. U.S. Geological Survey Water-Resources Investigations Report. 96-4109.

Levy, H. B. 1972. On evaluating the hazards of groundwater contamination by radioactivity from an underground nuclear explosion. Lawrence Livermore National Laboratory, Livermore, CA, UCRL-51278.

Lieser, K. H., and C. H. Bauscher. 1987. Technetium in the hydrosphere and in the geosphere. I. Chemistry of technetium and iron in natural waters and influence of the redox potential on the sorption of technetium. Radiochim. Acta, 42:205-213.

Liu, H. H, C. B. Haukwa, C. F. Ahlers, G. S. Bodvarsson, A. L. Flint, and W. B. Guertal. 2003. Modeling flow and transport in unsaturated fractured rock: An evaluation of the continuum approach. J. Contam. Hydrol., 62/63:173-188.

Maxwell, R. M., A. F. B. Tompson, J. T. Rambo, S. F. Carle, and G. A. Pawloski. 2000. Thermally induced groundwater flow resulting from an underground nuclear test. In L. R. Bentley et al. (eds.), Proceedings of the XIII International Conference on Contaminated Methods in Water Resources. Calgary, Canada. Comput. Methods Water Resourc., 13:4550 .

McAninch, J. E., R. E. Martinelli, and D. K. Smith. 2000. Measurements of technetium-99 in Nevada Test Site well water samples. In Hydrologic Resources Management Program and 
Underground Test Area FY 1999 progress report. Lawrence Livermore National Laboratory, Livermore, CA, UCRL-ID-139226, 35-44.

McMahon, M. A., and G. W. Thomas. 1974. Chloride and tritium flow in disturbed and undisturbed soil cores. Soil Sci. Soc. Amer. Proc., 38:727-732.

Nimz, G. J., and J. L. Thompson. 1992. Underground radionuclide migration at the Nevada Test Site. U.S. Department of Energy, Nevada Field Office (DOE/NV-246, UC-703).

Nitao, J. J. 1998. Reference manual for the NUFT flow and transport code, Version 2.0. Lawrence Livermore National Laboratory, Livermore, CA, UCRL-MA-130651.

Ogard, A. E. J. L. Thompson, R. S. Rundberg, K. Wolfsberg, P. Kubik, D. Elmore, and H. W. Bentley. 1988. Migration in alluvium of chlorine-36 and tritium from an underground nuclear test. Radiochim. Acta, 44/45:213-217.

Pawloski G. A., A. F. B. Tompson, and S. F. Carle (eds.) 2001. Evaluation of the hydrologic source term from underground nuclear tests on Pahute Mesa at the Nevada Test Site: The CHESHIRE test. Lawrence Livermore National Laboratory, Livermore, CA, UCRL-ID147023.

Rose, T. P., G. A. Pawloski, and D. K. Smith. 2000a. Environmentally closed nuclear test cavity-chimney systems: Evidence and controlling factors. Lawrence Livermore National Laboratory, Livermore, CA.

Rose, T. P., D. K. Smith, and J. K. Werner, Jr. 2000b. Lithologic, mineralogic, and petrographic characterization of alluvium from the U-1a $102 \mathrm{C}$ and $102 \mathrm{D}$ drifts of the U-1a tunnel complex, Nevada Test Site. In Hydrologic Resources Management Program and Underground Test Area FY 1999 progress report. Lawrence Livermore National Laboratory, UCRL-ID-139226, 77-110.

Rose, T.P., D. K. Smith, and D. L. Phinney. 2000c. Secondary ion mass spectrometry measurements of volcanic tuffs containing radionuclides from underground nuclear tests. Radiochim. Acta, 88:465-473.

Sawyer, D. A., J. L. Thompson, and D. K. Smith. 1999. The CHESHIRE migration experiment: A summary report. Los Alamos National Laboratory, Los Alamos, NM, LA-13555-MS.

Schroeder, N. C., D. Morgan, D. J. Rokop, and J. Fabryka-Martin. 1993. Migration of technetium-99 in the alluvial aquifer at the Nevada Test Site, Nevada. Radiochim. Acta, 60:203-209.

Schwartz, L., A. Piwinskii, F. Ryerson, H. Tewes, and W. Beiringer. 1984. Glass from underground nuclear explosions. J. Noncrystalline Solids. 67:559-591.

Seaman, J. C., 1998. Retardation of fluorobenzoate tracers in highly weathered soil and groundwater systems. Soil Sci. Soc. Am. J., 62:354-361. 
Seyfried, M. S. and Rao, P. S. C. 1987. Solute transport in undisturbed columns of an aggregated tropical soil: Preferential flow effects. Soil Sci. Soc. Am. J., 51:1434-1444.

Sheppard, M., and D. H. Thibault. 1992. Chemical behavior of iodine in organic and mineral soils. Appl. Geochem., 7:265-272.

Silva, R. J., R. Evans, J. H. Rego, and R. W. Buddemeier. 1988. Methods and results of Tc-99 analysis of Nevada Test Site groundwaters. J. Radioanaly. Nucl. Chem., 124:397-405.

Smith, D. K. 1993. A review of literature pertaining to the leaching and sorption of radionuclide associated with nuclear explosive melt glasses. Lawrence Livermore National Laboratory, Livermore, CA, UCRL-ID-113370.

Smith, D. K. 1995. Characterization of nuclear explosive melt debris. Radiochim. Acta, 69:157167.

Smith, D. K. 1998. A recent drilling program to investigate radionuclide migration at the Nevada Test Site. J. Radioanaly. Nucl. Chem., 235:159-166.

Smith, D. K. 2002. Evaluation of the radiochemistry of near-field water samples at the Nevada Test Site applied to the definition of a hydrologic source term. Lawrence Livermore National Laboratory, Livermore, CA, UCRL-ID-149049.

Smith, D.K., D.L. Finnegan, and S.M. Bowen. 2003. An inventory of long-lived radionuclides residual from underground nuclear testing at the Nevada test site, 1951-1992. J. Environ. Radioactivity. 67:35-51.

Smith, D. K., R. J. Nagle, and J. M. Kenneally. 1996. Transport of gaseous fission products adjacent to an underground nuclear test cavity. Radiochim. Acta, 73:177-183.

Smith, D. K., D. L. Finnegan, and S. M. Bowen. 2003. An inventory of long-lived radionuclides residual from underground nuclear testing at the Nevada Test Site, 1951-1992. J. Environ. Radioactivity. 67:35-51.

Smith, D. K., A. B. Kersting, J. L. Thompson, and D. L. Finnegan. 2001. Insights to repository performance through study of a nuclear test site. Scientific Basis for Nuclear Waste Management XXIV, Materials Research Society, 663:1023-1032.

Stead, F. 1963. Tritium distribution in groundwater around large underground fusion explosions. Science, 142:1163-1165.

Stewart, G. L. 1970. The potential use of deuterium and tritium to depict water flow and to study clay-water interactions. Agron. Abstr. American Society of Agronomy, Madison, WI, 89.

Stewart, G. L. 1972. Clay water interactions, the behavior of ${ }^{3} \mathrm{H}$ and ${ }^{2} \mathrm{H}$ in adsorbed water and the isotope effect. Soil Sci. Soc. Amer. Proc., 36:421-426.

Stewart, G. L., and J. H. Baker. 1973. Factors influencing the use of tritium as a tracer of soil water. Agron. Abstr. American Society of Agronomy, Madison, WI, 79. 
Thomas, G. W., and A. R. Swoboda. 1970. Anion exclusion effects on chloride movement in soils. Soil Sci., 110:163-166.

Thompson, J. L. (ed.) 1985. Laboratory and field studies related to the Radionuclide Migration Project, October 1, 1983-September 30, 1984. Los Alamos National Laboratory, Los Alamos, NM, LA-10372-PR.

Thompson, J. L. 1996. Radionuclide distribution in a nuclear test cavity: The Baseball event. Radiochim. Acta, 72:157-162.

Thompson, J. L. (ed.) 1997. Laboratory and field studies related to the Hydrologic Resources Management Program, October 1, 1995-September 30, 1996. Los Alamos National Laboratory, Los Alamos, NM, LA-13270-PR.

Thompson, J. L. (ed.) 1999. Laboratory and field studies related to radionuclide migration at the Nevada Test Site, October 1, 1997-September 30, 1998. Los Alamos National Laboratory, Los Alamos, NM, LA-13576-PR.

Ticknor, K. V., and Y. H. Cho. 1990. Interaction of iodide and iodate with granitic fracturefilling minerals. J. Radioanal. Nucl. Chem., 140:75-90.

Tompson, A. F. B., C. J. Burton, and G. A. Pawloski. 1999. Evaluation of the hydrologic source term from the underground nuclear tests in Frenchman Flat and the Nevada Test Site: The CAMBRIC test. Lawrence Livermore National Laboratory, Livermore, CA, UCRL-ID132300 .

Tompson, A. F. B., D. K. Smith, and G. B. Hudson. 2002. Analysis of radionuclide migration through a 200-m vadose zone following a 16-year infiltration event. Lawrence Livermore National Laboratory, Livermore, CA, UCRL-ID-146979.

Toner, C.V., D. L. Sparks, and T. H. Carski. 1989. Anion exchange chemistry of Middle Atlantic soils: Charge properties and nitrate retention kinetics. Soil Sci. Soc. Am. J., 53:1061-1067.

Treher, E. N., and N. A. Raybold. 1982. The elution of radionuclides through columns of crushed rock from the Nevada Test Site. Los Alamos National Laboratory, Los Alamos, NM, LA-9329-MS.

Turin, H. J., A. R. Groffman, L. E. Wolfsberg, J. L. Roach, and B. A. Strietelmeier. 2002. Tracer and radionuclide sorption to vitric tuffs of Busted Butte, Nevada. Appl. Geochem., 17:825836.

Tyler, S. W., W. A. McKay, and T. M. Mihevc. 1992. Assessment of soil moisture movement in nuclear subsidence craters. J. Hydrol., 139:159-181.

van Genuchten, M. T., and P. J. Wierenga. 1977. Mass transfer studies in sorbing porous media: 2. Experimental evaluation with tritium $\left({ }^{3} \mathrm{H}_{2} \mathrm{O}\right)$. Soil Sci. Soc. Am. J., 41:272-278. 
Viani, B. 2002. Formulation of recipes for synthetic J-13 groundwater that are predicted to be stable at $25^{\circ} \mathrm{C}$ and atmospheric $p \mathrm{CO}_{2}$. Lawrence Livermore National Laboratory, Livermore, CA.

Wharton, M. J., B. Atkins, J. M. Charnock, F. R. Livens, R. A. D. Pattrick, and D. Collison. 2000. An X-ray absorption spectroscopic study of the coprecipitation of Tc and Re with mackinawite (FeS). Appl. Geochem., 15:347-354.

Wierenga, P. J., van Genuchten, M. T., and F. W. Boyle. 1975. Transfer of boron and tritiated water through sandstone. J. Environ. Qual., 4:83-87.

Winograd, I. J., and F. N. Robertson. 1982. Oxygenated groundwater: Anomaly or common occurrence. Science, 216:1227-1229F.

Wolfsberg, A., L. Glascoe, G. Lu, A. Olson, P. Lichtner, M. McGraw, and T. Cherry. 2001. TYBO/BENHAM, Model analysis of groundwater flow and radionuclide migration from an underground nuclear test in southwestern Pahute Mesa, NTS. Los Alamos National Laboratory, Los Alamos, NM, LA-UR-01-2924.

Wolfsberg, K. 1978. Sorption-desorption studies of Nevada Test Site alluvium and leaching studies of nuclear explosion debris. Los Alamos National Laboratory, Los Alamos, NM, LA-7216-MS.

Yoshida, S., Y. Muramatsu, and S. Uchida. 1992. Studies on the sorption of $\mathrm{I}^{-}$(iodide) and $\mathrm{IO}_{3}{ }^{-}$ (iodate) onto andosols. Water, Air, Soil Pollu., 63:321-329.

Yuita, K. 1994. Overview and dynamics of iodine and bromine in the environment. 1. Dynamics of iodine and bromine in soil-plant system. JARQ, 28:90-99.

Zyvoloski, G. A., B. A. Robinson, Z. V. Dash, and L. L. Trease. 1997. Summary of the models and methods for the FEHM application-A finite-element heat- and mass-transfer code. Los Alamos National Laboratory, Los Alamos, NM, LA-13307-MS. 